\title{
Pore engineering of metal-organic frameworks with coordinating functionalities
}

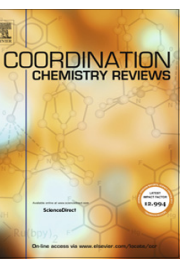

\author{
Sungeun Jeoung ${ }^{\mathrm{a}, 1}$, Seongwoo Kim ${ }^{\mathrm{b}, 1}$, Min Kim ${ }^{\mathrm{b}, *}$, Hoi Ri Moon ${ }^{\mathrm{a}, *}$ \\ a Department of Chemistry, Ulsan National Institute of Science and Technology (UNIST), Ulsan 44919, Republic of Korea \\ ${ }^{\mathrm{b}}$ Department of Chemistry and BK21Plus Research Team, Chungbuk National University, Cheongju, Chungbuk 28644, Republic of Korea
}

\section{A R T I C L E I N F O}

\section{Article history:}

Received 28 December 2019

Accepted 3 May 2020

Available online 15 June 2020

\section{Keywords:}

Metal-organic frameworks

Metalation

Post-synthetic modification

Coordinating functionalities

Catalytically active sites

\begin{abstract}
A B S T R A C T
Among porous materials, metal-organic frameworks (MOFs) take the lead in heterogeneous support catalysts because the structure of MOFs can be readily tuned by choice of metal and organic building blocks, and further be modified with diverse functional groups. In order to immobilize catalytically active metal sites on MOFs and efficiently utilize them, it would be essential to employ the coordinating functionalities to the pores and frameworks, which can anchor the metal sites with high stability and control the reactivity of the catalytic centres. However, in order not to obtain the unwanted structures by participation of additional coordinating groups in the framework construction of MOFs, the pore engineering with coordinating functionalities should be carefully implemented. In this review, we discuss various strategies of pore engineering to impart catalytic activities to the MOF architectures, classifying them into two approaches: pre-integrated ligand and sequential attachment. The former demonstrates the use of organic ligands that are already capable of possessing catalytic sites, and the ligands can directly integrate the metals before or after the production of the MOFs. The other approach is the post-synthetic attachment of coordinating functionalities through the sequential attachment process, in which immobilization of catalytically active metal sites also can be achieved by both pre- and post-metalation. Finally, this review will comprehensively discuss the representative catalytic reactions of MOF-based heterogeneous catalysts.
\end{abstract}

(c) 2020 Elsevier B.V. All rights reserved.

\section{Contents}

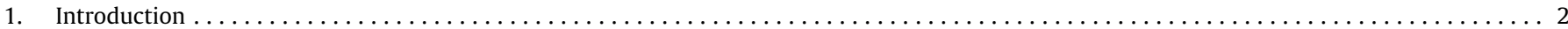

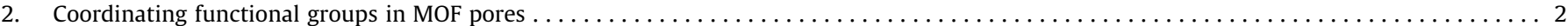

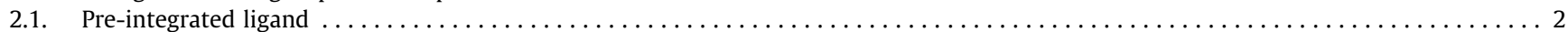

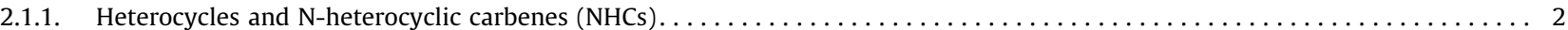

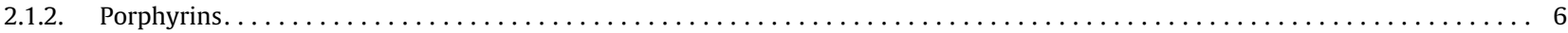

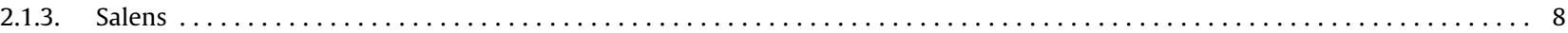

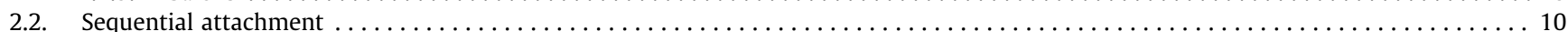

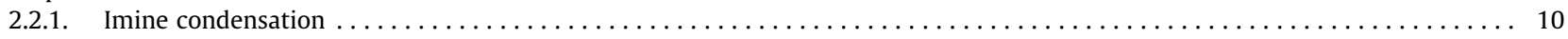

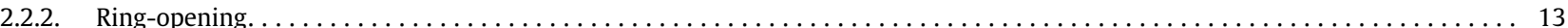

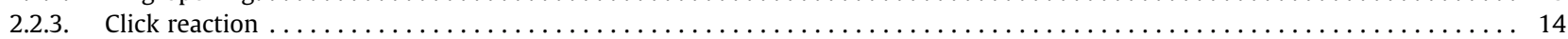

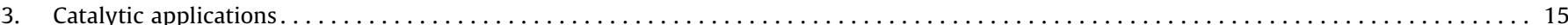

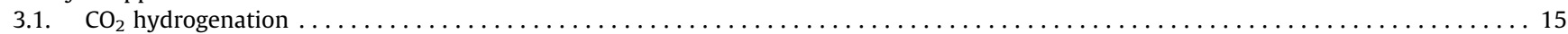

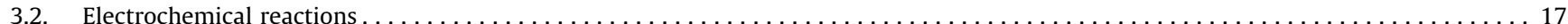

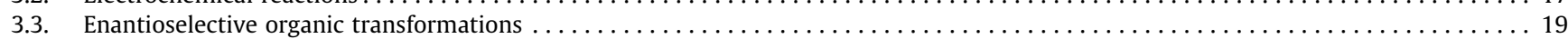

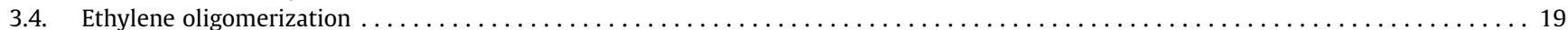

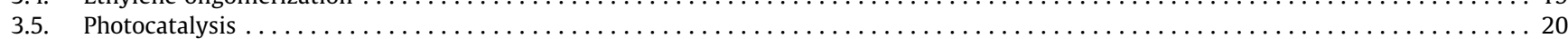

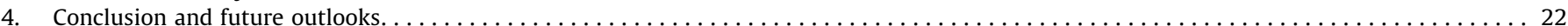

\footnotetext{
* Corresponding authors.

E-mail addresses: minkim@chungbuk.ac.kr (M. Kim), hoirimoon@unist.ac.kr (H.R. Moon).

1 These authors have the equivalent contribution to this work.
} 


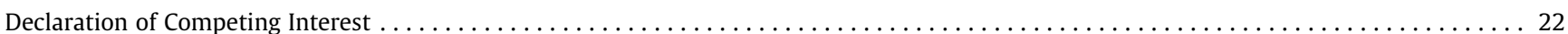

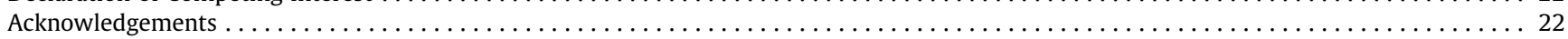

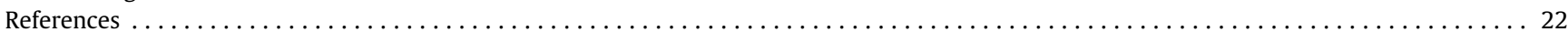

\section{Introduction}

Development of heterogeneous catalysts is mainly engaged in catalytically active sites and supports. Since the surface area of heterogeneous catalysts is a critical factor in the number of available active sites, porous materials have been widely used as catalyst supports to immobilize the active sites and maximize the advantages of heterogeneous catalysts such as easy catalyst separation and simple recycling. Zeolites and mesoporous silicate materials have been intensively studied as supports, but tunability of the pore structures and functionalization of the pore walls are still key hurdles [1-7]. Metal-organic frameworks (MOFs) have been highlighted for overcoming these limitations, because the structure of MOFs are well-tunable by selection of metal ions/clusters and organic bridging ligands and those components can be easily modified with various types of functionalities [8-10]. These MOF pores engineered with functional groups furnish numerous opportunities for the development of new porous materials for a plethora of applications, including guest adsorption and separation, drug delivery, sensing, proton conductivity, and catalysis [11-15]. Comprehensive review articles are available, covering the general methods of pore functionalization and various applications of these materials [16-31].

In order to anchor catalytically active metal sites in the pores of MOFs, it is essential to introduce coordinating constituents inside the MOF, which are additional sites to coordinating groups for construction of frameworks. However, since MOFs are built from coordination bonds between organic ligands and metal ions, additional coordinating sites on the organic ligands can produce unwanted and/or unexpected products. Therefore, introducing the target functional groups in a precisely designed manner is highly important. There are two main approaches for introducing coordinating functionalities in MOFs. One is the synthesis of MOFs using 'preintegrated ligands' in which two different coordinating sites coexist for framework construction and catalytic site immobilization (left panel of Fig. 1). In this method, integrating functionality into one organic ligand can be achieved from carboxylic acid or pyridine groups at the terminal sites and additional coordinating groups on the ligand struts such as heterocycles, N-heterocyclic carbenes, porphyrins and salens. The other approach is 'sequential attachment' of catalytic site coordinating functionalities on preconstructed MOFs (right panel of Fig. 1). In order to avoid the formation of an unpredictable framework by unselective coordination to framework metal ions and catalytic metal ions during MOF synthesis, MOFs are constructed with carboxylic acid or imidazolebased ligand containing amino or hydroxyl substituents for sequential coupling reactions with metal coordinating functionalities. For both approaches the catalytic metal sites can be introduced to coordinating functional groups via pre-metalation or post-metalation. Herein, we elaborate on the various strategies and examples of pore engineering with functional groups. According to the classification described above, this review aims to focus on the strategy of pore engineering of MOFs with coordinating functional groups to build active sites for catalyst applications. Furthermore, the use of MOFs obtained by these methods as heterogeneous catalysts will be described by classifying them as representative catalytic reaction.

\section{Coordinating functional groups in MOF pores}

\subsection{Pre-integrated ligand}

\subsubsection{Heterocycles and $\mathrm{N}$-heterocyclic carbenes (NHCs)}

2,2'-bipyridyl (bpy) is a common chelating ligand for transition metal (TM) complexes. As shown in Table 1, carboxylic acidcontaining bpy derivatives have been widely studied as a preintegrated ligand for MOF preparation with a variety of metal salts $\left(\mathrm{M}^{1}\right)[62,65,68,76,77]$ and metalation of bpy using various TMs $\left(\mathrm{M}^{2}\right)$ has been also intensively studied. These bpy-TMfunctionalized MOFs have been utilized in a wide range of organic transformations.

In 2010, Yaghi group reported that the synthesis of MOF-253 [Al $(\mathrm{OH})\left(\right.$ bpydc)] (bpydc $=2,2^{\prime}$-bipyridine-5,5'-dicarboxylic acid) with open 2,2'-bpy coordination sites for the first time [65]. Solvothermal reaction between $\mathrm{AlCl}_{3}$ and bpydc in DMF $(\mathrm{N}, \mathrm{N}-$ dimethylformamide) at $120{ }^{\circ} \mathrm{C}$ yielded colorless microcrystalline MOF-253, and then through the post-metalation process with

\section{Pre-integrated ligands \\ - Pre-metalation}

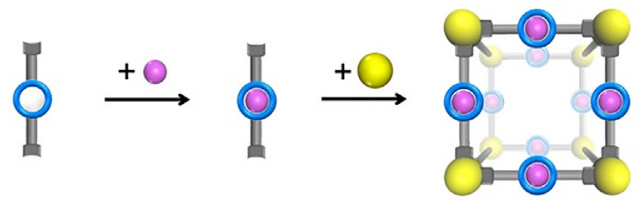

- Post-metalation

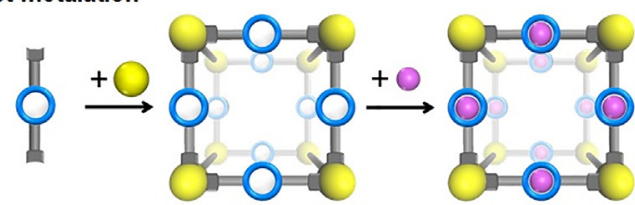

$\nabla=$ coo- or Pyridine $\quad \mathrm{O}=\begin{aligned} & \text { Heterocycles, } \mathrm{N} \text {-heterocyclic carbenes, } \\ & \text { Porphyrins, or Salens }\end{aligned}$
II. Sequential attachment

- Pre-metalation
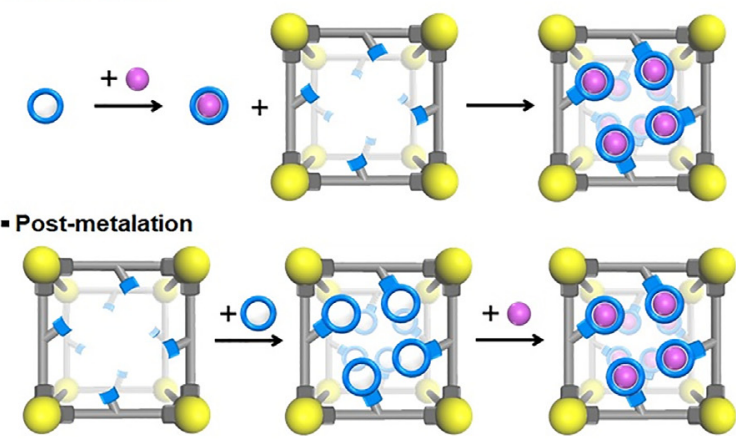

$\square=-\mathrm{NH}_{2},-\mathrm{COH},-\mathrm{OH}$, or $-\mathrm{N}_{3} \mathrm{O}=$ Imine, Carboxylic acid, or Triazole

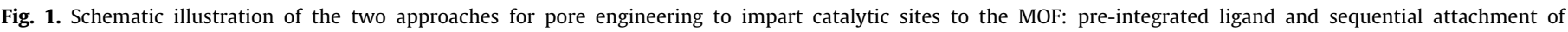
coordinating functionalities. 
Table 1

Various metal combinations ( $\mathrm{M}^{1}$ for MOF construction and $\mathrm{M}^{2}$ for catalysts) of bipyridyl-functionalized MOFs.

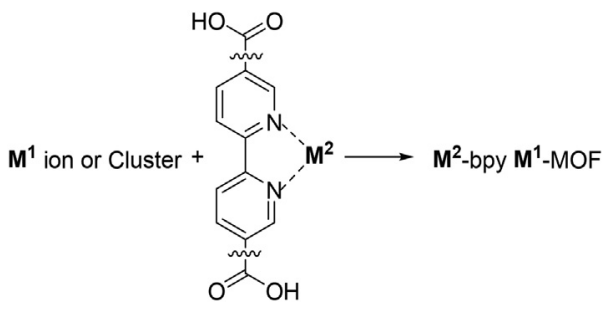

\begin{tabular}{|c|c|c|c|}
\hline $\mathbf{M}^{1}$ & $\mathbf{M}^{2}$ & $\mathbf{M}^{1}$ & $\mathbf{M}^{2}$ \\
\hline $\operatorname{Zr}(\mathrm{IV})$ & $\begin{array}{l}\text { Ir(III) [32,33], Re(I) [32,34,35], Ru(II) [32,36], Pd(II) [37-42], Ir(I) [33,39], Ir } \\
\text { (III) [40], Rh(II) [40], Rh(III) [43], } \mathrm{Pt}(\mathrm{II})[44-46], \mathrm{Mn}(\mathrm{II})[47,48], \mathrm{Cu}(\mathrm{II})[49,50], \\
\mathrm{Cu}(\mathrm{III})[42,45,49-52], \mathrm{Co}(\mathrm{II})[36,49], \mathrm{Fe}(\mathrm{II})[49], \mathrm{Cr}(0)[49], \mathrm{Mo}(\mathrm{VI})[53], \mathrm{Eu}(\mathrm{III}) \\
{[54,55], \mathrm{Tb}(\mathrm{III})[54], \mathrm{Ni}(\mathrm{II})[56]}\end{array}$ & Gd(III) & $\operatorname{Pd}(\mathrm{II})[69,71]$ \\
\hline $\operatorname{In}(\mathrm{III})$ & $\mathrm{Eu}(\mathrm{III})[57-60], \mathrm{Tb}(\mathrm{III})[57,58], \operatorname{In}(\mathrm{III})[61], \operatorname{Sm}(\mathrm{III})[58]$ & $\mathrm{Tb}(\mathrm{III})$ & $\operatorname{Pd}(\mathrm{II})[71]$ \\
\hline $\mathrm{Zn}(\mathrm{II})$ & $\mathrm{Zn}(\mathrm{II})[62,63], \mathrm{Ru}(\mathrm{II})[64], \mathrm{Os}(\mathrm{II})[64]$ & $\mathrm{Ga}(\mathrm{III})$ & $\mathrm{Eu}(\mathrm{III})[72,73]$ \\
\hline $\mathrm{Al}(\mathrm{III})$ & $\operatorname{Pd}(\mathrm{II})[65], \mathrm{Cu}(\mathrm{II})[65], \mathrm{Tb}(\mathrm{III})$ [66], Eu(III) [67] & $\mathrm{Eu}(\mathrm{III})$ & $\mathrm{Pd}(\mathrm{II})[71], \mathrm{Cu}(\mathrm{II})[74]$ \\
\hline Y(III) & $\mathrm{Pt}(\mathrm{II})[68], \mathrm{Pd}(\mathrm{II})[70]$ & $\mathrm{Pb}(\mathrm{II})$ & $\mathrm{Pd}(\mathrm{II})[75]$ \\
\hline $\mathrm{Ni}(\mathrm{II})$ & $\mathrm{Ni}(\mathrm{II})[62]$ & $\mathrm{La}(\mathrm{III})$ & $\operatorname{Pd}($ II) $[76]$ \\
\hline Co(II) & $\mathrm{Co}(\mathrm{II})[62,63]$ & $\mathrm{Ce}(\mathrm{IV})$ & $\operatorname{Pd}($ II) $[76]$ \\
\hline $\mathrm{Sm}(\mathrm{III})$ & $\operatorname{Pd}(\mathrm{II})[71]$ & $\mathrm{Nd}(\mathrm{IV})$ & $\operatorname{Pd}($ II) [76] \\
\hline
\end{tabular}

$\mathrm{PdCl}_{2}$ and $\mathrm{Cu}\left(\mathrm{BF}_{4}\right)_{2}$ in acetonitrile $(\mathrm{MeCN})$ solution, respectively, the site-selectively coordinated bimetallic MOFs were successfully prepared (Fig. 2a). Upon metalation, Brunauer-Emmett-Teller (BET) surface area of MOF-253 reduced from 2160 to 1780, 355, and $705 \mathrm{~m}^{2} / \mathrm{g}$ for MOF-253.0.08PdCl, $\mathrm{MOF}-253 \cdot 0.83 \mathrm{PdCl}_{2}$, and MOF-253.0.97Cu(BF $)_{2}$, respectively. Extended X-ray adsorption fine structure (EXAFS) spectroscopy confirmed the coordination environment of the Pd atom, whose bond distances with two $\mathrm{N}$ and two $\mathrm{Cl}^{-}$atoms are well-matched with crystallographic data of the analogous square planar complex (bpy) $\mathrm{PdCl}_{2}$ (Fig. 2b). In this study, MOF-253.0.97Cu( $\left(\mathrm{BF}_{4}\right)_{2}$ showed the enhanced $\mathrm{CO}_{2}$ sorption properties and the higher average isosteric heat of $\mathrm{CO}_{2}$ adsorption, which might be attributed to generation of electric dipoles on the surface of MOFs upon insertion of metal salts.
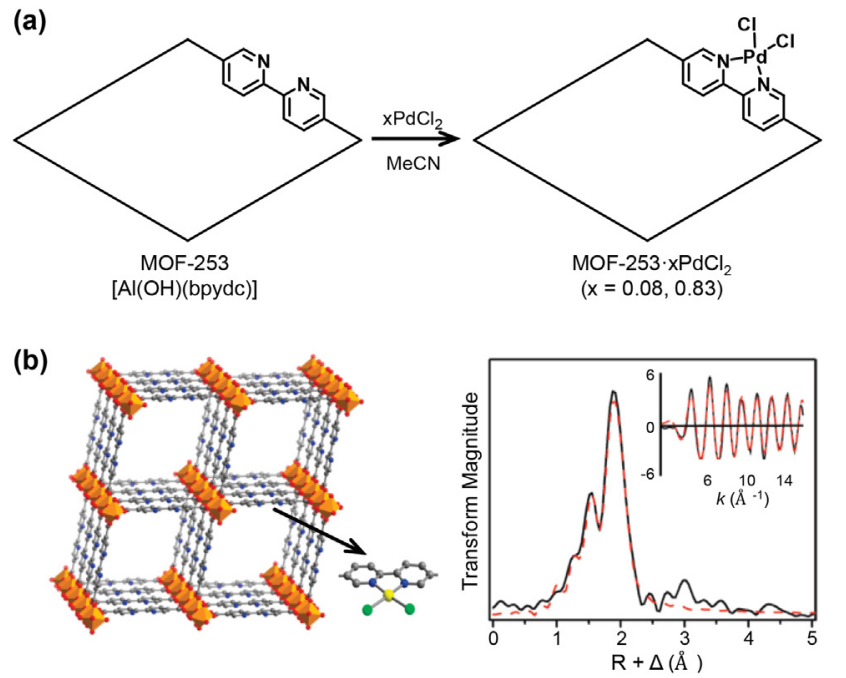

Fig. 2. (a) Palladation on bpy-functionalized MOF-253 and (b) their Pd K-edge EXAFS Fourier transforms and EXAFS spectrum (inset). Black lines show the experimental data, and red dashed lines show the best fits. Reprinted with permission from Ref. [65].
Lin and co-workers utilized chemically stable UiO-67 framework $\left(\mathrm{UiO}=\right.$ University of Oslo, $\mathrm{Zr}_{6} \mathrm{O}_{4}(\mathrm{OH})_{4}(\text { bpdc })_{6}$, bpdc $=$ parabiphenyldicarboxylic acid) for bpy-installed MOF preparation (Fig. 3a) [32]. In their approaches, UiO-67 was constructed with mixture ligands of bpdc and bpydc, in which bpydc was premetalated with Ir, Re, and Ru complexes to prepare six different types of metal-doped MOFs (Fig. 3b). In this study, the metal complexes for coordination to the bpy functionality were intentionally selected for water oxidation, $\mathrm{CO}_{2}$ reduction, and organic photocat-

(a)

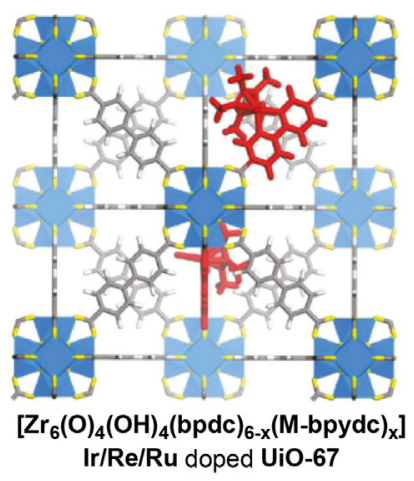

(b)

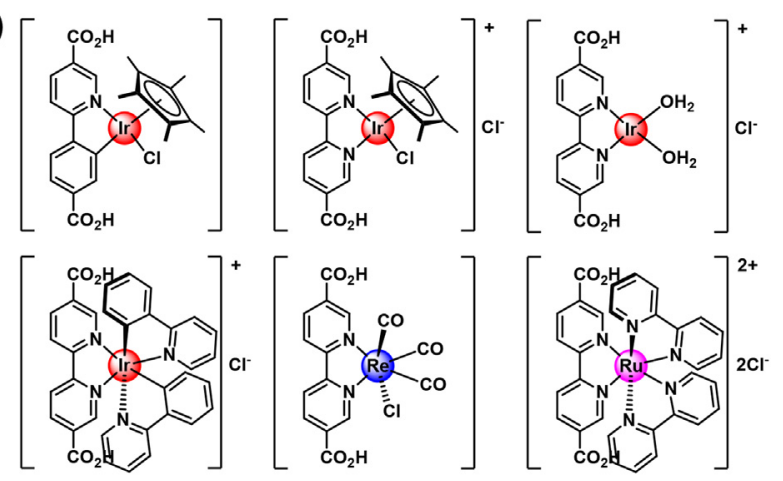

Fig. 3. (a) Structural representation of metal doping of the bpydc ligand into the UiO-67 framework. (b) Variation on metal for $\mathrm{Zr}_{6}(\mathrm{O})_{4}(\mathrm{OH})_{4}(\mathrm{bpdc})_{6-\mathrm{x}}(\mathrm{M}-\mathrm{bpydc})_{\mathrm{x}}$, $\mathrm{M}=\mathrm{Ir}$, Re, and Ru. Reprinted with permission from Ref. [32]. 
alytic reaction catalysts based on the successful demonstration of homogeneous catalysts. The solvothermal synthesis was carried out at $100{ }^{\circ} \mathrm{C}$ under the combination of ligand, DMF and $\mathrm{ZrCl}_{4}$. The UiO-67 framework synthesis only with metalated bpydc ligand was not successful, because the bulky environment of the ligand prevented the formation of frameworks, which was supported by structure modeling studies. Therefore, the mixed ligand system of metalated M-bpydc and bpdc is essential for the synthesis of $\mathrm{Ir} / \mathrm{Re} / \mathrm{Ru}$ doped UiO-67 frameworks. The isostructural frameworks of the metal-doped UiO-67 with pure UiO-67 were confirmed by X-ray powder diffraction (XRPD) patterns, and metal contents were analyzed by inductively coupled plasma-mass spectrometry (ICPMS). 2-8 wt\% of M-bpydc ligands were incorporated to UiO-67 frameworks in this approach.

By employing the MOF constructed with the bpydc ligand but having a different structure from UiO-67, Li and co-workers succeeded full metalation with $\mathrm{Pd}$ atoms on the bpy sites of the ligands (Fig. 4) [70]. $\mathrm{Pd}\left(\right.$ bpydc) $\mathrm{Cl}_{2}$, which is the pre-metalated building block, constructs the 3D-extended layered structures by coordinating Y(III) via carboxylate groups under microwave irradiation, resulting in the yellow crystalline powder. Originally, Szeto et al. have reported the $\mathrm{Pt} / \mathrm{Gd}$ and $\mathrm{Pt} / \mathrm{Y}$ bpydc-based bimetallic MOFs, which was synthesized in single crystals, and the structures were analyzed by single crystal X-ray diffraction (XRD) $[68,69]$. Based on this previous result, Li group confirmed the identical structure of the Pd/Y MOF with Pt/Gd and Pt/Y bpydc MOFs by comparing its XRPD pattern with the simulated patterns of them.

The post-metalation allows broader scopes for metal sources for M-loaded MOFs than pre-metalation approach. In 2014, Lin group reported that chemically stable and recyclable UiO-bpy-Pd and UiO-bpy-Ir catalysts were prepared through post-metalation of the UiO-bpy type MOF [39]. Next year, Long group presented a decent study for post-metalation, which was proceeded in single crystal-to-single-crystal (SCSC) transformation manner [49]. Assynthesized UiO-bpy MOF was metalated with a variety of solution- and gas-phased metal sources such as $\left(\mathrm{CuCl}_{2}\right)_{5.8}$, $(\mathrm{CuCl})_{6.8},\left(\mathrm{CoCl}_{2}\right)_{5.5},\left(\mathrm{FeBr}_{2}\right)_{6.1}$, and $\left(\mathrm{Cr}(\mathrm{CO})_{4}\right)_{5.6}$. In the metalated structures of $\mathrm{UiO}-\mathrm{bpy} \cdot\left(\mathrm{CuCl}_{2}\right)_{5.8}$, the collective distortions of strut linker molecules and zirconium clusters led structural transition from $\mathrm{Fm} 5 \mathrm{~m}$ to $\mathrm{Pa} 3$ symmetry (Fig. 5), and the metalated ligand environment was clearly characterized.

Further studies for metalation of bpy-MOF extended the range of metal species of TMs and lanthanides as listed in Table 1. Yan and co-workers extensively studied a series of bpy-lanthanidefunctionalized MOFs, and applied them in luminescence studies, selective sensing of various organic compounds, and detection of bio-markers [54,58,73]. Various TMs such as Mo, Tb, Re, Rh, Pt, and Os were also successfully installed in the bpy-MOF system $[32,49,54,64,68,74]$.

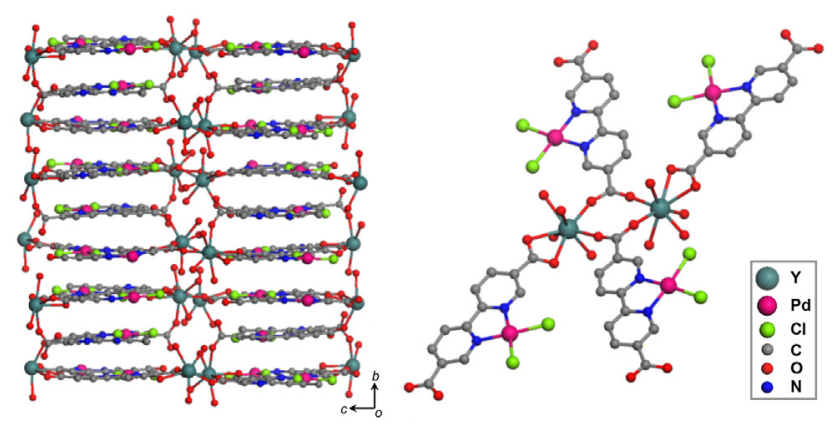

Fig. 4. (a) 3-D network structure of palladium-installed Y-MOF $\left(\mathrm{C}_{36} \mathrm{H}_{40} \mathrm{Y}_{2} \mathrm{Cl}_{6} \mathrm{~N}_{6}\right.$ $\mathrm{O}_{23} \mathrm{Pd}_{3}$ ). Reproduced with permission from Ref. [70].

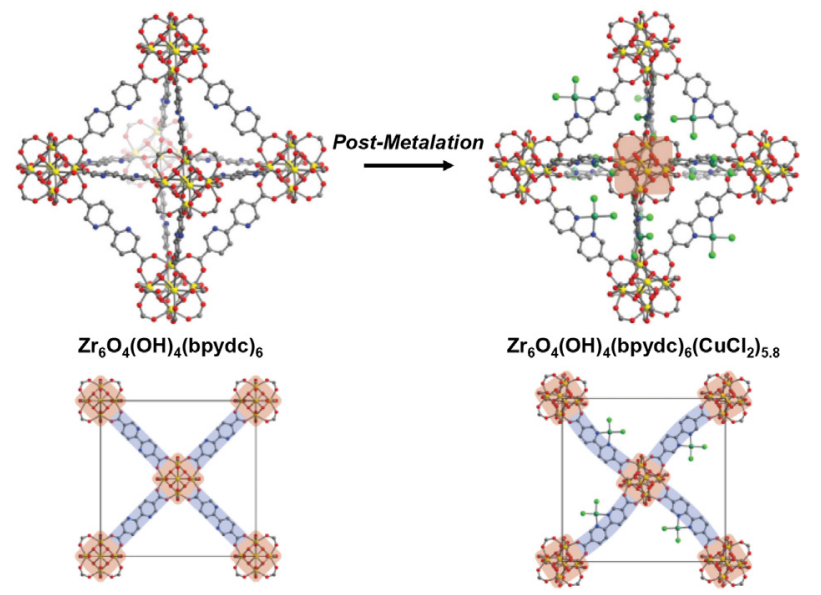

Fig. 5. Representation of SCSC metalation and the structure of the bipyridine metal complexes for bpy-UiO•( $\left.\mathrm{CuCl}_{2}\right)_{5.8}$. Reprinted with permission from Ref. [49].

Metalation on bpy-containing MOFs can be used to anchor metal precursors in the pore for preparing well-confined ultrasmall bimetallic nanoperticles (NPs) in MOFs [51]. As shown in Fig. 6, two steps post-metalation of UiO-bpy resulted in Zn@UiO-bpy$\mathrm{Cu}$. $\mathrm{Cu}$ (II) cation was coordinated to the bpy ligand to yield UiObpy-Cu, and the successive metalation with $\mathrm{ZnEt}_{2}$ formed $\mathrm{Zr}_{3}\left(\mu_{4^{-}}\right.$ OZnEt) from $\mathrm{Zr}_{3}\left(\mu_{4}-\mathrm{OH}\right)$ of secondary building units (SBUs), producing Zn@UiO-bpy-Cu. The product at each step was characterized by diffuse reflectance ultraviolet-visible and near infrared (UV-vis-NIR) and Fourier transform infrared (FT-IR). This bimetalated UiO MOF was in situ reduced at $250{ }^{\circ} \mathrm{C}$ and $4 \mathrm{MPa}$ with $\mathrm{H}_{2}$ / $\mathrm{CO}_{2}$ (3:1) gas was performed to generate $\mathrm{Cu} / \mathrm{ZnO}_{\mathrm{x}} \mathrm{NP}$ at $250{ }^{\circ} \mathrm{C}$ to form CuZn@UiO-bpy. Energy dispersive X-ray spectroscopy (EDS) confirmed that the homogeneous dispersion of $\mathrm{Cu}$ and $\mathrm{Zn}$ atoms even after the reduction process. In this study, the positioning ability of the bpy ligands was well-exploited for preparing new types of NPs.

Similarly with bpydc ligands, di-pyrazole groups can be the coordinating functionality of pre-integrated ligands among heterocyclic ligands. Doonan and Sumby groups employed bis(4-(4-car boxyphenyl)-1H-3,5-dimethyl pyrazolyl)methane $\left(\mathrm{H}_{2} \mathrm{~L}\right.$, Fig. 7$)$ as a ligand to construct the new Mn-based MOF, $\left[\mathrm{Mn}_{3}(\mathrm{~L})_{2}\left(\mathrm{~L}^{\prime}\right)\right]$, in which L coordinates $\mathrm{Mn}(\mathrm{II})$ via pyrazole as well as carboxylate, and L' forms coordination bonds only with carboxylate, having vacant di-pyrazole groups [78]. Through the post-synthetic modification (PSM), the MOF was quantitatively metalated with $\mathrm{CuCl}_{2}$ $.2 \mathrm{H}_{2} \mathrm{O}, \quad \mathrm{CoCl}_{2} \cdot 6 \mathrm{H}_{2} \mathrm{O}$, and $\left[\mathrm{Rh}(\mathrm{CO})_{2} \mathrm{Cl}_{2}\right.$, retaining its single crystallinity, and thus $\mathrm{X}$-ray crystal structures revealed not only
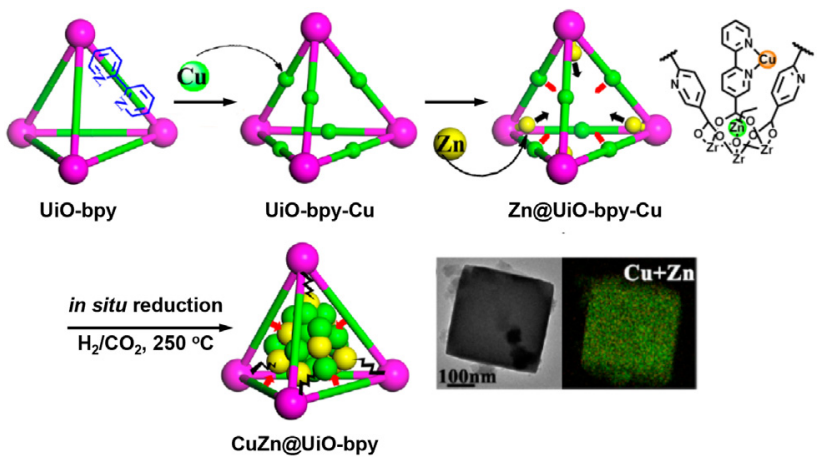

Fig. 6. Synthetic scheme for Zn@UiO-bpy-Cu and CuZn@UiO-bpy with EDS mapping. Reprinted with permission from Ref. [51]. 


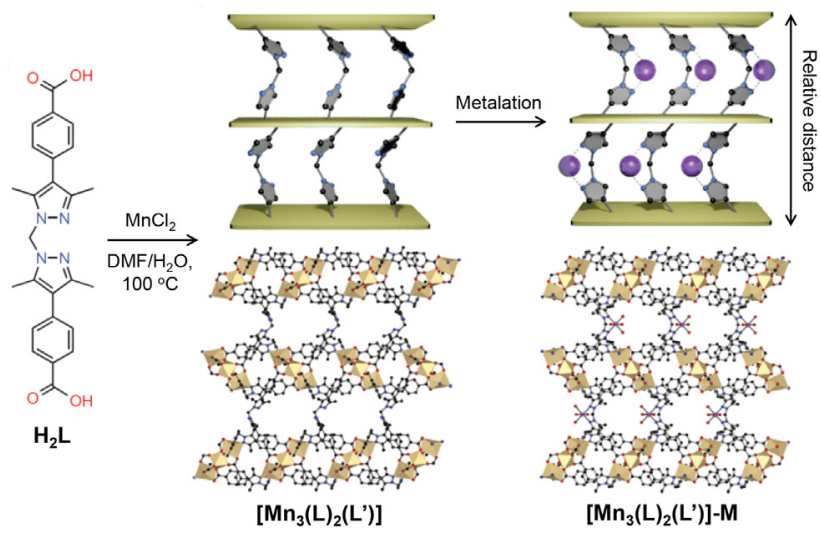

Fig. 7. Schematic representations and perspective views of X-ray crystal structures before and after metalation in $\left[\mathrm{Mn}_{3}(\mathrm{~L})_{2}\left(\mathrm{~L}^{\prime}\right)\right]$. Reproduced with permission from Ref. [78].

the ligand environmental changes but also the entire structure flexibility (Fig. 7).

$\mathrm{N}$-heterocyclic carbenes (NHCs)-containing carboxylic acid ligands are also good candidates to decorate the pores of MOFs with additional coordinating sites. The carbene between two nitrogen atoms in imidazolium are very good coordinating sites for specific metalation such as Pd and Ru in MOFs. The synthesis of imidazole salt (i.e., NHC precursor)-containing MOFs has been extensively attempted for the preparation and metalation of NHC-MOFs [79-89], and various types of NHC-containing carboxylic acid ligands for MOF synthesis are drawn in Fig. 8. In 2010, Yaghi et al. showed how to immobilize organometallic complexes within the pores of MOFs [80]. They initially prepared linear ditopic ligand having NHC moiety, 4,7-bis(4-carboxylphenyl)-1,3dimethylbenzimidazium to synthesize a MOF-5 type structure, IRMOF-76 (Fig. 9a).

Fixation of $\mathrm{Pd}(\mathrm{II})-\mathrm{NHC}$ organometallic complexes within the IRMOF-76 pores was not successful by a post-metalation approach, and instead the direct MOF synthesis with the pre-metalated NHCcontaining ligand ([4,7-bis(4-carboxylphenyl)-1,3-dimethylbenzi midazol-2-ylidene](pyridyl)palladium(II) iodide) led the formation of the desired organometallic complexes immobilized IRMOF-76 (IRMOF-77). The single-crystal structure (Fig. 9b) and $\mathrm{N}_{2}$ adsorption isotherm verified that IRMOF-77 is successfully synthesized without losing the MOF's porosity and its structural order. (a)

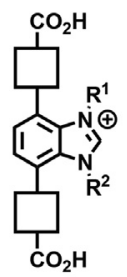

(b)

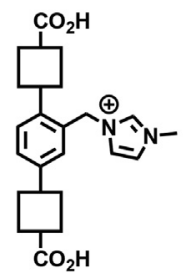

(c)

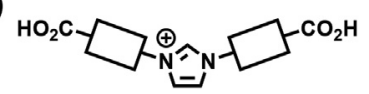

(d)

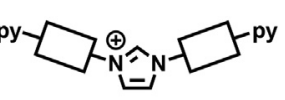

(e)

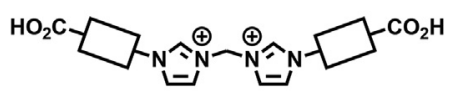

(f)<smiles>O=C(O)C1CCC(n2cc(-[n+]3ccn(C4CCC(C(=O)O)C4)c3)cn2)CC1</smiles>

Fig. 8. Six types of NHC-containing carboxylic acid ligands for MOF preparations. Reproduced with permission from Ref. [79]. (a) $\mathrm{cos}^{\mathrm{r}}$

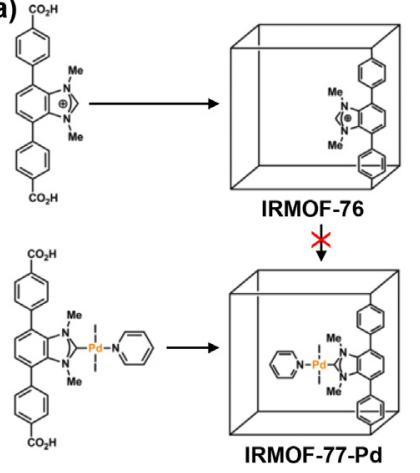

(b)

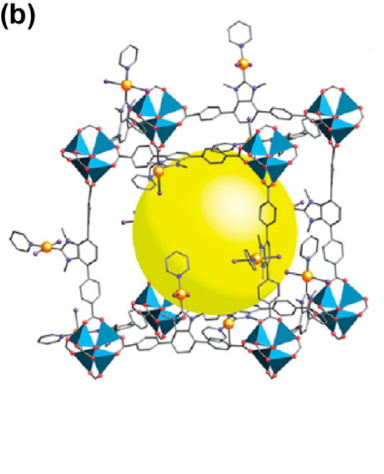

Fig. 9. (a) Synthetic route and strategy for IRMOF-76 and IRMOF-77. (b) Singlecrystal structure of IRMOF-77 $\left[\mathrm{Zn}_{4} \mathrm{O}\left(\mathrm{C}_{28} \mathrm{H}_{21} \mathrm{I}_{2} \mathrm{~N}_{3} \mathrm{O}_{4} \mathrm{Pd}\right)_{3}\right]$ shown with pcu net. Atom colors: blue tetrahedron, $\mathrm{Zn}$; purple, I; orange, Pd; red, O; blue sphere, $\mathrm{N}$. Reprinted with permission from Ref. [80].

Manipulation of porosity is an important factor in view of application of MOFs as catalysts. Scheidt and coworkers controlled the catenation of MOFs by incorporation of different numbers of azolium moieties (one or two) into biphenyl dicarboxylic acid as a dangling group (NHC in strut; Fig. 8b) [81]. By projecting more number of sterically demanding groups into the pore (two azolium moieties), they reduced the degree of catenation and secured the porosity.

$\mathrm{Wu}$ and colleagues utilized a linear-type NHC ligand (NHC in strut; Fig. 8c) to tether catalytic active metal sites in MOF. By heating a mixture of the $\mathrm{NHC}$ ligand $(\mathbf{L})$ and $\mathrm{Cu}\left(\mathrm{NO}_{3}\right)_{2} \cdot 3 \mathrm{H}_{2} \mathrm{O}$ in a solvent yielded blue crystals of $\left[\mathrm{Cu}_{2} \mathbf{L}_{2}(\mathrm{MeOH})_{2}\right] \cdot 4 \mathrm{NH}_{3} \cdot \mathrm{H}_{2} \mathrm{O}$ (1). Subsequently, $11.0 \%$ of $\mathrm{Pd}(\mathrm{II})$ could be immobilized into 1 though postmetalation and the material showed good catalytic activity for Suzuki-Miyaura cross-coupling reactions [82]. Martin-Matute's research team synthesized and introduced a new iridium NHC metallolinker into a PCN-56, which is constituted with $2^{\prime}, 5^{\prime}$-dime thylterphenyl-4,4"-dicarboxylate (dmtpdc) and $\mathrm{Zr}$ clusters via both direct synthesis and post-synthetic exchange (PSE) [83].

The bis-carbene type dicarboxylic acid ligand was utilized for palladium pre-metalation. Recently, Dong et al. initially prepared a palladium N-heterocyclic bis-carbene dicarboxylate ligand, Pdnhdc- $\mathrm{H}_{2} \mathrm{~L}$, through a four-step reaction, and introduced the ligand into UiO-67 type MOF via a direct synthesis and mixed ligand strategy with bpdc (Fig. 10a) [84]. Due to the huge size of Pd-nhdc- $\mathrm{H}_{2} \mathrm{~L}$ ligand than pore size of the MOF, size-matched bpdc ligand were

(a)

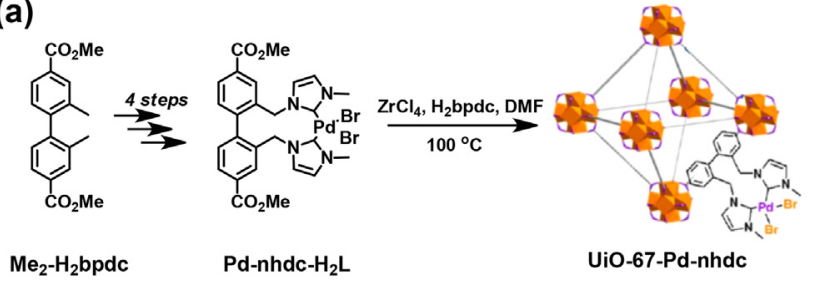

(b)
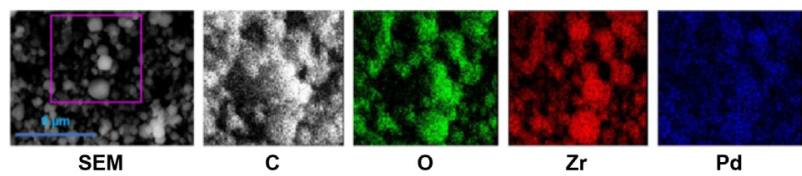

Fig. 10. (a) Synthesis of bis-carbene type UiO-67-Pd-nhdc through pre-metalation and (b) their atom mapping on scannig electron microscope (SEM). Reprinted with permission from Ref. [84]. 
mixed together for solvothermal synthetic condition with $\mathrm{ZrCl}_{4}$ to UiO-67-Pd-nhdc. The BET surface area and pore size that calculated by non-linear density functional theory (NLDFT) of UiO-67-Pdnhdc were slightly decreased from $2113 \mathrm{~m}^{2} \mathrm{~g}^{-1}$ and $10.97 \AA$ to $1540 \mathrm{~m}^{2} \mathrm{~g}^{-1}$ and $8.751 \AA$, relative to UiO-67, respectively. The EDS showed that the dispersion of Pd species in the MOF matrix is uniform (Fig. 10b). As a result, the obtained UiO-67-Pd-nhdc were successfully applied to Heck cross-coupling and intermolecular benzyne-benzyne-alkene insertion reactions with high catalytic activity and recyclability. Nevertheless, post-synthetic metalation of NHC precursors and the introduction of free carbene into MOFs are very challenging tasks as deprotonation of the NHC precursor to generate carbene requires external, strong bases such as NaOtBu [82,85-89].

\subsubsection{Porphyrins}

Porphyrin units are very important coordination sites as a preintegrated ligand for the pore engineering of MOFs, where metalloporphyrins have been widely employed in conjunction with various TMs. Coordination between the metalloporphyrin linkers and metal ion (or cluster) produces Porph-MOFs. Porph-MOFs have been extensively studied and reviewed by many research teams such as Goldberg, Choe, Wu, Ma, and Kim [20,213-219]. The most well-known porphyrin-based linkers are $\mathrm{H}_{4} \mathrm{~L}$-type tcpp and tpyp (tcpp = tetrakis(4-carboxyphenyl)porphyrin, tpyp = tetrakis (4-pyri dyl)porphyrin). Additionally, $\mathrm{H}_{6} \mathrm{~L}$ and $\mathrm{H}_{8} \mathrm{~L}$ ligands were also devel- oped. Herein, we focus on the core metal of the metalloporphyrin and pore engineering of MOF using these species (Table 2).

Although both pre-metalation and post-metalation strategies are possible for porphyrin type ligand, pre-metalation method was mainly utilized for metalloporphyrin preparation on MOFs. In the early stage, porphyrin-based 2D layered structures (i.e., PPF series) were reported by Choe and co-workers. Co(cisZndcpp)(bpy) (cis-Zndcpp = zinc-5,10-di(4-carboxyphenyl)-15,20diphenylporphyrin, bpy $=4,4^{\prime}$-bipyridine) was obtained by solvothermal condition with $\mathrm{Co}\left(\mathrm{NO}_{3}\right)_{2} \cdot 6 \mathrm{H}_{2} \mathrm{O}$, cis-Zndcpp and bpy in DMF/EtOH mixed-solvent (Fig. 11a). Pillar insertion into 2Dlayered structures and pillar ligand exchange were performed by the same group to generate 3D structures [90,93,94,107]. However, the catalytic application of these materials was restricted because the core metals of the porphyrin were also coordinated to the frameworks.

From this point of view, the Choe group obtained 3D-porphyrin MOFs without coordination between metal sites on porphyrin and pillar ligands in 2010 [95]. Modification of pillar strut with methyl substituents allowed the strut to selectively coordinate to the axial positions of the paddle wheel clusters not the porphyrin core in the MOFs (Fig. 11b). This approach enables the synthesis of four new porphyrin-based, pillared-paddlewheel frameworks: PPF-11-Zn/ $\mathrm{Zn},-\mathrm{Co} / \mathrm{Co},-\mathrm{Mn} / \mathrm{Zn}$, and $-\mathrm{Fe} / \mathrm{Zn}$. The next year, the research team of Nguyen and Hupp developed pillar ligands in the PPF series to generate MOFs with accessible active metal sites [122]. Two main

\section{Table 2}

Various metal combinations ( $\mathrm{M}^{1}$ for MOF formation and $\mathrm{M}^{2}$ for catalysts) of porphyrin-functionalized MOFs.

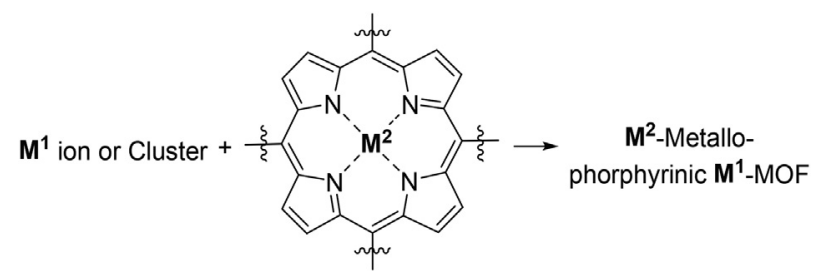

\begin{tabular}{|c|c|c|c|c|c|}
\hline Linkertype & $\mathbf{M}^{\mathbf{1}}$ & $\mathbf{M}^{2}$ & Linkertype & $\mathbf{M}^{\mathbf{1}}$ & $\mathbf{M}^{2}$ \\
\hline \multirow{25}{*}{$\mathrm{OH}$} & Co & Zn(II) [90], Co(II) [92,94,96-99,139], Co(III) [95,98], Pd(II) [94], Fe(III) [100], & & $\mathrm{Rh}$ & $\mathrm{Zn}(\mathrm{II})[189]$ \\
\hline & (II) & $\mathrm{Fe}(\mathrm{II})[101,102], \mathrm{Ni}(\mathrm{II})[100], \mathrm{Pt}(\mathrm{II})[100], \mathrm{V}(\mathrm{IV})[100], \mathrm{Mn}(\mathrm{III})[100,193]$ & & (II) & \\
\hline & $\mathrm{Zn}$ & $\mathrm{Zn}(\mathrm{II})[93-95,103-117,122,139], \mathrm{Mn}(\mathrm{III})[95,100,118-121], \mathrm{Fe}(\mathrm{II})$ & & $\mathrm{Ce}$ & $\mathrm{Zn}(\mathrm{II})$ [190], Co(II) [190] \\
\hline & (II) & $\begin{array}{l}{[101,102,114], \mathrm{Fe}(\mathrm{III})[95,100,120,122], \mathrm{Pd}(\mathrm{II}) \text { [122], } \mathrm{Al}(\mathrm{III})[122], \mathrm{Mg}(\mathrm{II})} \\
{[123], \mathrm{Cu}(\mathrm{II})[124]}\end{array}$ & & (IV) & \\
\hline & $\mathrm{Cu}$ & Co(II) [125,126], Cu(II) [105,127-133], Zn(II) [91,134,135], Ni(II) [135,136], & & $\mathrm{Hf}$ & $\mathrm{Zn}(\mathrm{II})$ [91], Ir(III) [191], Ni(II) [168] \\
\hline & (II) & $\mathrm{Pd}(\mathrm{II})$ [135], Mn(III) [135,136], Ru(II) [135], $\mathrm{Fe}(\mathrm{II})[101,102]$ & & (IV) & \\
\hline & $\mathrm{Cd}$ & $\mathrm{Pd}(\mathrm{II})[137,140], \mathrm{Cd}(\mathrm{II})[110,138,139], \mathrm{Fe}(\mathrm{II})$ [140], Fe(III) [120], Mn(III) & & $\mathrm{Cd}$ & Pd(II) [193], Cd(II) [194], Mn(III) [195], Cd(II) \\
\hline & (II) & {$[120,141], \mathrm{Co}(\mathrm{II})[138,140], \mathrm{Zn}(\mathrm{II})$ [140], Ni(II) [140], Cu(II) [140] } & & (II) & {$[208,211]$} \\
\hline & $\mathrm{Fe}$ & $\mathrm{Ni}(\mathrm{II})[142], \mathrm{Fe}(\mathrm{II})$ [143], $\mathrm{Fe}(\mathrm{III})$ [143] & & $\mathrm{Zn}$ & $\mathrm{Al}(\mathrm{III})[112], \mathrm{Sn}(\mathrm{IV})[112,196], \mathrm{Co}(\mathrm{II})[112], \mathrm{Mn}$ \\
\hline & (II) & & & (II) & $\begin{array}{l}\text { (III) }[117,122], \mathrm{Zn}(\mathrm{II})[112,117,122,197- \\
202,208], \mathrm{Cu}(\mathrm{II})[202]\end{array}$ \\
\hline & $\begin{array}{l}\text { Fe } \\
\text { (III) }\end{array}$ & $\begin{array}{l}\mathrm{Mn}(\mathrm{II})[144], \mathrm{Fe}(\mathrm{II})[144,145], \mathrm{Fe}(\mathrm{III}) \text { [143], Co(II) [144], Ni(II) [144], Cu(II) } \\
{[144], \mathrm{Zn}(\mathrm{II})[145]}\end{array}$ & & $\begin{array}{l}\text { Co } \\
\text { (II) }\end{array}$ & $\mathrm{Co}(\mathrm{II})[99,203,204], \mathrm{Fe}(\mathrm{II})[203,204]$ \\
\hline & $\mathrm{Zr}$ & $\mathrm{Fe}(\mathrm{II})[146,147,149-154], \mathrm{Fe}(\mathrm{III})[148,149,155-161], \mathrm{Mn}(\mathrm{II})$ & & $\mathrm{Cu}$ & $\mathrm{Cu}(\mathrm{I})$ [205], Cu(II) [206-209] \\
\hline & (IV) & {$[146,152,154,162], \mathrm{Co}(\mathrm{II})[146,148,150,152-154,156,162,164,165], \mathrm{Ni}(\mathrm{II})$} & & (II) & \\
\hline & & {$[146,148,152,162,165-168], \mathrm{Co}(\mathrm{III})[163], \mathrm{Cu}(\mathrm{II})$} & & & \\
\hline & & {$[146,147,152,156,165,169,170], \mathrm{Zn}(\mathrm{II})[146,150,152,162-164,167,171-176]$,} & & & \\
\hline & & $\mathrm{Ir}(\mathrm{III})$ [177], Pd(II) [165], Cd(II) [165], Hg(II) [178], Ru [179] & & & \\
\hline & $\mathrm{Pb}$ & $\mathrm{Co}(\mathrm{II})$ [180], Ni(II) [180], Cu(II) [180], V(IV) [180] & & $\mathrm{Cu}$ & $\mathrm{Cu}(\mathrm{II})[210,211]$ \\
\hline & (II) & & & (I) & \\
\hline & $\mathrm{Mn}$ & $\operatorname{Mn}(\mathrm{II})[181], \mathrm{Mn}(\mathrm{III})[140,192], \mathrm{Ni}(\mathrm{II})[141]$ & & Mn & $\operatorname{Mn}(\mathrm{IV})[210], \mathrm{Mn}(\mathrm{III})$ [208] \\
\hline & In & In(III) [182,183], Co(II) [184], Co(III) [185] & & (II) & $\mathrm{Mn}(\mathrm{IV})[210] \mathrm{Mn}(\mathrm{IU})[210]$ \\
\hline & (III) & & & (III) & $\operatorname{lVIn}(\operatorname{IV})[210], \operatorname{lin}(11)[210]$ \\
\hline & $\begin{array}{l}\mathrm{Al} \\
(\mathrm{III})\end{array}$ & $\mathrm{Zn}(\mathrm{II})[145,186], \mathrm{Co}(\mathrm{II})$ [184], Zn(II) [184], Cu(II) [184], Fe(II) [145] & & $\begin{array}{l}\text { Fe } \\
\text { (II) }\end{array}$ & $\mathrm{Co}(\mathrm{II})[203,204], \mathrm{Fe}(\mathrm{II})[203,204]$ \\
\hline & $\mathrm{Ni}$ & $\mathrm{Ni}(\mathrm{II})[187,188], \mathrm{Mn}(\mathrm{III})[192]$ & & $\mathrm{Cu}$ & $\mathrm{Cu}(\mathrm{II})[212]$ \\
\hline & (II) & & & $(0)$ & \\
\hline & & & & $\begin{array}{l}\mathrm{Cd} \\
\text { (II) }\end{array}$ & Pd(II) [193], Cd(II) [194], Mn(III) [195] \\
\hline
\end{tabular}




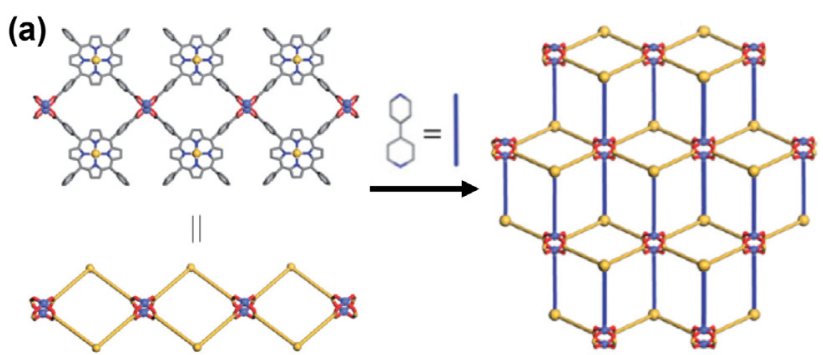

(b)

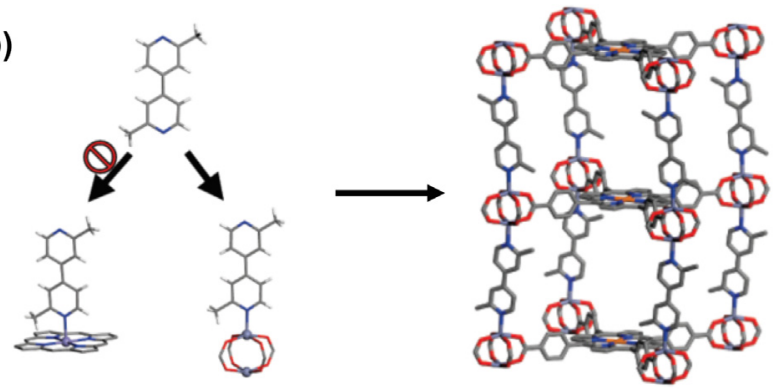

Fig. 11. (a) Schematic illustration of 2D porphyrinic layers assembled from cobalt paddle wheels and cis-Zndcpp and subsequent pillar insertion. Reproduced with permission from Ref. [90]. (b) Synthetic strategy for 3D porphyrinic MOFs with accessible metal centres through modification of pillar ligand. Reprinted with permission from Ref. [95].

strategies were applied to incorporate pillar ligand to cluster and not to metalloporphyrin. First, electron-withdrawing group substituted porphyrin (e.g., -F group in the benzene ring) was used for decreasing installation number of pillar ligand by steric factor. Second, the solubility differences between carboxylate type porphyrin and pyridyl type porphyrin. Pyridyl type porphyrin are less soluble to DMF-EtOH system than carboxylate type porphyrin. As a result, the $\mathbf{M}^{\mathbf{1}} \mathbf{M}^{\mathbf{2}}$-RPMs ( $\mathbf{M}^{\mathbf{1}}$ designates the metal in $\mathbf{L}^{\mathbf{1}}, \mathbf{M}^{\mathbf{2}}$ designates the metal in $\mathbf{L}^{\mathbf{2}}$, and $\mathbf{R P M}$ means robust porphyrinic material) with formula of $\mathrm{Zn}_{2}\left(\mathbf{L}^{\mathbf{1}}\right)\left(\mathbf{L}^{\mathbf{2}}\right)$ was successfully obtained confirmed those structures and metal ratio by analyzing single-crystal XRD and ICP-optical emission spectrometry (ICP-OES) (Fig. 12). Moreover, the $\mathbf{Z n}^{\mathbf{1}} \mathbf{M n}^{\mathbf{2}}$-RPM was utilized in several oxidation reactions and in the hydroxylation of alkanes. Although the reactivity was moderate for organic transformations, this study provided a good strategy for pore engineering of porphyrin-based MOFs for catalytic applications. This strategy has been considered by good followup studies because of the potential for varying piller ligands and metals [108,113,200,201].

In 2012, a significant progress was reported in porphyrin MOF system by Zhou's research team. They generated a highly stable, mesoporous porphyrinic Zr-MOF, $\mathrm{PCN}-222(\mathrm{Fe})(\mathrm{PCN}=$ porous coordination network), which includes catalytic active sites [146]. The solvothermal reaction of $\mathrm{ZrCl}_{4}$ and Fe-tcpp with DMF at $120^{\circ} \mathrm{C}$ produced needle shape crystals. $\mathrm{Zr}_{6}$ cluster was connected with eight tcpp ligands, and the $\mathrm{PCN}-222(\mathrm{Fe})$ has very large hexagonal 1D meso-channels, with triangular micro-channels.

The PCN-222(Fe) showed type IV $\mathrm{N}_{2}$ sorption isotherms with $1009 \mathrm{~cm}^{3} \mathrm{~g}^{-1}$ (STP) of uptake and $2200 \mathrm{~m}^{2} \mathrm{~g}^{-1}$ of BET surface area, suggesting mesoporosity. Also, a NLDFT calculation from $\mathrm{N}_{2}$ curve indicated two kinds of pores with 1.3 and $3.2 \mathrm{~nm}$, which wellmatched with the structural analysis. Moreover, the PCN-222(Fe) exhibited superior chemical stability due to high oxophilic character of zirconium. The $\mathrm{Zr}$ - and porphyrin-based $\mathrm{PCN}-222$ is stable under aqueous conditions and even in dilute $\mathrm{HCl}$ solution, as evidenced by XRPD and $\mathrm{N}_{2}$ isotherms.

In 2013, this $\mathrm{Zr}$ - and porphyrin-based MOF were applied to other isostructural MOFs including $\mathrm{Zr}_{8}$ and $\mathrm{Hf}_{8}$ clusters systems [156]. Another Zr- and porphyrin-based PCN-223 was obtained through kinetically controlled synthetic condition. PCN-223 has hexagonal prismatic 12 -connected $\mathrm{Zr}_{6}$ clusters, and showed good stability to wide range of $\mathrm{pH}$ based on the high connectivity [157]. In addition, PCN-224 series (without metal on porphyrin, $\mathrm{Ni}$, Co, Fe-installed) were prepared with 6 -connected $\mathrm{Zr}_{6}$ cluster by ligand displacement strategy. PCN-224 series displayed the highest BET surface area among the porphyrin-based MOFs $\left(2600 \mathrm{~m}^{2} \mathrm{~g}^{-1}\right)$ [148]. The structural difference of $\mathrm{PCN}-224,-222$, and -223 upon the control of connectivity was illustrated in Fig. 13. Moreover, a derivation on this $\mathrm{Zr}$-based porphyrin type MOFs allows additional PCN-221, PCN-223, PCN-225 series $[148,156,157,171,228]$, and many related applications such as electrochemical or visible-light-driven reduction of $\mathrm{CO}_{2}$ or $\mathrm{O}_{2}$, various organic transformations, photodynamic therapy, light-harvesting, bio or colourmetric or luminescence sensor have been reported

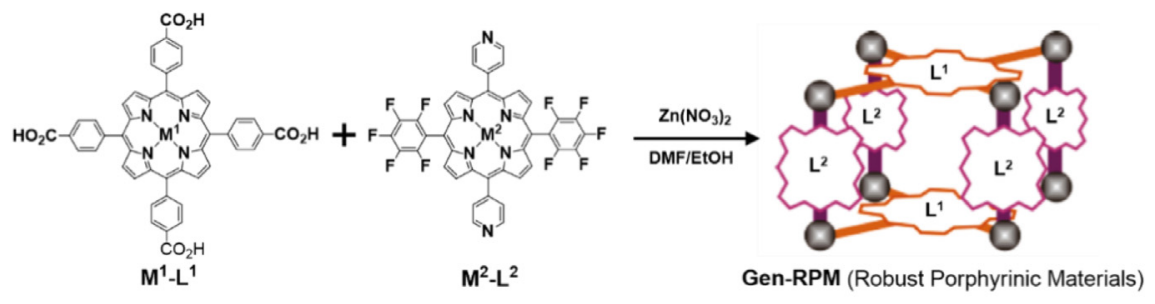

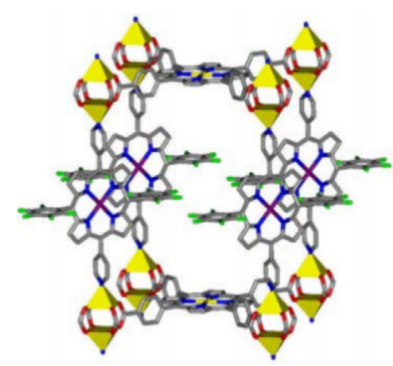

ZnMn-RPM

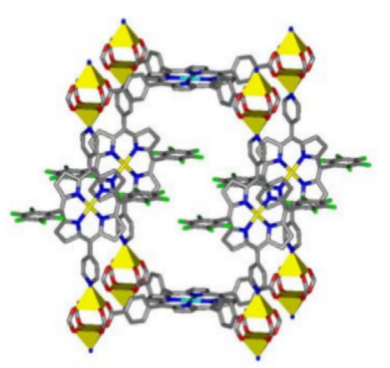

AIZn-RPM

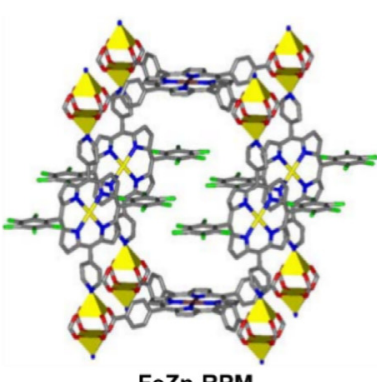

FeZn-RPM

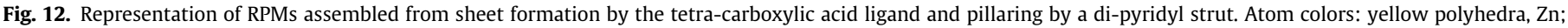
yellow, Zn; brown, Fe; purple, Mn; teal, Al; red, oxygen; green, F; blue, N; gray, C. Reprinted with permission from Ref. [122]. 


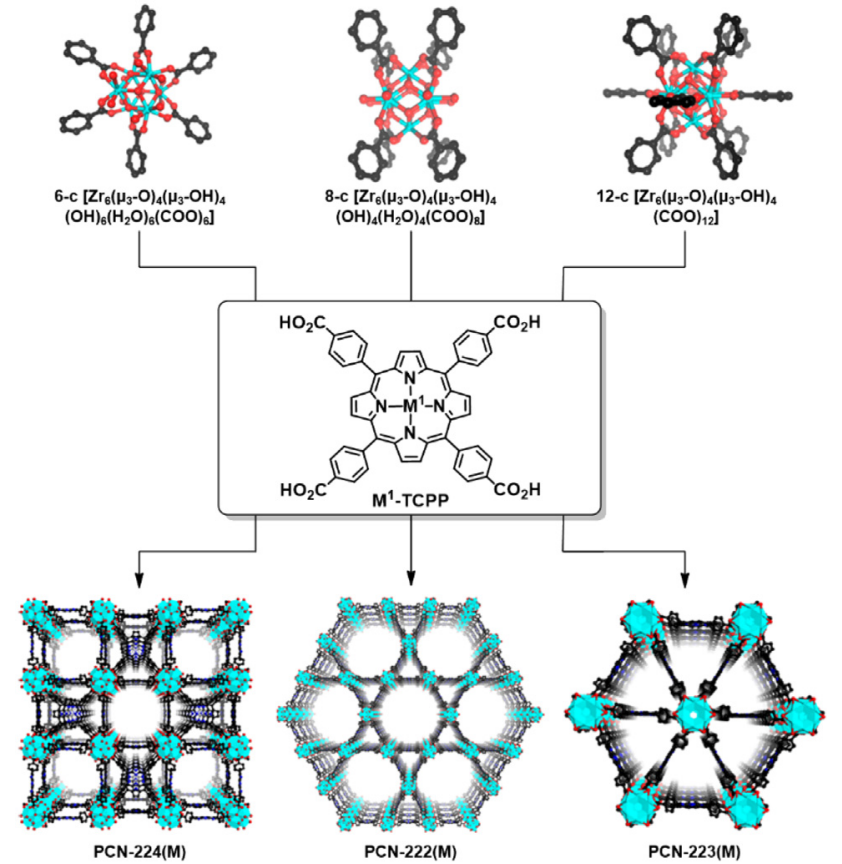

Fig. 13. PCN series with porphyrin-based tcpp ligand and connectivity controls of Zr clusters. Reprinted with permission from Ref. [228].

utilizing PCN series [147,151-154,158-167,169,172-174,177,220227]. Recent studies of porphyrin-MOFs are focused on the applications of these materials such as catalysis rather than the preparation of metalloporphyrin-functionalized MOFs. Reported both pre-metalation and post-metalation have been widely used for further preparations.

\subsubsection{Salens}

Salen (i.e., [(R,R)-N, $N^{\prime}$-bis(5-tert-butylsalicylidene)-1,2-cyclohex anediamine]) is a representative chelating ligand for catalysis such as the asymmetric ring-opening reactions of epoxides and aziridines, the enantioselective addition of alkynes to ketones, and the symmetric oxidation of sulfides to sulfoxides. As shown in Table 3, salen-based struts have been studied as a pre-integrated ligand for the synthesis of MOFs with various combinations of $\mathrm{M}^{1}$ for MOFconstruction (in SBU) and $\mathrm{M}^{2}$ for the salen centre (Table 3). $\mathrm{M}^{2}$ is crucial for catalytic applications of salen-based MOFs.

\section{Table 3}

Various metal combinations ( $\mathrm{M}^{1}$ for MOF formation and $\mathrm{M}^{2}$ for for catalysts) of salen type-functionalized MOFs.

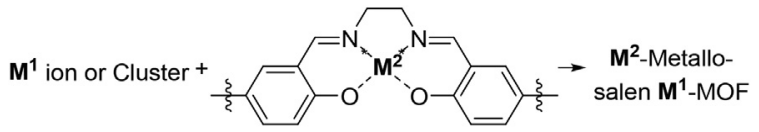

\begin{tabular}{|c|c|}
\hline $\mathbf{M}^{1}$ & $\mathbf{M}^{2}$ \\
\hline $\mathrm{Zn}$ & (II) \\
\hline Mn & $\begin{array}{l}\text { (III) [229-236], Cr(II) [234], Co(II) [234], Mn(II) [234], Ni(II) [234], } \\
\mathrm{Cu}(\mathrm{II}) \text { [234-238], Zn(II) [234], V(IV) [235], Cr(III) [235], } \mathrm{Fe}(\mathrm{III}) \text { [235], } \\
\mathrm{Co}(\mathrm{III}) \text { [235], Th(IV) [236] }\end{array}$ \\
\hline $\mathrm{Cu}$ & (II) \\
\hline $\mathrm{Cr}$ & (III) [239], Cu(II) [240], Pd(II) [240], Ni(II) [240,241] \\
\hline $\mathrm{Cd}$ & (II) \\
\hline Co & $\begin{array}{l}\text { (II) [242], Ni(II) [242-244], Cu(II) [237,244-247], Cr(III) [248], V(IV) } \\
{[201,247,249,250], \mathrm{Fe}(\mathrm{III}) \text { [249] }}\end{array}$ \\
\hline $\mathrm{Zr}$ & (IV) \\
\hline $\mathrm{Cu}$ & $\begin{array}{l}\text { (II) [251], Fe(III) [251], Cr(III) [251], V(IV) [251], Mn(III) [251,252], } \\
\text { Ni(II) [252] }\end{array}$ \\
\hline
\end{tabular}

The chiral Mn-salen system for the epoxidation of alkenes is the proto-type for catalytic applications of MOFs. In 2006, Schmitt and co-workers employed Mn-salen strut, $(R, R)-(-)-1,2-$ cyclohexanediamino- $N, N$ '-bis(3-tert-butyl-5-(4-pyridyl)

salicylidene $\mathrm{Mn}(\mathrm{III}) \mathrm{Cl}$ (1) as a catalytic site for MOF construction [229]. In combination with bpdc (2) and zinc ions, a robust, pillared-paddlewheel MOF could be synthesized (left direction of Fig. 14a). The MOF with the formula $\mathrm{Zn}_{2}(\mathrm{bpdc})_{2}(\mathbf{1})$ crystallized in unobstructed channel with dimensions of $15.7 \times 6.2 \AA$, comprised of interpenetrating pairs of networks. The Hupp and Nguyen's reaserch team induced that a non-interpenetrated Mn-salen MOF by replacing the dicarboxylic linker (2) with the tetracarboxylic acid (3) as shown in right direction of Fig. 14a [232]. The MnSO-MOF $\left[\mathrm{Zn}_{2}(\mathbf{3})(\mathbf{1})\right]$ secured porosity with channel with dimensions of 22 . $4 \times 11.7 \AA$, which larger than that of $\mathrm{Zn}_{2}(\mathrm{bpdc})_{2}(\mathbf{1})$. As a result, MnSO-MOF exhibited great activity for the epoxidation of 2,2dimethylchromene with 4000 turnovers. In the meantime, the Mn-salen containing MOF strut was expanded by various combination of carboxylic acid-based and pyridyl-based multivalent ligands [230].

The strategy of preparing a series of metallosalen-based MOFs was introduced by the Hupp and Nguyen group in the same year [234]. Initially, they attempted to synthesize the Co(III) analogue of MnSo-MOF using dipyridyl $\mathrm{Co}$ (salen) as a reactant by direct method. However, the dipyridyl $\mathrm{Co}$ (salen) aggregated during MOF synthesis due to high affinities of $\mathrm{Co}(\mathrm{III})$ for nitrogeneous ligands. As an alternative, the selective PSM strategy for demetalation and re-metalation was used to prepare a series of metallosalen-containing MOFs (Fig. 14b). The de-manganation of MnSO-MOF was achieved with $\mathrm{H}_{2} \mathrm{O}_{2}$, resulting in the depletion of almost Mn(III) (named dSO-MOF) as evidenced by ICP-OES. That enabled the re-metalation of a variety of metal precursors such as $\mathrm{Mn}(\mathrm{II}), \mathrm{Zn}(\mathrm{II}), \mathrm{Cr}(\mathrm{III}), \mathrm{Co}(\mathrm{II}), \mathrm{Ni}(\mathrm{II})$, and $\mathrm{Cu}(\mathrm{II})$ to dSO-MOF and form each isostructural MSO-MOFs. The amount of remetalation in various MSO-MOFs was determined with ICP-OES and the metallosalen moiety was confirmed by matrix assisted laser desorption/ionization time-of-flight (MALDI-TOF) MS.

Carboxylic acid-based Mn-salen ligands were extensively studied by the group led by Wenbin Lin $[231,233]$. In 2010, the isoreticular CMOFs 1-5 (CMOF = chiral MOFs) of the primitive cubic network topology were obtained by combining $\left[\mathrm{Zn}_{4}\left(\mu_{4}-\mathrm{O}\right)\right.$ $\left.\left(\mathrm{O}_{2} \mathrm{CR}\right)_{6}\right]$ SBUs and chiral Mn-salen with length-controlled dicarboxylate ligands such as $\mathrm{L}_{1} \mathrm{H}_{2}, \mathrm{~L}_{2} \mathrm{H}_{2}$, and $\mathrm{L}_{3} \mathrm{H}_{2}$ as presented in Fig. 15 [231]. As a result, the pore channel and sizes of the CMOFs could be managed systematically depending on the type of Mnsalen struts and the degree of interpenetration. The rates of asymmetric epoxidation reactions highly depend on the pore size of CMOF and the catalytic activities of non-interpenetrated CMOFs $\mathbf{2}$ and $\mathbf{4}$ is comparable that of a homogeneous catalyst. A year later, the Lin group synthesized longer Mn-salen dicarboxylate ligand than $\mathrm{L}_{3} \mathrm{H}_{2}$ by a Schiff base condensation between $(R, R)$ cyclohexanediamine and (E)-4-(3-tert-butyl-5-formyl-4-hydroxys tyryl)benzoic acid and subsequent Mn metalation [233]. As a result of MOF formation with the ligand, the MOF crystallized in the twofold interpenetrated scaffold with $2.9 \mathrm{~nm}$ of pore diameter and $87.8 \%$ of accessible void volume.

MOF catalysts with multiple active sites has long been of great interest for versatile and tandem/sequential reactions. In particular, chiral multifunctional MOF catalysts are less explored and still challenging work. In this aspect, Cui and co-workers expanded the chiral salen-based MOF system to multivariate MOFs (MTV-MOFs) with strategically placed multiple metallosalen active sites [235]. The catalytically active metallosalen derived dicarboxylate ligands $\mathrm{H}_{2} \mathbf{L}^{\mathbf{M}}[\mathrm{M}=\mathrm{Cu}, \mathrm{VO}, \mathrm{CrCl}, \mathrm{MnCl}, \mathrm{Fe}(\mathrm{OAc})$, and $\mathrm{Co}(\mathrm{OAc})]$ were synthesized by metalation of salen with $\mathrm{Cu}\left(\mathrm{NO}_{3}\right)_{2}, \mathrm{VOSO}_{4}, \mathrm{CrCl}_{2}, \mathrm{Mn}$ $(\mathrm{OAc})_{2}, \mathrm{Fe}(\mathrm{OAc})_{2}$, and $\mathrm{Co}(\mathrm{OAc})_{2}$ in methanol, and the combination 

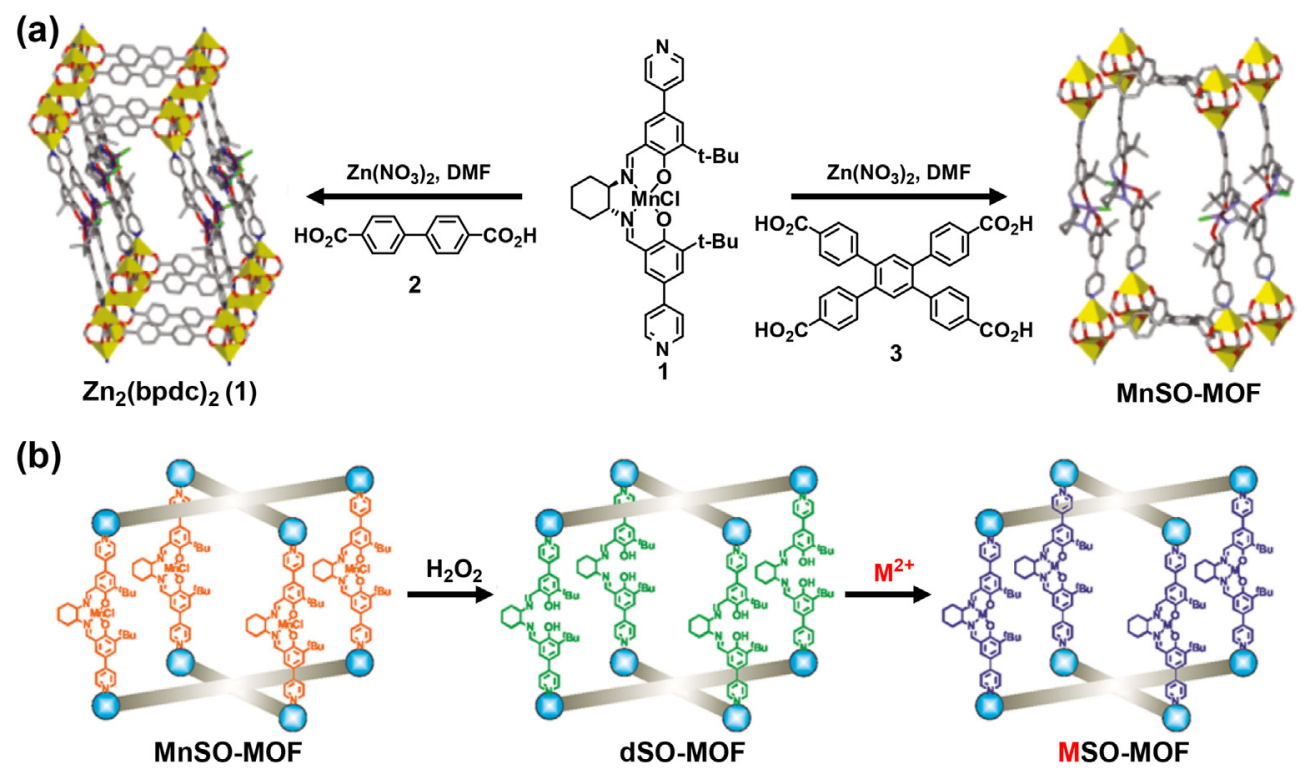

Fig. 14. (a) Synthesis of salen-containing MOFs from different carboxylic acid-based and pyridyl-based salen combinations. Reprinted with permission from Ref. [232]. (b) PSM strategy for generating various metallosalen-based MOF. Reprinted with permission from Ref. [234].
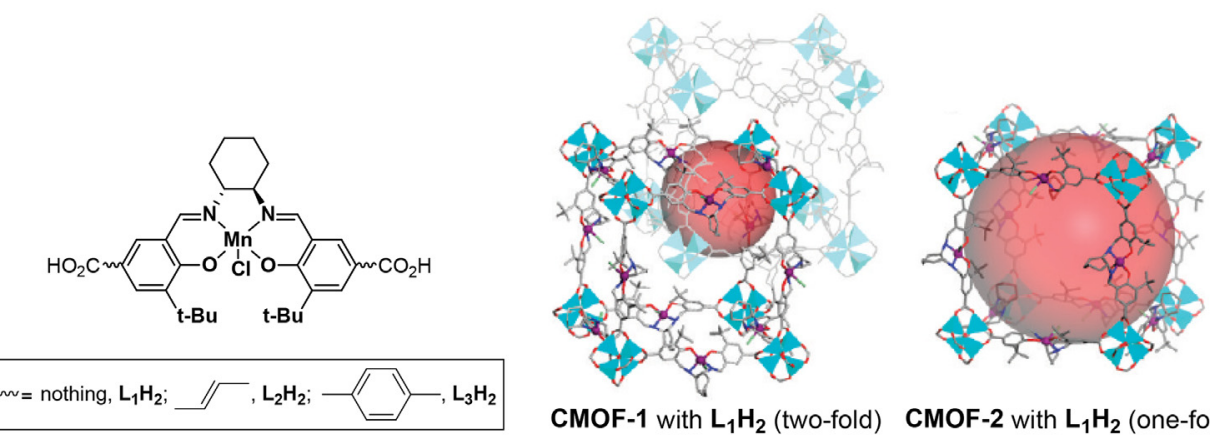

CMOF-1 with $\mathrm{L}_{1} \mathrm{H}_{2}$ (two-fold) CMOF-2 with $\mathrm{L}_{1} \mathrm{H}_{2}$ (one-fold)
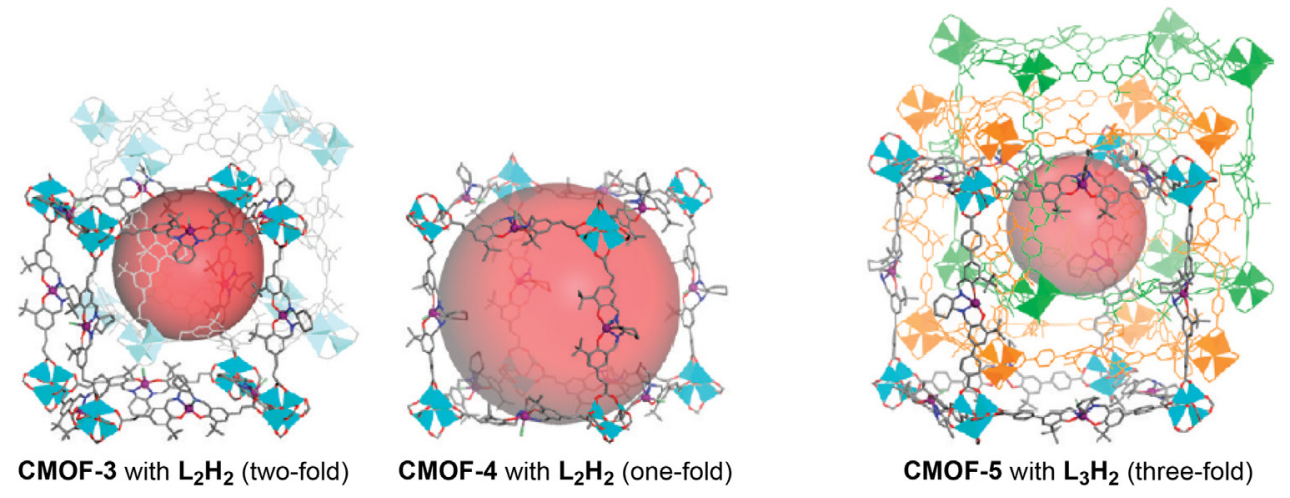

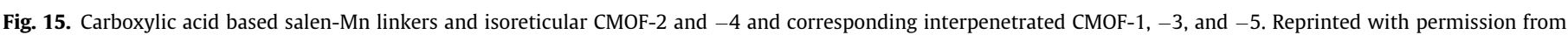
Ref. [231].

of metal-loaded salen ligands generated eight MTV-MOFs with two-interpenetrate framework (Fig. 16a). Indeed, the various combinations of ligands produced seven mixed crystals variants $[\mathrm{M}=\mathrm{CuV}, \mathrm{CuMn}, \mathrm{CuCr}, \mathrm{CuFe}, \mathrm{CuCo}, \mathrm{CuMnCr}$, and CuMnCo], and molar ratio of metal was determined by ICP-OES. In case of ternary MTV-MOFs, EDS revealed that the conformation of metal is well mixed-component compounds rather than physical mixtures of homoleptic series (Fig. 16b and c). The interpenetrated framework provided more adjacent species for cooperative catalysis between different metals than the non-interpenetrated structures. Thus, the catalytic efficiency and enantioselectivity of the MTV system was enhanced. In addition, the strategic combination of metallosalen complexes provided an efficient catalytic platform for sequential tandem reactions. For example, $\mathrm{Cu} / \mathrm{Mn} / \mathrm{Fe}-$ loaded salen complexes are good catalysts for epoxidation, and $\mathrm{Co} / \mathrm{Cu}$ are suitable metals for asymmetric epoxide ring-opening reactions. $\mathrm{Cu} /$ $\mathrm{Mn} / \mathrm{Fe}$-loaded MOF exhibited good catalytic activity for the asymmetric epoxidation/ring-opening reactions of various alkenes.

Recently, the multivariate salen-based MOF system was demonstrated to highly stable $\mathrm{Zr}(\mathrm{IV})$-based UiO-68-Me, which is 
(a)
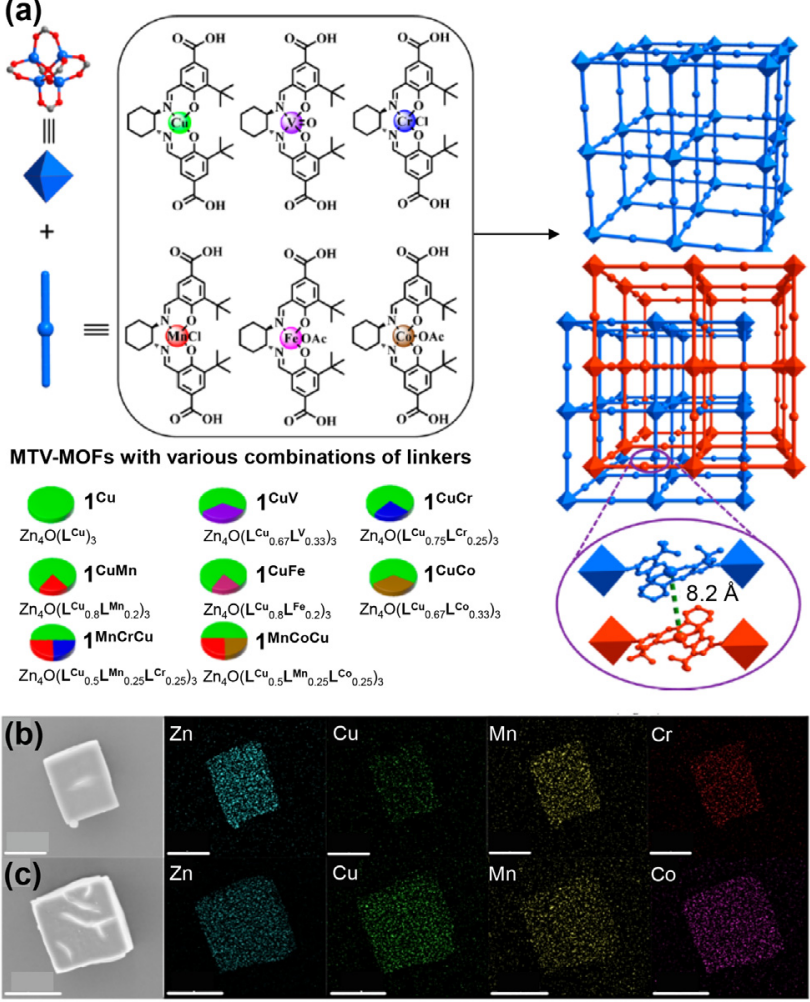

Fig. 16. (a) Organization of MOF $\mathbf{1}^{\mathrm{Cu}}$ and corresponding MTV-MOFs $\mathbf{1}^{\mathrm{CuM}}$ and $\mathbf{1}^{\text {CumM' }}$ with various different metallosalen linkers two-fold interpenetrated structures and adjacent distance between network. EDS mappings of (b) $\mathbf{1}^{\mathrm{CuMnCr}}$ and (c) $\mathbf{1}^{\text {CuMnCo}}$. Reprinted with permission from Ref. [235].

composed of $\mathrm{Zr}_{6} \mathrm{O}_{4}(\mathrm{OH})_{4}$ clusters and 2-methyl-terphenyl dicarboxylate ligand $\left(\mathrm{H}_{2}\right.$ TPDC-Me) [251]. Due to the similar length and connectivity of $\mathrm{H}_{2}$ TPDC-Me and $\mathrm{H}_{2} \mathrm{~L}^{\mathbf{M}}$ linkers, UiO-68-Me could easily transformed into single and mixed $\mathrm{M}$ (salen)introduced UiO-68-M in one and two-step PSE approach ( $\mathrm{M}=\mathrm{Cu}$, $\mathrm{Cr}, \mathrm{Mn}, \mathrm{Fe}, \mathrm{V}, \mathrm{Mn}-\mathrm{Cr}$, and $\mathrm{Mn}-\mathrm{V}$ ). All UiO-68-Ms are stable in air and common organic solvents and those BET surface areas decreased ranging from 2566 to $2758 \mathrm{~m}^{2} \mathrm{~g}^{-1}$, relative to the value of parent UiO-68-Me $\left(3738 \mathrm{~m}^{2} \mathrm{~g}^{-1}\right.$ ) because of the bulky M(salen) moiety. In addition, EDS show uniformly distribution of $\mathrm{M}$ and $\mathrm{Zr}$.

Fine-tuning the pores of MOFs is crucial for enhancing the selectivity for separation of mixtures. Specifically, the development of a chiral pore environment using chiral ligands is an important feature for the separation of chiral molecules. In 2012, Chen and coworkers reported isostructural mixed-metal organic frameworks (M'MOF 4-7) using two chiral salen type ligands $[(1 R, 3 S)-1,2$, 2-trimethyl-1,3-diaminocyclopentane and (1R,2R)-(-)-1,2cyclohexanediamine)] (i.e., cdc and bdc) (Fig. 17) [237]. M'MOF 4-7 from the various combinations of ligands exhibited a variety of pore environments and matched with chiral molecules. These fine-tuned MOFs showed good separation efficiency with a maximum of $82.4 \%$ ee for 1-phenyl ethanol, 2-butanol, and 2-pentanol.

\subsection{Sequential attachment}

'Pre-integrated ligand' approach, discussed in detail above, still remains relatively limited by the unpredictable framework caused by potential coordination of the functional groups to the metal ions during MOF construction. In this regard, post-synthetic attachment represents a powerful tool for anchoring coordinating functionalities that are able immobilize catalytic sites. In this section, we describe examples of 'Sequential attachment' approaches such as imine condensation, ring-opening, and the Click reaction.
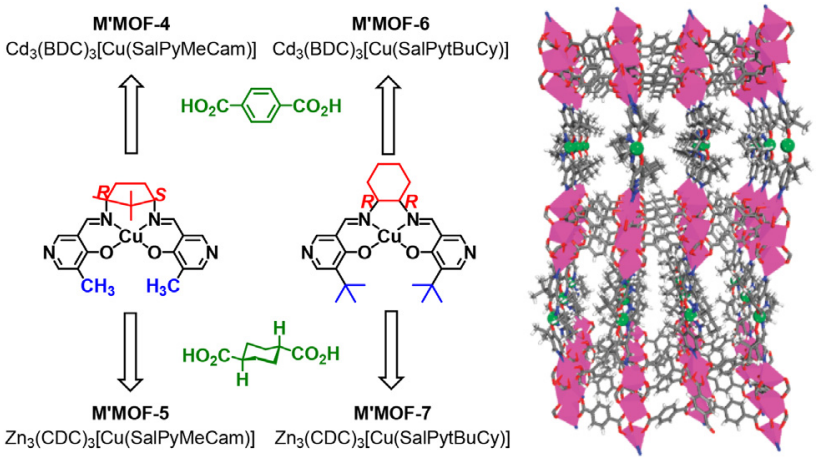

Fig. 17. Synthesis of four isostructural mixed-metal organic frameworks (M'MOF 4-7). Reprinted with permission from Ref. [237].

\subsubsection{Imine condensation}

Imines or Schiff bases can be synthesized from an amine and a carbonyl compound by dehydration. Imine (or Schiff base) condensation on amine- or aldehyde-tagged MOFs has proven to be a highly beneficial field of research. Especially, imine functionalization opens a route for incorporating active metal sites into MOFs. In 2007, the group led by Rosseinsky executed covalent transformation on amine-functionalized IRMOF-3 ([( $\left.\mathrm{Zn}_{4} \mathrm{O}\right)\left(\mathrm{O}_{2} \mathrm{C}-\right.$ $\left.\left.\mathrm{C}_{6} \mathrm{H}_{3}\left(\mathrm{NH}_{2}\right)-\mathrm{CO}_{2}\right)_{3}\right]_{\mathrm{n}}$, iso-reticular MOF-3) via imine condensation resulting in the bidentate ligand, salicylidene $\left(\mathrm{R}-\mathrm{N}=\mathrm{C}-\mathrm{C}_{6} \mathrm{H}_{4} \mathrm{OH}\right)$ (Fig. 18a) [253].

The solvent in the pores of IRMOF-3 was firstly exchanged with chloroform, followed by further guest exchange with aldehydecontaining salicylaldehyde in toluene solvent (IRMOF-3-tol ${ }_{x}$ ) over the course of seven days. This method produced stoichiometric ca. $13 \%$ (0.4 salicylidene groups per cavity) converted MOF, IRMOF-3-sal $\mathrm{S}_{0.4}\left(\left(\mathrm{Zn}_{4} \mathrm{O}\right)\left(\mathrm{O}_{2} \mathrm{C}-\mathrm{C}_{6} \mathrm{H}_{3}\left(\mathrm{NH}_{2}\right)-\mathrm{CO}_{2}\right)_{2.6}\left(\mathrm{O}_{2} \mathrm{C}-\mathrm{C}_{6} \mathrm{H}_{3}-\mathrm{N}=\mathrm{C}(\mathrm{H})\right.\right.$ $\left.\left.\left.\mathrm{C}_{6} \mathrm{H}_{4} \mathrm{OH}\right)-\mathrm{CO}_{2}\right)_{0.4}\right)$ with good crystallinity. The successful imine condensation was initially indicated by a colour change of the (a)

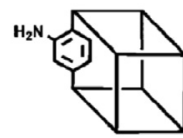

IRMOF-3

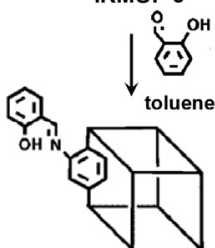

IRMOF-3-sal

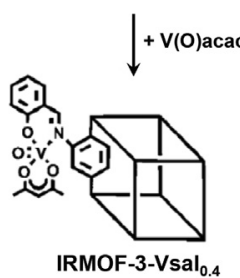

(b)

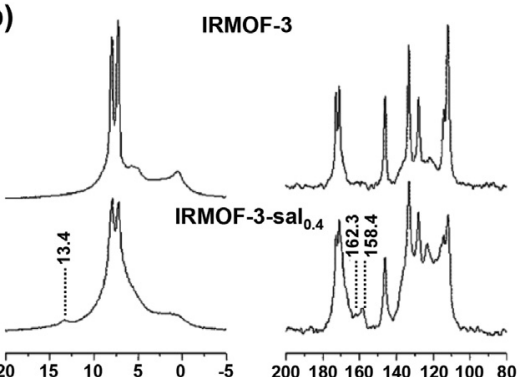

(c)

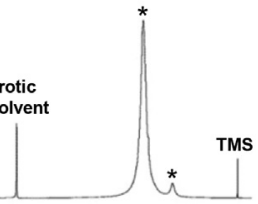

IRMOF-3-sal $\left.\right|_{0.4}$

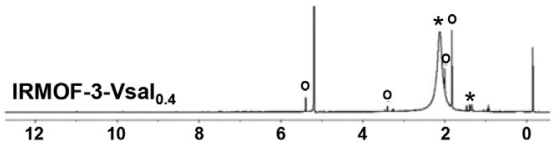

Fig. 18. (a) Schematic of post-synthetic functionalization of IRMOF-3 with salicylaldehyde and subsequent binding of vanadyl complex. (b) Solid state ${ }^{1} \mathrm{H}$ MAS NMR spectra (left) and ${ }^{1} \mathrm{H}-{ }^{13} \mathrm{C} \mathrm{CP} /$ MAS NMR spectra of IRMOF-3 (top) and IRMOF-3-sal $\mathrm{I}_{0.4}$ (bottom). (c) ${ }^{1} \mathrm{H}$ spectra of IRMOF-3-sal $\mathrm{I}_{0.4}$ and IRMOF-3-Vsal $\mathrm{I}_{0.4},{ }^{*}=\mathrm{V}(\mathrm{O}) \mathrm{acac}_{2} \cdot \mathrm{H}_{2} \mathrm{O}$ resonances, $\mathrm{O}=$ resonances for acetylacetone. Reproduced with permission from Ref. [253]. 
microcrystals from cream to yellow and confirmed by the solidstate UV-vis absorption centred at $450 \mathrm{~nm}$, which is a characteristic of the salicylidine moiety. Moreover, imine formation in IRMOF-3-sal ${ }_{0.4}$ was verified by solid-state ${ }^{1} \mathrm{H}-{ }^{13} \mathrm{C}$ cross polarization magic angle spinning nuclear magnetic resonance (CP/MAS NMR) (Fig. 18b). The two resonance peaks appearing at 162 and $158 \mathrm{ppm}$ were assigned to $\mathrm{C}=\mathrm{N}$ and aryl $\mathrm{C}-\mathrm{OH}$, and no aldehyde resonance was observed at $\mathrm{ca} .195 \mathrm{ppm}$. Moreover, the resonance of IRMOF-3-sal 0.4 at $13.4 \mathrm{ppm}$ in the ${ }^{1} \mathrm{H}$ MAS NMR spectrum indicated that the salicylidene $\mathrm{OH}$ was hydrogen-bonded to the imine $\mathrm{N}$. This transformation promoted metal ion inclusion in IRMOF-3, leading to heterogenization of the vanadyl complex. IRMOF-3$\mathrm{sal}_{0.4}$ was immersed in $\mathrm{VO}(\mathrm{acac})_{2} \cdot \mathrm{H}_{2} \mathrm{O}$ (acac = acetylacetonate) solution to investigate the metal-binding ability, resulting in the formation of IRMOF-3-Vsal ${ }_{0.4}$ with the empirical formula $\left(\mathrm{Zn}_{4} \mathrm{O}\right)$ $\left(\mathrm{O}_{2} \mathrm{C}-\mathrm{C}_{6} \mathrm{H}_{3}\left(\mathrm{NH}_{2}\right)-\mathrm{CO}_{2}\right)_{2.6}\left(\mathrm{O}_{2} \mathrm{C}-\mathrm{C}_{6} \mathrm{H}_{3}\left(\mathrm{NC}(\mathrm{H})-\mathrm{C}_{6} \mathrm{H}_{4} \mathrm{O}-[\mathrm{VO}(\right.\right.$ acac $\left.)]\right)-$ $\left.\mathrm{CO}_{2}\right)_{0.4}$. After inclusion of the vanadium ion, a $\mathrm{Zn} / \mathrm{V}$ ratio of ten was determined by EDS analysis, and new resonances appeared in the ${ }^{1} \mathrm{H}$ NMR spectrum, corresponding to acetylacetone (Fig. 18c).

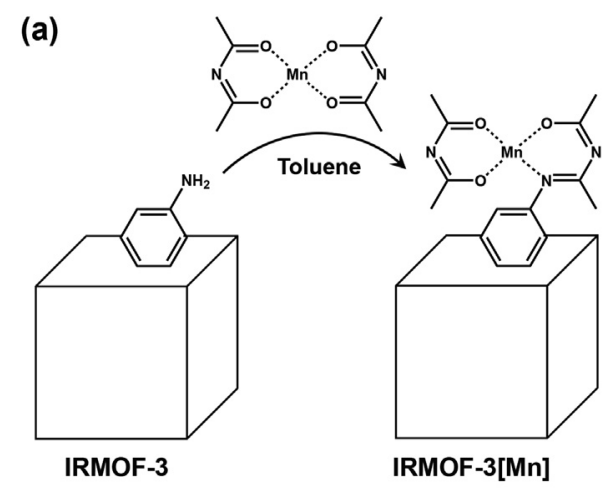

(b)

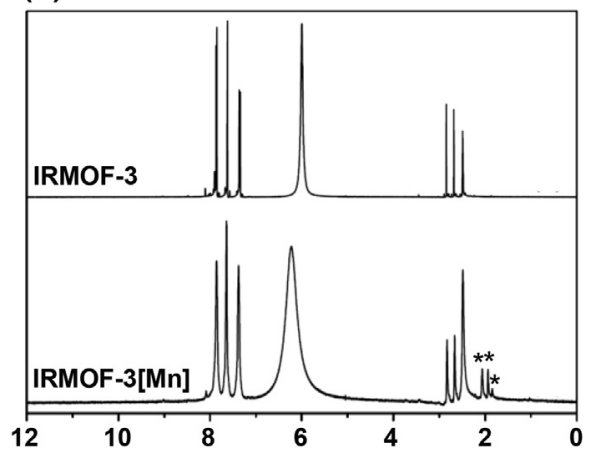

Fig. 19. (a) One-step post-functionalization to generate IRMOF-3[Mn] from IRMOF3 and (b) the corresponding ${ }^{1} \mathrm{H}$ NMR spectra. Reproduced with permission from Ref. [254].
Ahn and colleagues extended this approach to other metal complexes in 2011 [254]. They described the binding of $\mathrm{Mn}(\mathrm{acac})_{2}$ to IRMOF-3 via one-step post-functionalization, as demonstrated in Fig. 19a. IRMOF-3 was firstly immersed in toluene for one day, and subsequently soaked in $\mathrm{Mn}(\mathrm{acac})_{2}$ toluene solution and treated at $55{ }^{\circ} \mathrm{C}$ for $20 \mathrm{~h}$, resulting in IRMOF-3[Mn]. The amount of bound manganese complex determined by ICP-MS and elemental analysis (EA) was $0.23 \mathrm{mmol} \mathrm{g}^{-1}$. The original IRMOF-3 framework structure was preserved with high integrity even after postfunctionalization. The Langmuir surface area and pore volume of IRMOF-3[Mn] decreased only by the mass of $\mathrm{Mn}(\mathrm{acac})_{2}$. The FTIR spectrum of IRMOF-3[Mn] exhibited a new peak at $1523 \mathrm{~cm}^{-1}$, attributed to the vibration of the acetylacetonate anion, and three new peaks appeared at 2.06, 1.94, and $1.85 \mathrm{ppm}$ in the ${ }^{1} \mathrm{H}$ NMR spectrum, indicating the presence of imine-functionalized acac species (Fig. 19b).

As described in previous studies, IRMOF-3 represents a great model system for sequential attachment of coordinating functionalities. Koner's group also developed a new Pd(II)-containing heterogeneous catalyst by applying the PSM strategy to the IRMOF-3 scaffold [255]. The free $\mathrm{NH}_{2}$ groups reacted with pyridine-2-caroxaldehyde (Py-CHO) though a simple imine condensation, where the 2-pyridyl-imine $\left(\mathrm{R}-\mathrm{N}=\mathrm{C}-\mathrm{C}_{5} \mathrm{H}_{4} \mathrm{~N}\right)$ moiety comprised $7 \%$ of the total $\mathrm{NH}_{2}$ groups as a bidentate ligand (IRMOF-3-PI). Functionalization provided an environment for Pd (II) complex immobilization within the pores of IRMOF-3 (IRMOF-3-PI-Pd), as presented in Fig. 20. The FT-IR spectrum of IRMOF-3-PI showed two new peaks at 1653 and $1616 \mathrm{~cm}^{-1}$, ascribed to the vibration bands of the azomethine group $(>\mathrm{C}=\mathrm{N}-$ ) and vibration of the $\mathrm{C}=\mathrm{N}$ bond of the pyridine ring. The vibration bands of azomethine and the $\mathrm{C}=\mathrm{N}$ bond were shifted to lower frequency in the case of IRMOF-3-PI-Pd, indicating coordination of palladium(II). The strong band centred at $325 \mathrm{~nm}$ in the solidstate UV-vis spectrum of IRMOF-3-PI-Pd was ascribed to the charge transfer transition stemming from $\pi$-electron interactions between the metal and ligand.

IRMOF-3 undergoes a low degree of functionalization due to its small pore aperture ( $8 \AA$ ) that restricts access of the reactants. In this regard, Yaghi and co-workers proposed $\left(\mathrm{Zn}_{4} \mathrm{O}\right)_{3}\left(\mathrm{BDC}-\mathrm{NH}_{2}\right)_{3}$ $(\mathrm{BTB})_{4}(\mathrm{~A})\left(\mathrm{BTB}=4,4^{\prime}, 4^{\prime \prime}\right.$-benzene-1,3,5-triyl-tribenzoate) having large cages with internal diameters of 30.7 and $23.2 \AA$ as a scaffold for introducing coordinating functionalities into the pores to achieve a high degree of functionalization [256]. As shown in Fig. 21a, A was reacted with Py-CHO and was completely transformed to the iminopyridine ligated $\left(\mathrm{Zn}_{4} \mathrm{O}\right)_{3}\left(\mathrm{BDC}-\mathrm{C}_{6} \mathrm{H}_{5} \mathrm{~N}_{2}\right)_{3}(\mathrm{BTB})_{4}$ (B), and subsequently reacted with $\mathrm{PdCl}_{2}\left(\mathrm{CH}_{3} \mathrm{CN}\right)_{2}$ to furnish the palladium-containing derivative, $\left(\mathrm{Zn}_{4} \mathrm{O}\right)_{3}\left(\mathrm{BDC}-\mathrm{C}_{6} \mathrm{H}_{5} \mathrm{~N}_{2} \mathrm{PdCl}_{2}\right)_{3}$ $(\mathrm{BTB})_{4}(\mathrm{C})$ with high crystallinity. To precisely define the $\mathrm{Pd}$ coordination environment within the framework, material $\mathbf{C}$ was subjected to Pd K-edge EXAFS pectroscopic analysis (Fig. 21b). The results indicated the presence of two $\mathrm{Pd}-\mathrm{N}$ and two $\mathrm{Pd}-\mathrm{Cl}$

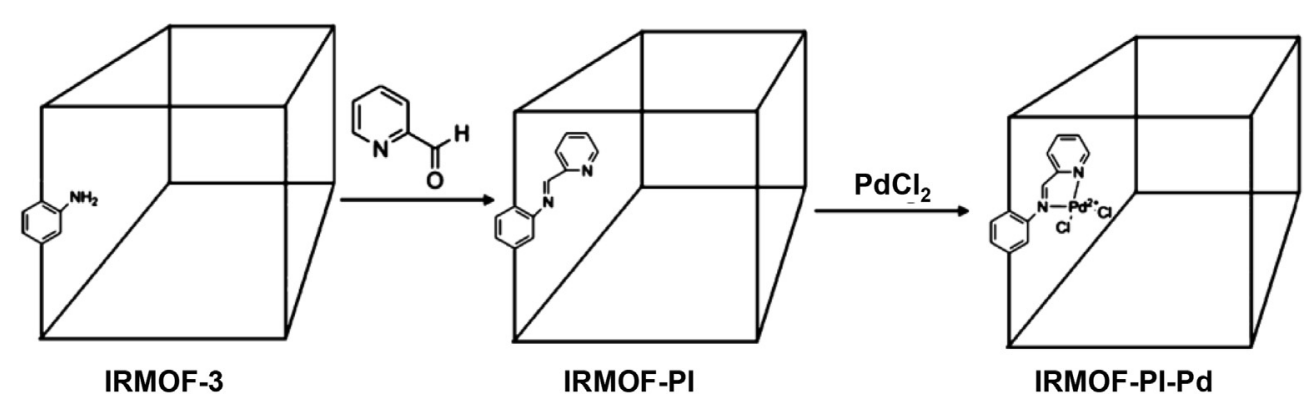

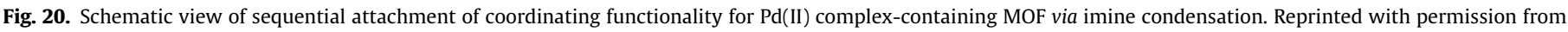
Ref. [255]. 
(a)

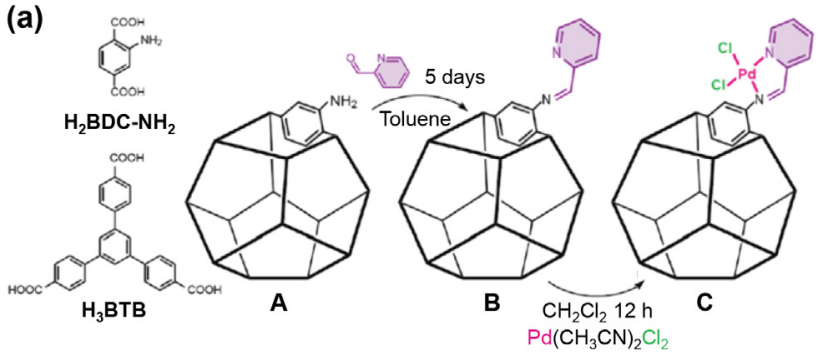

(b)

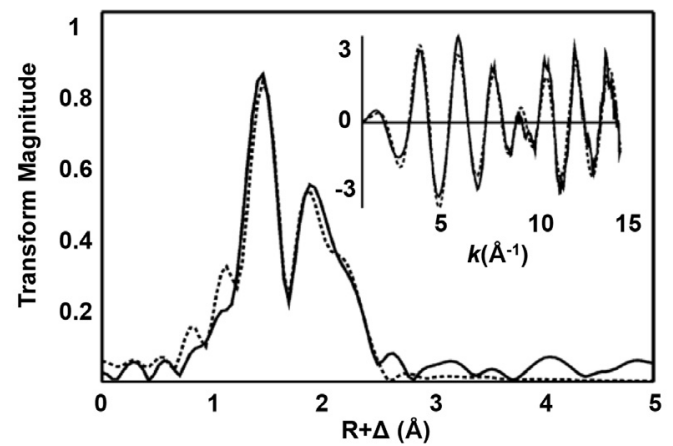

Fig. 21. (a) Ligands constituting MOF scaffold and schematic representation of isoreticular post-covalent functionalization followed by metalation. (b) Pd K-edge EXAFS Fourier transforms and EXAFS spectra for $\mathbf{C}$ (inset). The experimental data and the best fits using the determined parameters are represented as solid and dotted lines, respectively. Reprinted with permission from Ref. [256].

linkages with respective distance of 1.993(2) and 2.276(2) $\AA$, which are well-matched with those estimated for the $\mathbf{C}$ moiety.

The Zr-based UiO framework series (including UiO-66 and UiO67 ) is especially rigid and chemically robust, which indicates that the UiO frameworks are appropriate supports for PSM and can withstand harsh catalytic conditions. Kühn and colleagues immobilized a $\mathrm{Mo}(\mathrm{VI})$ complex on UiO-66 and UiO-67 with varying contents of $\mathrm{NH}_{2}$ groups via the procedure presented in Fig. 22 [257].

The UiO-MOFs were reacted with salicylaldehyde to provide salicylidene-tethered MOFs (UiO-SI MOFs) through a vapour diffu-

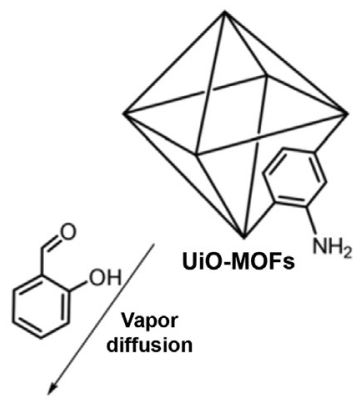

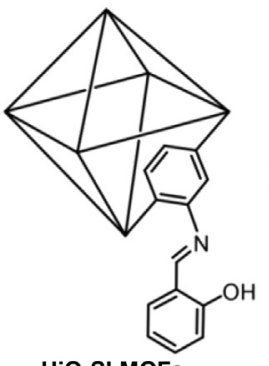

UiO-SI MOFs

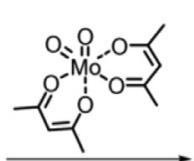

$\mathrm{CH}_{2} \mathrm{Cl}_{2}, 4$ days, $\mathrm{RT}$

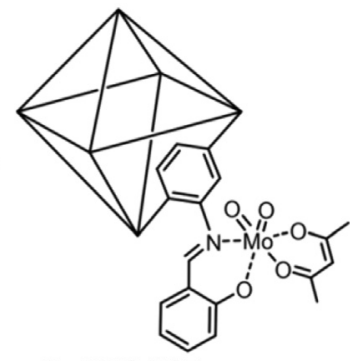

Mo@UiO MOFs
Fig. 22. Procedure for post-functionalization of UiO-MOFs with salicylaldehyde and $\left[\mathrm{MoO}_{2}(\mathrm{acac})_{2}\right]$. Reproduced with permission from Ref. [257]. sion reaction. Thereafter, the UiO-SI MOFs were treated with a solution of $\mathrm{MnO}_{2}(\mathrm{acac})_{2}$ in $\mathrm{CH}_{2} \mathrm{Cl}_{2}$ over four days under inert atmosphere (Mo@UiO MOFs). ${ }^{13} \mathrm{C}$ NMR showed additional peaks at $24-$ $25 \mathrm{ppm}$, corresponding to the methyl groups of acetylacetonate in the Mo@UiO MOFs. Moreover, the splitting of the X-ray photoelectron spectroscopy (XPS) peak at a binding energy of $3.2 \mathrm{eV}$ and the relative intensities (59:41) of the Mo 3d peaks provided evidence of the $6+$ oxidation state of molybdenum (the expected values are $3.13 \mathrm{eV}$ and a 3:2 ratio, respectively.) [257].

The introduction of appropriate ligands into the MOF pores during preparation could provide a suitable stereochemical and electronic environment around the active metal centre. The groups of Corma and Iglesias described the coordination properties of pincer-type ligands based on aminopyridineimines (Fig. 23) [258]. UiO-66- $\mathrm{NH}_{2}$ or UiO-67- $\mathrm{NH}_{2}$ was firstly functionalized with (S)-N-(tert-butyl)-1-((6-formylpyridin-2-yl)methyl)pyrrolidine-2-c arboxamide ((S)-L2) or (S)-6-((hexahydropyrrolo[1,2- $\alpha$ ]pyrazin-2 (1H)-yl)methyl)picolinaldehyde ((S)-L3) via imine condensation to form the imine NNN-pincer UiO-66-N=L or UiO-67-N=L. Thereafter, the materials were reacted with $\left[\mathrm{M}(\operatorname{cod})(\mathrm{THF})_{2}\right] \mathrm{BF}_{4}$ $(\mathrm{M}=\mathrm{Rh}, \mathrm{Ir} ;$ cod $=$ cyclooctadiene $)$.

The synthesis of heterogeneous catalyst via imine condensation of the MOFs could be extended to other stable MOF series. In 2013, the group led by Canivet reported the one-pot post-synthetic grafting of $\mathrm{Ni}(\mathrm{II})$-based organometallic active sites in a (Fe)MIL-101$\mathrm{NH}_{2}$ framework (Fig. 24) [259]. To prevent $\mathrm{N}$-coordination of the pyridyl units with the unsaturated metal sites of (Fe)MIL-101$\mathrm{NH}_{2}$, the nickel(II) complex ( $\mathrm{Ni}(\mathrm{PyCHO}) \mathrm{Cl}_{2}$ ) was firstly prepared. The nickel complex was then directly anchored into (Fe)MIL-101$\mathrm{NH}_{2}$ via imine condensation to finally generate $\mathrm{Ni} @(\mathrm{Fe}) \mathrm{MIL}-101$. The condensation yield could be adjusted by varying the amount of reactant and suspension time.

Moreover, an aldehyde-functionalized ZIF (zeolitic imidazole framework) structure, ZIF-90 was proposed as an adequate scaffold for immobilizing metal active sites [260-262]. As shown in Fig. 25,
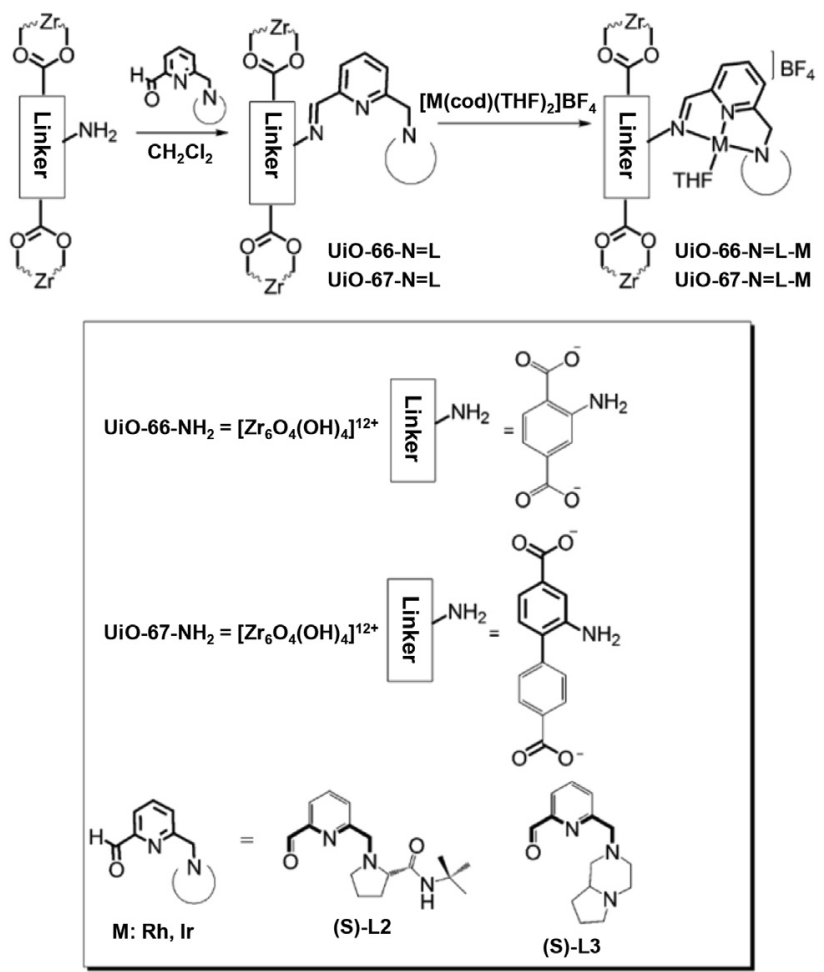

Fig. 23. Post-synthetic functionalization of UiO-66- $\mathrm{NH}_{2}$ and $\mathrm{UiO}-67-\mathrm{NH}_{2}$ with pincer ligands. $\mathrm{M}=\mathrm{Rh}$, Ir. Reprinted with permission from Ref. [258]. 


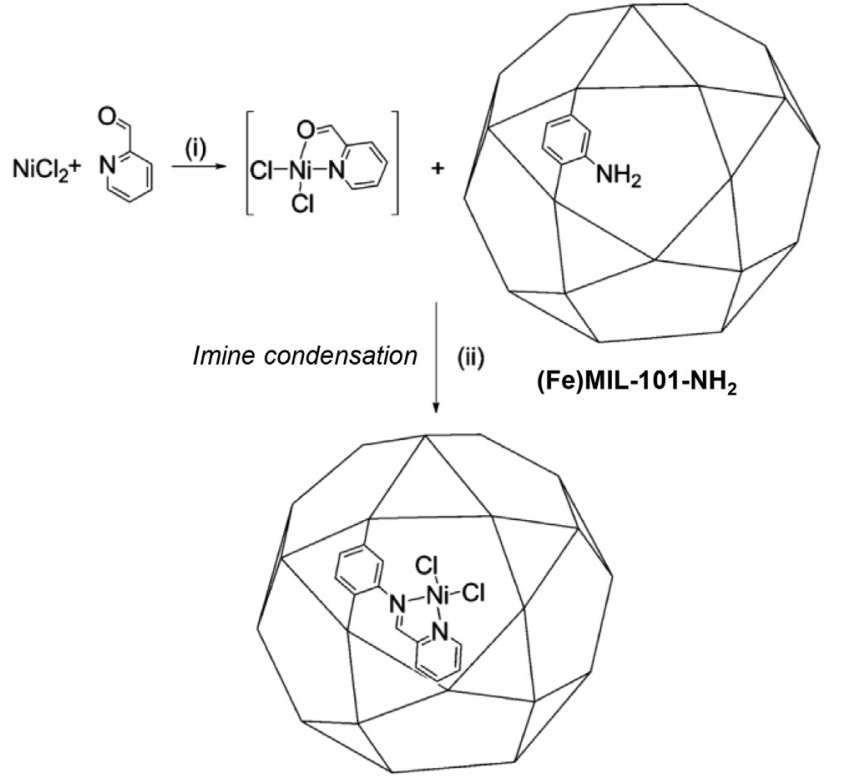

Ni@(Fe)MIL-101

Fig. 24. Schematic illustration of one-pot synthesis of the MOF-anchored nickel complex Ni@(Fe)MIL-101. Conditions: (i) $\mathrm{NiCl}_{2}$ and $\mathrm{PyCHO}$ in $\mathrm{MeOH}$; (ii) (Fe)MIL$101-\mathrm{NH}_{2}\left(\sim 0.3-1\right.$ equiv $\left.-\mathrm{NH}_{2}\right)$ stirred at room temperature. Reprinted with permission from Ref. [259].

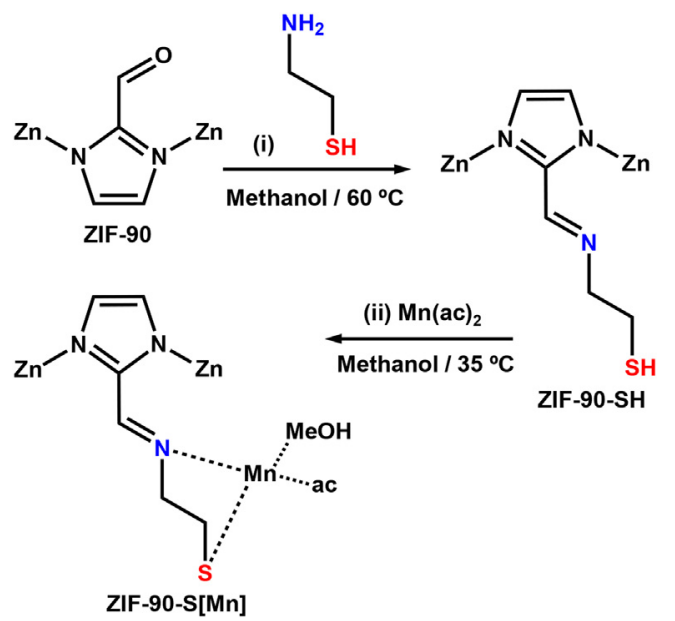

Fig. 25. Post-synthesis functionalization of ZIF-90 with (i) 2-mercaptoethylamine and (ii) manganese(II) acetate. Reproduced with permission from Ref. [262].

ZIF-90 was reacted with 2-mercaptoethylamine to produce thiolfunctionalized ZIF-90 (ZIF-90-SH) via imine condensation [262]. Subsequent reaction with $\mathrm{Mn}(\mathrm{II})$ acetate led to the construction of a novel $\mathrm{Mn}$ (II) anchored active material (ZIF-90-S[Mn]). The ZIF-90 structure was well-retained with high integrity even after functionalization and post-metalation. The disappearance of the -CHO IR stretching at $1675 \mathrm{~cm}^{-1}$ and the appearance of a new band at $1627 \mathrm{~cm}^{-1}$ indicated successful imine condensation within ZIF-90. Even though the authors did not assign the fingerprint bands of the acetate unit of ZIF-90-S[Mn] at $1500-1350 \mathrm{~cm}^{-1}$, the amount of anchored manganese was determined to be $0.08 \mathrm{mmol} \mathrm{g}^{-1}$ by ICP-MS.

\subsubsection{Ring-opening}

Ring-opening was used to facilitate chain-growth polymerization, where the ends of the open reactive monomer participated

in the formation of longer polymers. The principle of ringopening has been used to engineer coordinating functionalities in the pores of MOFs via sequential attachment. Generally, the treatment of cyclic anhydrides produces materials containing free carboxylic acid groups [263]. Incorporating free carboxylic acids into MOFs is an outstanding approach because free carboxylates provide coordinating functionalities.

Cohen et al. selected 3-hydroxyphthalic anhydride and 2,3pyrazinedicarboxylic anhydride as reactants for providing adequate metal-binding sites within UMCM-1- $\mathrm{NH}_{2}$, which is composed of 4,4',4'-benzene-1,3,5-triyl-tribenzoate (BTB), 2-amino1,4-benzenedicarboxylate ( $\left.\mathrm{NH}_{2}-\mathrm{BDC}\right)$, and $\mathrm{Zn}(\mathrm{II})$ ions [264]. Under mild reaction conditions, UMCM-1- $\mathrm{NH}_{2}$ was successfully transformed into UMCM-1-AMsal and UMCM-1-AMpz that could bind active metal ions (Fig. 26). The ${ }^{1} \mathrm{H}$ NMR spectroscopy and mass spectrometry data indicated that the product of these anhydrides form substituents with free carboxylate groups rather than generating imide products. The crystallinity and surface areas of UMCM1-AMsal and UMCM-1-AMpz are comparable to those of pristine UMCM-1-NH $\mathrm{N}_{2}$. The capability of the salicylate and pyrazine carboxylate moieties of UMCM-1-AMsal and UMCM-1-AMpz to bind metal ions was investigated. Addition of $\left[\mathrm{Fe}(\mathrm{acac})_{3}\right]$ to UMCM-1AMsal induced an immediate colour change from pale yellow to dark red (UMCM-1-AMFesal). In like manner, UMCM-1-AMpz underwent a colour change to bluish-green in the presence of [Cu(acac) $\left.)_{2}\right]$ (UMCM-1-AMCupz). The diffuse reflectance spectra of UMCM-1-AMFesal and UMCM-1-AMCupz displayed distinct bands centred at $500 \mathrm{~nm}$ and approximately $700 \mathrm{~nm}$, proving the pres-

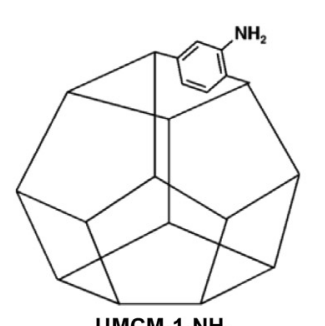

UMCM-1- $\mathrm{NH}_{2}$
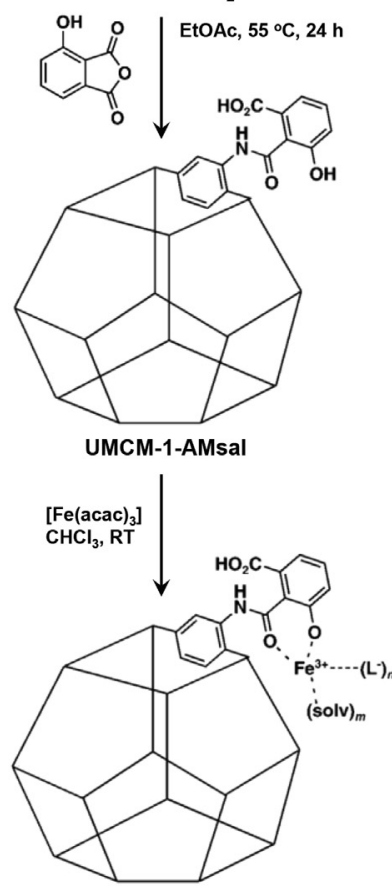

Fig. 26. Illustration of synthesis of coordinating-functionalized MOFs from UMCM1- $\mathrm{NH}_{2}$ and subsequent metalation. Reprinted with permission from Ref. [264]. 
ence of the $\mathrm{Fe}(\mathrm{III})$ salicylate and $\mathrm{Cu}(\mathrm{II})$ pyrazine carboxylate compounds, respectively. UMCM-1-AMFesal comprised $0.77 \mathrm{wt} \%$ of $\mathrm{Fe}(\mathrm{III})$ ions and UMCM-1-AMCupz contained $1.76 \mathrm{wt} \%$ of $\mathrm{Cu}(\mathrm{II})$ ions, while the uptake of $\mathrm{Fe}(\mathrm{III})$ and $\mathrm{Cu}(\mathrm{II})$ ions was insignificant in unmodified UMCM-1- $\mathrm{NH}_{2}$ based on atomic absorption analysis. In a follow-up study by Cohen and colleagues a year later, UMCM$1-\mathrm{NH}_{2}$ was post-synthetically modified with different combinations of chelating groups and metal ions [265]. Modified UMCM1-AMpz and UMCM-1-AMsal exposed to In(acac) 2 solution generated UMCM-1-AMInpz and UMCM-1-AMInsal with 3.76 and $2.96 \mathrm{wt} \%$ of $\operatorname{In}(\mathrm{III})$, respectively. These values indicated that about $70 \%$ of the coordinating sites were bound to active In(III) ions.

Kleist's group described a similar strategy for the design of heterogeneous catalysts with well-defined anchored Pd complexes through PSM of MIL-53- $\mathrm{NH}_{2}(\mathrm{Al})$ [266]. The amine-tethered MIL53- $\mathrm{NH}_{2}(\mathrm{Al})$ was reacted with maleic anhydride, resulting in transformation of the chelating chain thereby facilitating the immobilization of $\mathrm{Pd}(\mathrm{II})$ ions (Fig. 27a). MIL-53 series MOFs are known to exhibit a breathing effect, which means that the pore size can change depending on the substrate or guest molecules inside the pores. From this point of view, when the bulky coordinating functionalities were attached via PSM, all of the peaks except those corresponding to the $\left(\begin{array}{lll}2 & 0 & 0\end{array}\right)$ and $\left(\begin{array}{lll}4 & 0 & 0\end{array}\right)$ planes $\left(9.28\right.$ and $18.62^{\circ}$, respectively) were shifted to lower angles in the XRPD patterns (Fig. 27b). The decreased intensity of the $\mathrm{N}-\mathrm{H}$ stretching peak and the appearance of the $\mathrm{C}=\mathrm{O}$ vibrational FT-IR band signified successful post-synthetic functionalization. Furthermore, the Pd coordination environment was proved by EXAFS analysis. For MIL-53- $\mathrm{NH}_{2}(\mathrm{Al})-\mathrm{Mal}-\mathrm{Pd}, 3.9$ oxygen atoms were fitted at a distance of $2.008 \AA$, which is in good agreement with anchored Pd (II) complexes coordinated by four oxygen moieties (Fig. 27c).

Hupp and Nguyen attempted to find a MOF having pores large enough to accommodate the carboxylic acid functional groups [267]. They chose the $\mathrm{Zn}$-based pillared paddlewheel MOF 1, Zn $\mathrm{n}_{2}(-$ TCPB)(DPG) (TCPB = 1,2,4,5-tetrakis(4-carboxyphenyl)-benzene, and DPG = meso-1,2-bis(4-pyridyl)-1,2-ethanediol). Most of the pillared paddlewheel MOFs were doubly or triply interpenetrated rather than assembling with the di-topic ligands, leading to relatively small pores. In contrast, they obtained non-interpenetrated structures 1 by applying the tetra-topic ligand, TCPB featuring lar- ger pores. The other ligand, DPG, constituting MOF 1, possesses free hydroxyl functionalities that facilitate reaction with cyclic anhydrides to produce free carboxylic acid-tethered MOFs (left procedure in Fig. 28) The new strong carbonyl stretches of the ester and free carboxylic acids at $1700-1725 \mathrm{~cm}^{-1}$ and $1750 \mathrm{~cm}^{-1}$ in the FT-IR spectrum, the considerable integrated peak area of the methylene hydrogens of the succinic acid in the ${ }^{1} \mathrm{H}$ NMR profile, and the large peak corresponding to the doubly-functionalized DPG in the MALDI-TOF data conclusively revealed the free car-

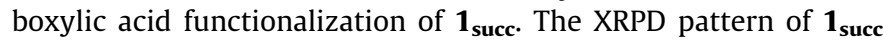
was consistent with that of highly crystalline $\mathbf{1}$. $\mathbf{1}_{\text {succ }}$ was further immersed in a $75 \mathrm{ppm}$ aqueous solution of $\mathrm{CuCl}_{2}$ to prove the utility of the free carboxylic acids (right procedure in Fig. 28). The concentration of copper in the supernatant solution was reduced to $20 \mathrm{ppm}$ based on ICP-OES analysis, and $\mathbf{1}_{\text {succ }}$ underwent a colour change from colourless to blue-green after $\mathrm{Cu}(\mathrm{II})$ ion metalation, which was detected by the naked eye.

\subsubsection{Click reaction}

Among the developed PSM methods, Click chemistry is a useful methodology for MOF functionalization, allowing chemical diversification of MOFs. The Click reaction is a $\mathrm{Cu}(\mathrm{I})$-catalyzed cycloaddition reaction between an azide and an alkyne. One early example of a PSM Click reaction was presented by Sada and colleagues in 2008, where external alkynes with various functional groups were reacted with azide-containing MOFs [268]. Since then, many studies have reported using Click chemistry as a PSM method for engineering various functionalities into MOF pores, including coordinating functionalities such as hydroxyl, carboxylic acid, and heterocyclic N or S [269-274].

In 2015, the group led by Li proposed a strategy for incorporating $2,2^{\prime}: 6^{\prime}, 2^{\prime \prime}$-terpyridine, a $\pi$-conjugated tridentate oligopyridine $\sigma$-donor chelator, into azide-tagged MIL-101(Cr)- $\mathrm{N}_{3}$ via a Click PSM reaction (Fig. 29) [274]. Nitration of MIL-101(Cr) and subsequent reduction initially yielded $\mathrm{MIL}-101(\mathrm{Cr})-\mathrm{NH}_{2}$. Thereafter, MIL-101(Cr) $-\mathrm{NH}_{2}$ was reacted with tert-butylnitrite ( $\left.t \mathrm{BuONO}\right)$ and azidotrimethylsilane (TMS- $\mathrm{N}_{3}$ ) in THF to give an azidofunctionalized MOF, MIL-101(Cr)- $\mathrm{N}_{3}$. The presence of a new peak at ca. $2123 \mathrm{~cm}^{-1}$ due to the $-\mathrm{N}_{3}$ symmetric stretching vibration in the FT-IR spectrum and new aromatic signals at 7.74-

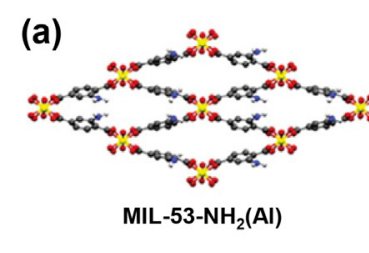

(b)

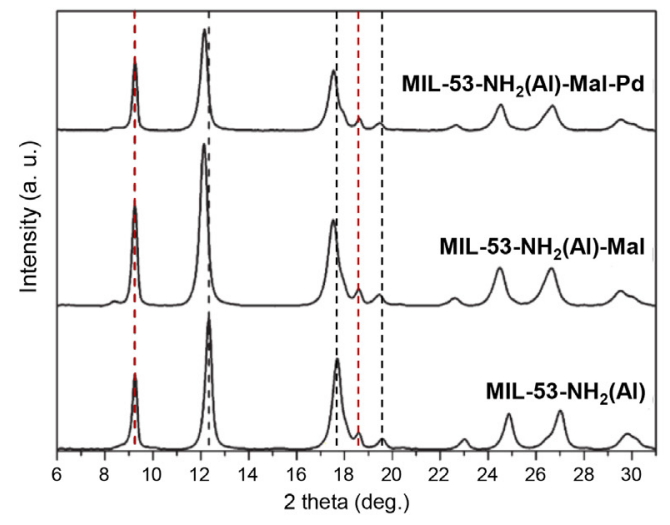

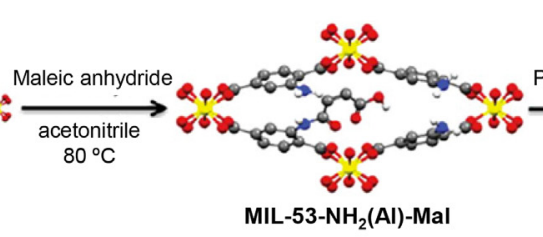

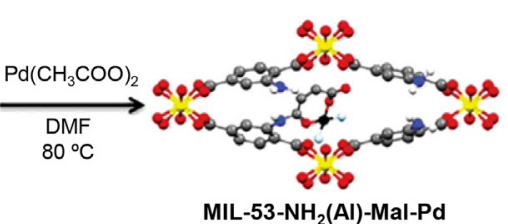

(c)

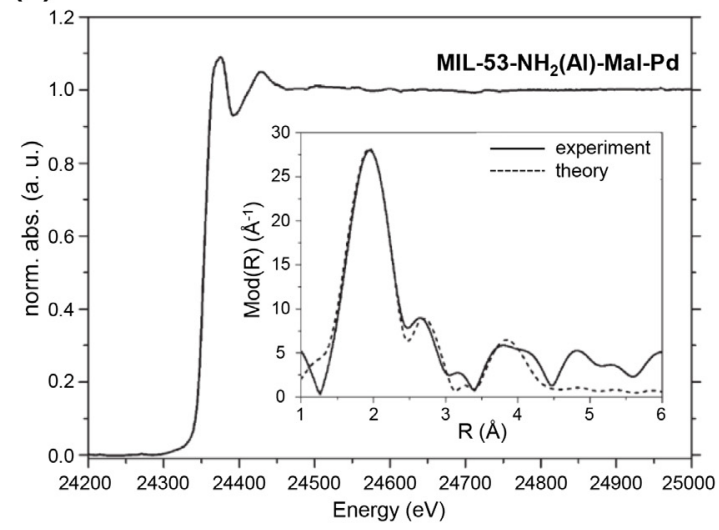

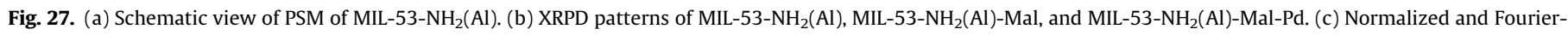
transformed (inset) EXAFS spectra of MIL-53- $\mathrm{NH}_{2}(\mathrm{Al})-\mathrm{Mal}-\mathrm{Pd}$. Reproduced with permission from Ref. [266]. 


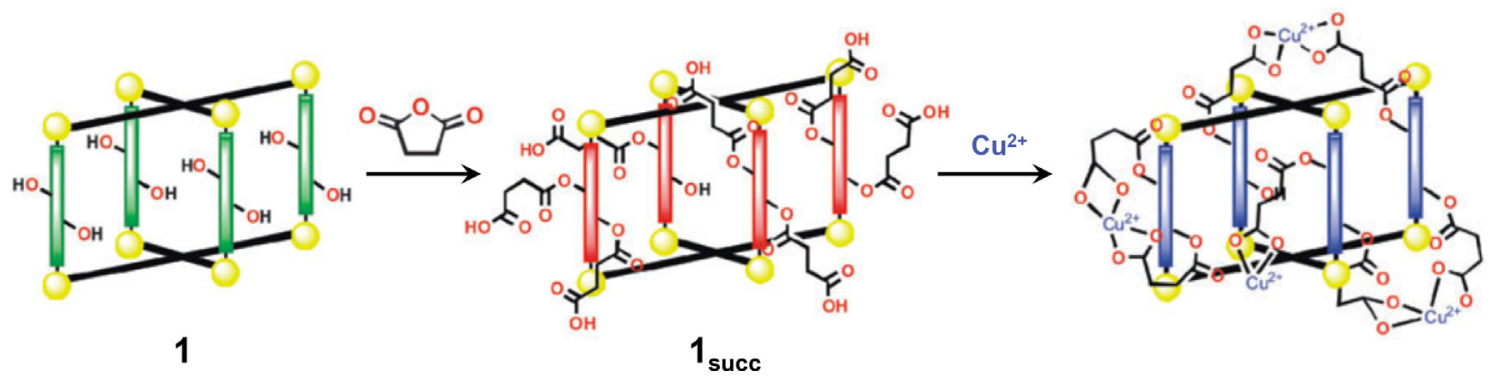

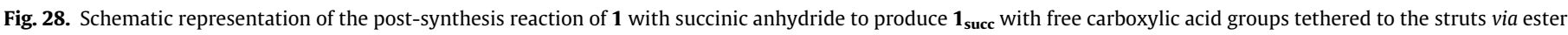
linkages (left) and a schematic of Cu(II) chelation (right). Reproduced with permission from Ref. [267].
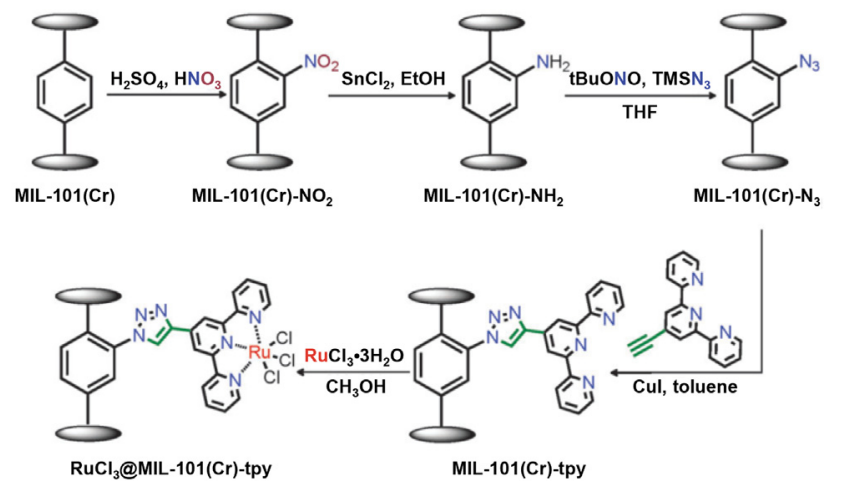

Fig. 29. Schematic illustration of PSM of MIL-101(Cr) to MIL-101(Cr)- $\mathrm{N}_{3}$ and subsequently to MIL-101(Cr)-tpy through click chemistry, and the immobilization of a single-site heterogeneous $\mathrm{Ru}(\mathrm{III})$ catalyst. Reproduced with permission from Ref. [274].

$7.83 \mathrm{ppm}$ in the ${ }^{1} \mathrm{H}$ NMR spectrum verified successful conversion of the amino groups to azido groups. Modified MIL-101(Cr)- $\mathrm{N}_{3}$ was employed in the azide-alkyne cycloaddition with $4^{\prime}$-ethynyl-2,2' $6^{\prime}, 2^{\prime \prime}$-terpyridine to generate MIL-101(Cr)-tpy. The intensity of the FT-IR and the liquid chromatography-high resolution mass spectrometry (LC-HRMS) peaks of the azido group in MIL-101 (Cr)-tpy decreased after the Click reaction, and a peak appeared at $m / z c a .465\left([\mathrm{M}+\mathrm{H}]^{+}\right)$, which is attributed to the triazole product formed by cycloaddition.

Interestingly, that research group showed that MIL-101(Cr)-tpy with open terpyridyl groups was an excellent platform for the chelation of active transition metal complexes. MIL-101(Cr)-tpy was soaked in a methanolic solution of $\mathrm{RuCl}_{3}$ to obtain $\mathrm{RuCl}_{3} @$ MIL-101(Cr)-tpy, as shown in Fig. 29. The amount of immobilized $\mathrm{Ru}$ was $\sim 1.0 \mathrm{wt} \%$, as determined by atomic absorption spectroscopy (AAS). Chelation of the Ru(III) ions by MIL-101(Cr)-tpy was verified by the Ru $3 p$ and $\mathrm{N} 1 s$ XPS spectra. The binding energies of the $\mathrm{Ru}$ (III) bands were down-shifted by ca. $0.5 \mathrm{eV}$ compared to those of pristine $\mathrm{RuCl}_{3}$, and the peak at $398.1 \mathrm{eV}$, ascribed to the three nitrogen atoms of the terpyridine unit, was up-shifted by $0.6 \mathrm{eV}$ in the case of MIL-101(Cr)-tpy relative to that of $\mathrm{RuCl}_{3} @$ MIL-101(Cr)-tpy.

A follow-up study by the same group led by Li was performed in 2018 [275]. They successfully anchored a biomimetic di- $\mu$-oxo dimanganese complex containing two triazole-binding tridentate ligands inside a MOF through Click reaction and metalation (Fig. 30). Conversion of MIL-101(Cr) to MIL-101(Cr)- $\mathrm{NH}_{2}$ subsequently to MIL-101(Cr)- $\mathrm{N}_{3}$ was achieved as in the previously presented study, and formation of azide groups was proven by FT-IR, ${ }^{1} \mathrm{H}$ NMR, XPS, and LC-HRMS. Subsequently, MIL-101(Cr)- $\mathrm{N}_{3}$ was subjected to azide-alkyne cycloaddition with $4^{\prime}$-ethynyl-2,2': $6^{\prime}$, $2^{\prime \prime}$-terpyridine via Click chemistry. The N 1s XPS spectrum showed

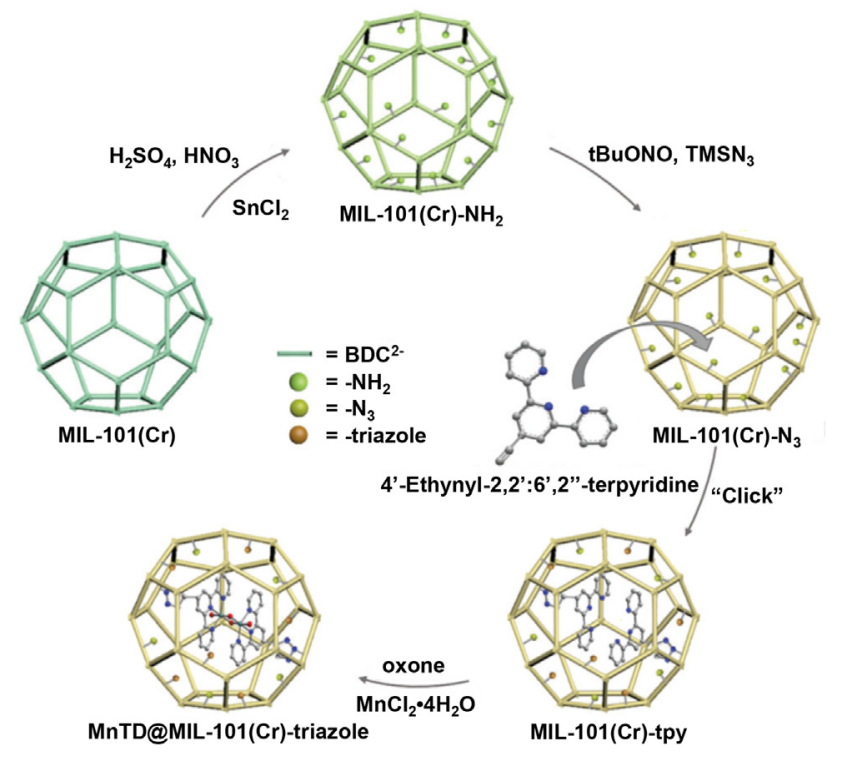

Fig. 30. Schematic representation of synthesis of MnTD@MIL-101(Cr)-triazole. Reproduced with permission from Ref. [275].

two peaks of the $\mathrm{N}-\mathrm{C}$ and $\mathrm{N}=\mathrm{N}$ bonds of the triazole unit and $\mathrm{N}$ of the terpyridine unit, clearly indicating that the terpyridine group was connected to the MOF scaffold via formation of the triazole ring. Lastly, the tridentate terpyridine moiety accepted $\mathrm{Mn}$ (II) and eventually anchored a di- $\mu$-oxo dimanganese moiety; subsequent treatment with an oxidant gave MnTD@MIL-101(Cr)triazole. The electron paramagnetic resonance (EPR) spectrum of MnTD@MIL-101(Cr)-triazole presented multi-line hyperfine splitting patterns, representing a mixed-valence $\mathrm{Mn}(\mathrm{III} / \mathrm{IV})$ complex. Upon anchoring the $\mathrm{Mn}_{2}(\mu-\mathrm{O})_{2}$ species, MIL-101(Cr)- $\mathrm{NH}_{2}$ underwent a visible colour change from grass-green to a dark green colour. Overall, the final product contained a di- $\mu$-oxo dimanganese fragment, $\left[\left(\mathrm{OH}_{2}\right) \text { (triazole-tpy)- } \mathrm{Mn}^{\mathrm{III}}(\mu-\mathrm{O})_{2} \mathrm{Mn}^{\mathrm{IV}}(\text { tpy-triazole })\left(\mathrm{OH}_{2}\right)\right]^{3+}$, which is an analogue of MnTD $\left[\left(\mathrm{OH}_{2}\right)(\mathrm{tpy})-\mathrm{Mn}^{\mathrm{III}}(\mu-\mathrm{O})_{2} \mathrm{Mn}^{\mathrm{IV}}\right.$ (tpy) $\left.\left.\left(\mathrm{OH}_{2}\right)\right]^{3+}\right)$, tethered in the MIL-101(Cr)- $\mathrm{NH}_{2}$ pores.

\section{Catalytic applications}

In this section, we describe selected examples of heterogeneous reactions employing MOFs with engineered pores containing coordinating functionalities. The catalytic reactions are summarized in the Table 4 for easy understanding.

\section{1. $\mathrm{CO}_{2}$ hydrogenation}

The hydrogenation of $\mathrm{CO}_{2}$ to generate $\mathrm{HCO}_{2} \mathrm{H}$ (formic acid) is a valuable and green process. However, the formation of formic acid 
Table 4

Coordinating functionalities in MOF pores for various catalytic applications.

\begin{tabular}{|c|c|c|c|}
\hline Applications & MOF scaffolds & Catalytic sites & References \\
\hline \multirow[t]{2}{*}{$\mathrm{CO}_{2}$ hydrogenation } & UiO-67 & TM-bpys & {$[32-34,47,51]$} \\
\hline & $\begin{array}{l}\text { UiO-67, MOF-545, MIL-101, } \\
\text { SION-105 }\end{array}$ & FLPs & {$[276-286]$} \\
\hline \multirow[t]{2}{*}{ Electrochemical reactions } & MOF-52 & M-porphyrins & {$[151,159,184]$} \\
\hline & PCN-223 & & \\
\hline Organic transformations & M'MON & M-salens & {$[230,235,241,242,244,246-248,251]$} \\
\hline \multirow[t]{3}{*}{ Ethylene oligomerizations } & MIL-101- $\mathrm{NH}_{2}$ & M-iminopyridine & {$[56,259,298]$} \\
\hline & IRMOF-3 & M complexM-bpy & \\
\hline & UiO-67 & & \\
\hline
\end{tabular}

is not spontaneous, and humidity is an issue that leads to low efficiency due to the solubility of $\mathrm{H}_{2}$ gas in water. MOFs have been considered as catalytic platforms for the hydrogenation of $\mathrm{CO}_{2}$ due to their high gas adsorption properties and controllable sites for catalyst loading. The first example of MOF-based catalysts for $\mathrm{CO}_{2}$ reduction was reported by Lin and co-workers in 2011 using the Re-bpydc and UiO MOF series [32]. The MOF catalyst selectively reduced $\mathrm{CO}_{2}$ to $\mathrm{CO}$ and the molar ratio of $\mathrm{CO}$ and $\mathrm{H}_{2}$ production was about ten. Unfortunately, the catalyst became inactive in $\mathrm{CO}_{2}$ reduction after two reaction cycles due to the Re leaching from the bpydc in the MOF framework as evidenced by ICP-MS. Since the first report using the UiO series, various attempts have been made to improve the catalytic activity. Cohen's group introduced Mn-bpydc-(CO) species into the $\mathrm{UiO}$ series for photocatalytic $\mathrm{CO}_{2}$ reduction. The UiO-67- $\mathrm{Mn}$ (bpy) $(\mathrm{CO})_{3} \mathrm{Br}$ catalyst displayed a turnover number (TON) of 110 over $18 \mathrm{~h}$, outperforming the homogenous system. Also, a catalytic recyclability tests was conducted to figure out the catalytic stability. The catalytic activity reduced from $\sim 48 \%$ to $\sim 34 \%$ after three cycles, and FT-IR and ICP-OES data presented the loss of catalytic $\mathrm{Mn}(\mathrm{CO})_{3}$ moiety with catalytic cycles [47].

Recently, Lin and co-workers developed a Soxhlet-type Reflux system for efficient hydrogenation of $\mathrm{CO}_{2}$ in the gas phase. An Ir (III) catalyst was loaded into bpdc-OH-based on UiO-67 MOFs through a PSM strategy, and activated $\operatorname{Ir}($ II) was generated by three-step activation. The UiO-67-Ir(II) catalyst was placed between a flask and condenser, and formic acid formation was maximized by contact flow between gaseous $\mathrm{CO}_{2}$ and $\mathrm{H}_{2}$ (TON of 6149 over $15 \mathrm{~h}$ ). The hydrogenation of $\mathrm{CO}_{2}$ was accelerated by equilibrium control through neutralization in $\mathrm{NaHCO}_{3}(a q)$ solution (Fig. 31a) [33]. In addition, catalytic cycle was proposed by NLDFT calculation and kinetic isotope effect (KIE, $\mathrm{H}_{2} \mathrm{O} / \mathrm{H}_{2}-\mathrm{H}_{2} \mathrm{O}$ / $D_{2}$ ) results (Fig. $\left.31 \mathrm{~b}\right)$. Activation energy of transition state $\left(A^{*}\right)$ for $\mathrm{H}_{2}$ heterolysis was confirmed for $\mathrm{E}_{\mathrm{a} 1}=0.34 \mathrm{kcal} \mathrm{mol}^{-1}$, and activation energy of another transition state $\left(\mathrm{C}^{*}\right)$ for proton-hydride transfer pathway was $16.26 \mathrm{kcal} \mathrm{mol}^{-1}\left(\mathrm{E}_{\mathrm{a} 2}\right)$. Therefore, transition of $\mathrm{C}^{*}$ state was designated for rate-determining step in the proposed mechanistic pathways.

The synergic effect of a metal-chelated ligand and NPs was determined through formation of a composite. Yaghi and co-workers prepared a core-shell type composite material, $\mathrm{Ag} \subset \mathrm{Re}_{3}$ MOF, form bpydc-Re-ligands using $\mathrm{Ag}$ nanotubes and UiO $\mathrm{Re}_{3}$ MOF (Fig. 32). This designed catalyst showed improved photocatalytic activity based on the localized photoactive centre in the MOF pores and enhancement of the electric field near the plasmonic silver nanotubes. Therefore, Re exhibited a seven-fold enhancement in the photocatalytic reduction of $\mathrm{CO}_{2}$ on the surface of the $\mathrm{Ag}$ nanotubes. In addition, the activity was retained for a maximum of $48 \mathrm{~h}$ under visible light, and the transmission electron microscope (TEM) images and FT-IR spectroscopy after long-term measurement reinforced the evidence of catalytic stability [34]. (a)
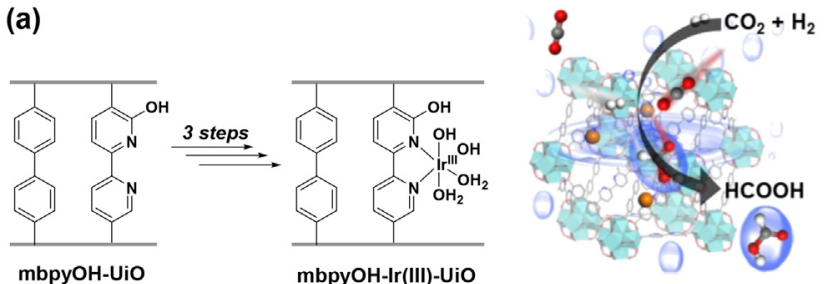

TON: $6149 \pm 50$ (0.1 $\left.\mathrm{MPa} \mathrm{H}_{2} / \mathrm{CO}_{2}, 85^{\circ} \mathrm{C}, 15 \mathrm{~h}\right)$

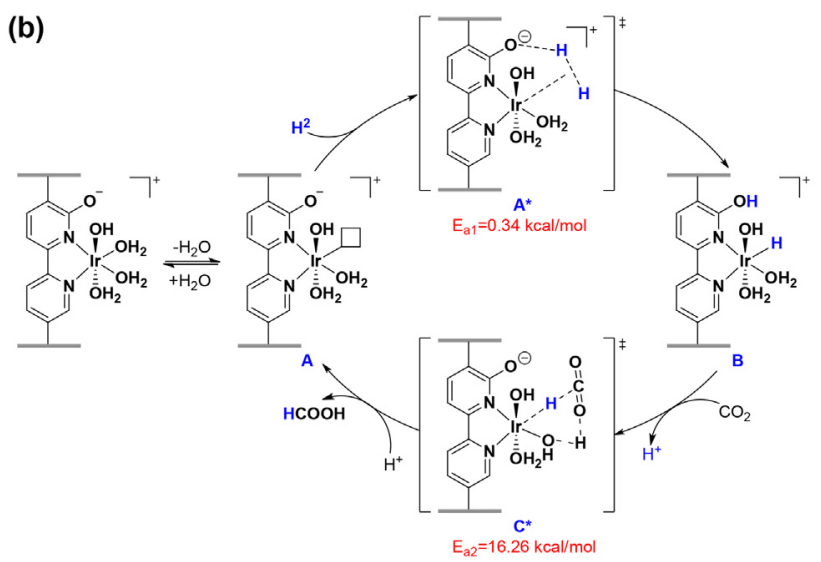

Fig. 31. (a) Scheme showing the PSM of mbpyOH-Ir(III)-UiO-67 via three-step protocol and (b) proposed mechanism of $\mathrm{CO}_{2}$ hydrogenation. Reprinted with permission from Ref. [33].

The hydrogenation of $\mathrm{CO}_{2}$ produces methanol as well as formic acid and CO. Zn@UiO-bpy-Cu could be prepared by exploiting the chelating ability of bpy and metal clusters. The generated Zn@UiO-bpy-Cu was successfully reduced in situ to generate a methanol formation catalyst, CuZn@UiO-bpy [51]. Ultra-small Cu/ $\mathrm{ZnO}_{\mathrm{x}} \mathrm{NPs}$ were stabilized by fine-tuning the characteristics of the MOFs and installed in the tetrahedral and octahedral cages of the UiO MOFs (Fig. 33a). Although the catalytic activity was reduced by half and selectivity was decreased from $62.7 \%$ to $44.3 \%$ for commercial $\mathrm{Cu} / \mathrm{ZnO} / \mathrm{Al}_{2} \mathrm{O}_{3}$ catalyst during $15 \mathrm{~h}$ reaction time, CuZn@UiO-bpy catalyst for $\mathrm{CO}_{2}$ hydrogenation with $\mathrm{H}_{2}$ retained the selectivity for $100 \mathrm{~h}$ at $250{ }^{\circ} \mathrm{C}$, and only less than $10 \%$ of reactivity was reduced (Fig. 33b and c). Mechanistic study using XPS revealed that the redox cycles of $\mathrm{Zr}(\mathrm{IV} / \mathrm{III})$ and $\mathrm{Zn}(\mathrm{II} / 0)$ were strongly involved in the hydrogenation of $\mathrm{CO}_{2}$. As suggested in Fig. 33d, homolytic dissociation of $\mathrm{H}_{2}$ on $\mathrm{Cu}$ surface was occurred first, then the dissociated hydrogen attached to $\mathrm{Zr}$ and $\mathrm{ZnO}_{\mathrm{x}}$ sites. At the same time, $\mathrm{CO}_{2}$ was absorbed at $\mathrm{Zr}$ and $\mathrm{ZnO} \mathrm{x}_{\mathrm{x}}$ sites, and hydrogenation to methanol was followed. The synergistic combination of $\mathrm{ZnO}_{\mathrm{x}}, \mathrm{Zr}$ on $\mathrm{SBU}$, and $\mathrm{Cu}$ sites allowed good catalytic activity of this system. 


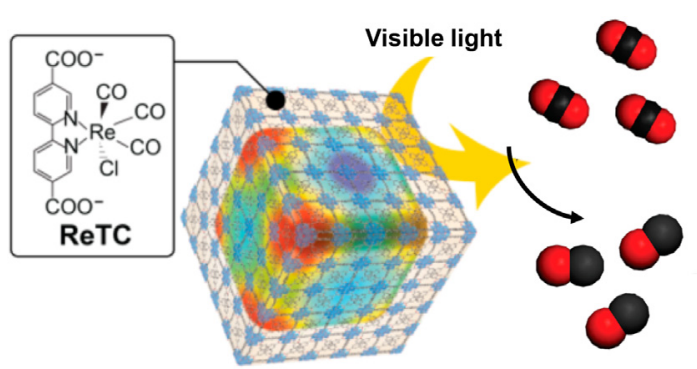

$\mathrm{Ag} \subset \mathrm{Re}_{3}-\mathrm{MOF}$

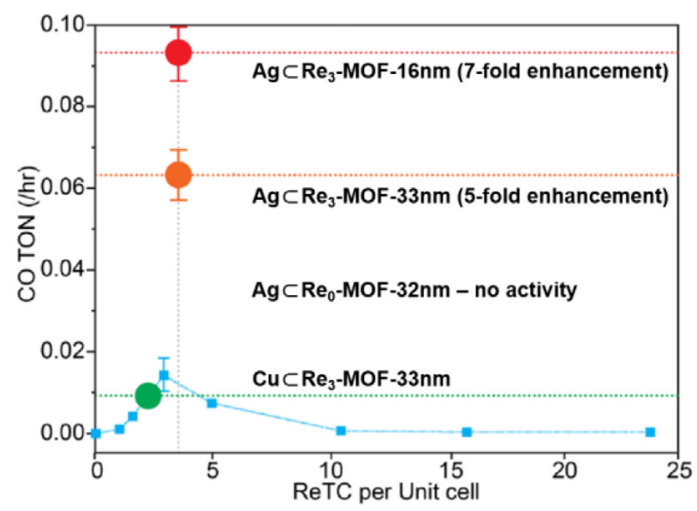

Fig. 32. $\mathrm{Re}_{3}-\mathrm{MOF}$ doped on a Ag nanocube for enhanced photocatalytic conversion of $\mathrm{CO}_{2}$. Reprinted with permission from Ref. [34].

A Frustrated Lewis Pair (FLP) are molecules or molecular complexes containing both Lewis acids and Lewis base together. Two orthogonal reaction sites are separated by structural issues (e.g., sterically bulky substituents), and FLPs have been widely utilized as an efficient molecular catalyst to small molecule activation such as $\mathrm{CO}_{2}$ and $\mathrm{H}_{2}$ [276-278]. The struts, the rigid frames of pores in MOFs could also be considered as a structural restriction between Lewis acidic and Lewis basic sites. In 2018, Ma group successfully introduced FLPs in MIL-101 structure through PSM strategy, and applied FLP-anchored MOFs to reduction of imines and olefins with molecular hydrogen [279-281]. Interestingly, in two years earlier, Johnson and co-workers reported that the simulated UiO-66 and UiO-67 series with FLP catalytic sites in the pore for $\mathrm{CO}_{2}$ reduction through the computational approaches [282-284].

Further studies for FLP chemistry in the pores extended to enhance the advantages of MOFs such as gas adsorption and postsynthetic functionalization of pores. Dyson group developed porphyrin-based MOF-545 and triaryl borane-based SION-105 systems for ideal platform of FLP installation and activity [285,286]. The FLP@MOF-545 from in situ condition displayed good catalytic performance for hydrogenation of $\mathrm{CO}_{2}$, and Eu-based SION-105 allowed efficient transformation of diamines to benzimidazoles with $\mathrm{CO}_{2}$ as a C1-feedstock. Especially, in case of FLP@MOF-545, the dual roles of the nitrogen atom in porphyrin and FLP formation from the encapsulated BCF guest molecule (i.e., $\left.\mathrm{B}\left(\mathrm{C}_{6} \mathrm{~F}_{5}\right)_{3}\right)$ allowed methoxide formation from $\mathrm{CO}_{2}$ through non-metal-mediated pathways at a relatively low temperature and working pressure (Fig. 34). The catalytic activity of FLP@MOF-545 was retained up to 3 times without loss, and the stability of catalyst was confirmed by PXRD, FT-IR, and the comparison of $\mathrm{CO}_{2}$ uptakes [286]. These works presented that practical formation of FLP with in situ manner in the MOF pores, and the efficient fixation and reduction of $\mathrm{CO}_{2}$ with porous functionalized MOFs.

\subsection{Electrochemical reactions}

A variety of homogeneous and heterogeneous catalysts have been intensively studied for electrochemical $\mathrm{CO}_{2}$ reactions. Catalyst selectivity for the reaction and long-term stability are still challenging issues because electrocatalytic $\mathrm{CO}_{2}$ reduction generally

(a)

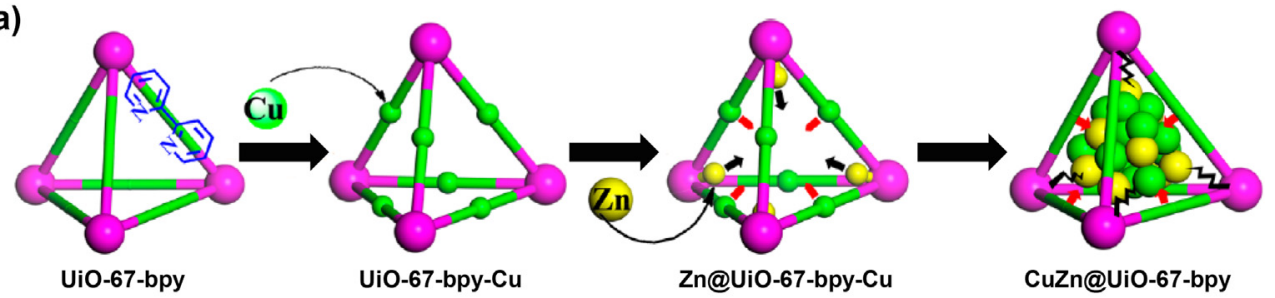

(b)

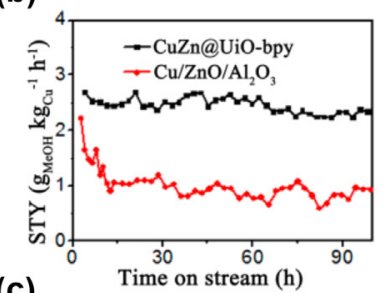

(c)

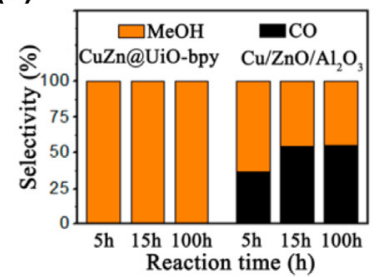

(d)

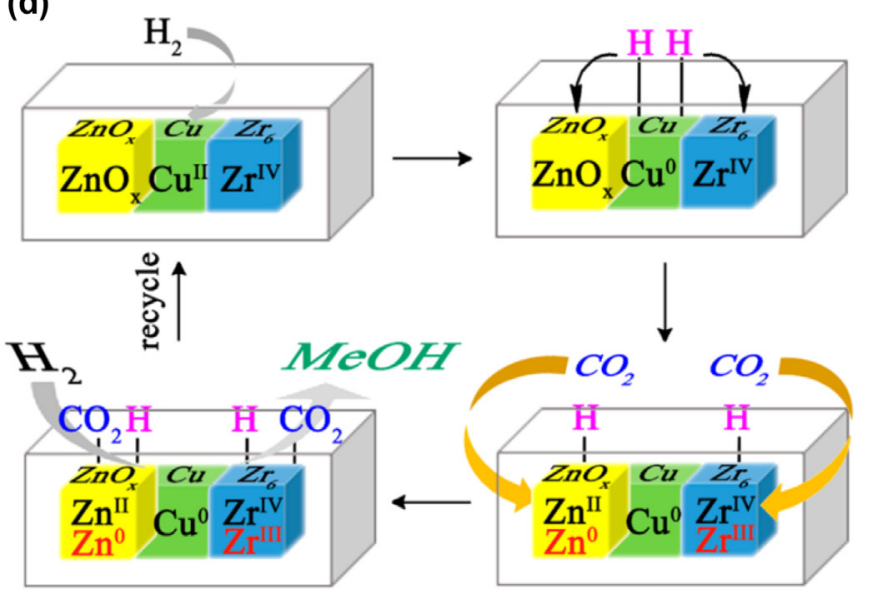

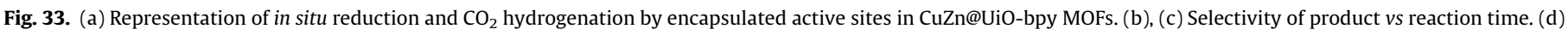
Schematic showing the functions of metal sites in $\mathrm{CO}_{2}$ hydrogenation. Reprinted with permission from Ref. [51]. 


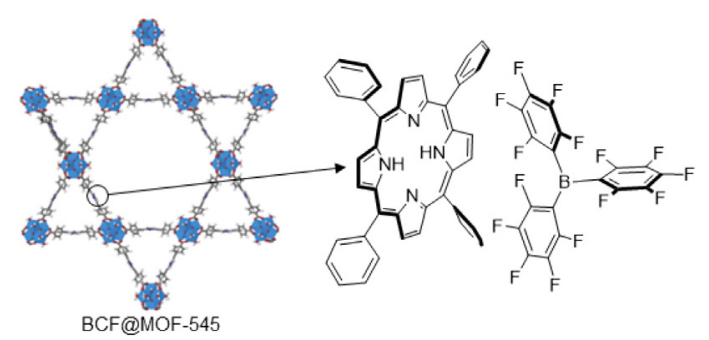

(b)
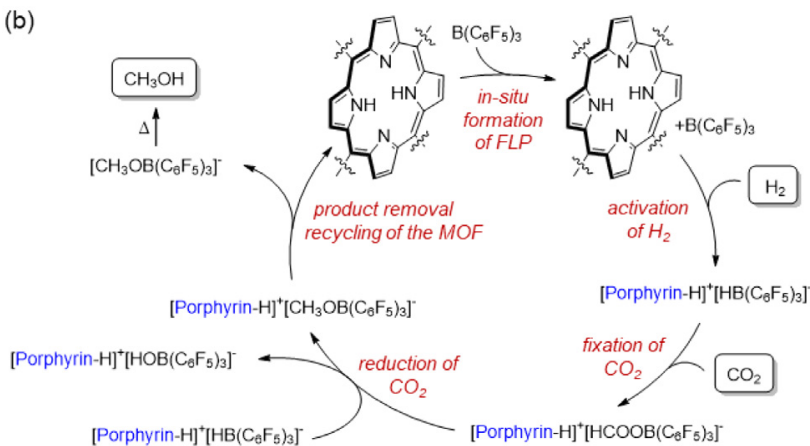

Fig. 34. (a) Systematic illustration of BCF@MOF-545. (b) Strategy for $\mathrm{MeOH}$ production through in-situ formation of FLP and fixation of $\mathrm{CO}_{2}$ inside of the MOF-545 structure. Reprinted with permission from Ref. [286].

occurs through proton abstraction from solvent molecules, and various products can be formed depending on the reaction conditions. Because the repeating units and frameworks of MOFs are suitable for fine-tuning and $\mathrm{CO}_{2}$ capture, MOFs are considered a good platform for electrochemical $\mathrm{CO}_{2}$ reduction, and many catalytic approaches are recorded in the literature [287-289].

Yang's group reported that the combination of a 'redox active site' and MOFs provides good electrocatalytic activity for $\mathrm{CO}_{2}$ reduction. Thin-films for covering the electro-conducting plate were prepared using an Al-based MOF and Co-porphyrin ligand. The optimal thickness for $\mathrm{CO}_{2}$ reduction was determined by screening various catalytic reaction conditions (Fig. 35). The optimal $\mathrm{Al}_{2}(\mathrm{OH})_{2}$ tcpp-Co thin-film showed more than $76 \%$ selectivity with a TON of 1400 for $\mathrm{CO}_{2}$ reduction to $\mathrm{CO}$ [184].

Around the same time, Hupp's group reported a Fe-porphyrin system for MOF-based $\mathrm{CO}_{2}$ electrocatalytic reduction. Fe-MOF-52 from $\mathrm{Zr}$-clusters and Fe-tcpp was the main catalyst, and could be installed on the electrode surface with a high concentration ( 900 monolayer). Therefore, highly efficient surface coverage to furnish catalytically active sites was achieved, and $\sim 100 \%$ Faradaic efficiency for $\mathrm{CO}_{2}$ reduction to $\mathrm{CO}$ and $\mathrm{H}_{2}$ was observed using FeMOF-52 [151].

The good redox activity of the $\mathrm{M}$-porphyrin system is an attractive feature for MOF-based electrocatalytic reactions. The M-porphyrin system is highly effective for the oxygen reduction reaction. Morris and co-workers applied an Fe-porphyrin system [151], which was previously applied for electrochemical $\mathrm{CO}_{2}$ reduction, to the oxygen reduction reaction [159]. In that study, a $\mathrm{Zr}_{6} \mathrm{O}_{4}(\mathrm{OH})_{4}\left(\mathrm{Fe}(\mathrm{III})(\mathrm{tcpp})_{3}\right) \quad(\mathrm{PCN}-223-\mathrm{Fe})$ thin-film on FTO (Fluorine-doped Tin Oxide) produced a high catalytic current when used as a cathode, and good efficiency for reduction of $\mathrm{O}_{2}$ to $\mathrm{H}_{2} \mathrm{O}$, along with high $\mathrm{H}_{2} \mathrm{O} / \mathrm{H}_{2} \mathrm{O}_{2}$ selectivity (less than $6 \% \mathrm{H}_{2} \mathrm{O}_{2}$ production) (Fig. 36). Further, PCN-223-Fe was observed between the two proton sources, acetic acid (AA) and trichloroacetic acid (TCA). Although TCA is a stronger acid than AA, AA showed better product selectivity than TCA. The study indicated that the catalytic site for $\mathrm{CO}_{2}$ reduction and selection of an adequate proton donor
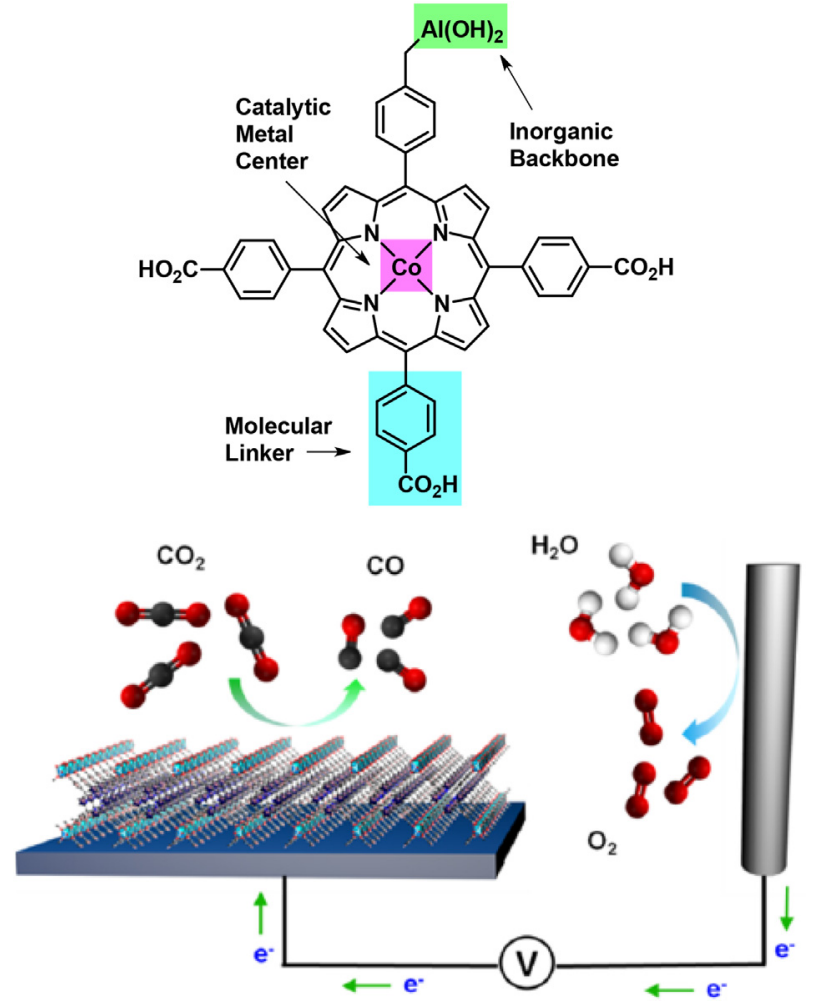

Fig. 35. Co-metalated tcpp and $\mathrm{CO}_{2}$ electrochemical reduction system. Reprinted with permission from Ref. [184].

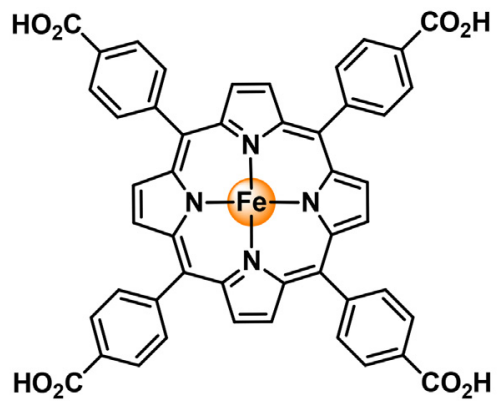

Fe-TCPP

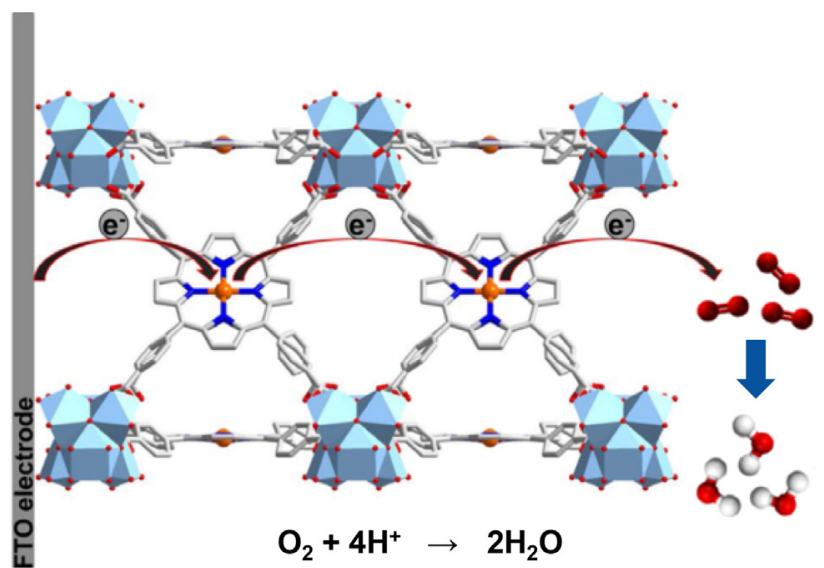

Fig. 36. Fe-metalated TCPP ligand and electrocatalytic oxygen reduction system with PCN-223-Fe film deposited on FTO electrode. Reprinted with permission from Ref. [151]. 
for modification of the pores of the MOFs were critical issues for the electrocatalytic reactions.

\subsection{Enantioselective organic transformations}

As shown in Fig. 37, metallosalen ligands with chiral properties are widely utilized for MOF-based asymmetric catalysis. For example, Lin and co-workers applied a Mn-salen-based CMOF series $\left[\left(\mathrm{Zn}_{4}\left(\mu_{4}-\mathrm{O}\right)\left(\mathrm{O}_{2} \mathrm{CR}\right)_{6}\right.\right.$; where $\mathrm{R}=$ Mn-salen di-carboxylic acid ligands) to the asymmetric epoxidation of alkenes. The active site of CMOF allowed $92 \%$ ee for the stereoselective conversion of alkenes to epoxides [231]. The group led by Cui synthesized Co-salen and Ni-salen based chiral, porous Cd-MOFs. The asymmetric environment of the MOF channel provided a good platform for the heterogeneous hydrolytic kinetic resolution (HKR) of racemic epoxides (up to $99.5 \%$ ee) [242]. Moreover, the catalyst could be recycled and reused without significant loss of catalytic activity and enantioselectivity for the following four cycles, and the integrity of the catalyst was confirmed through XRPD, XPS, and ICP-MS data.

They successfully prepared various metallosalen complexes for application in MOFs, even though the ligand preparation and selective metalation were quite challenging. VO-salen-containing CdMOFs were applied to the cyanation of aldehydes, providing better efficiency and stereoselectivity than the homogeneous system (99.5\% ee) due to the enhanced chiral environment of the MOF channel [247] Even though catalytic activity was gradually decreased to $84 \%$ ee, the crystallinity and V oxidation state were retained after 10 cycles. Further, Cui's and Jiang's teams success-

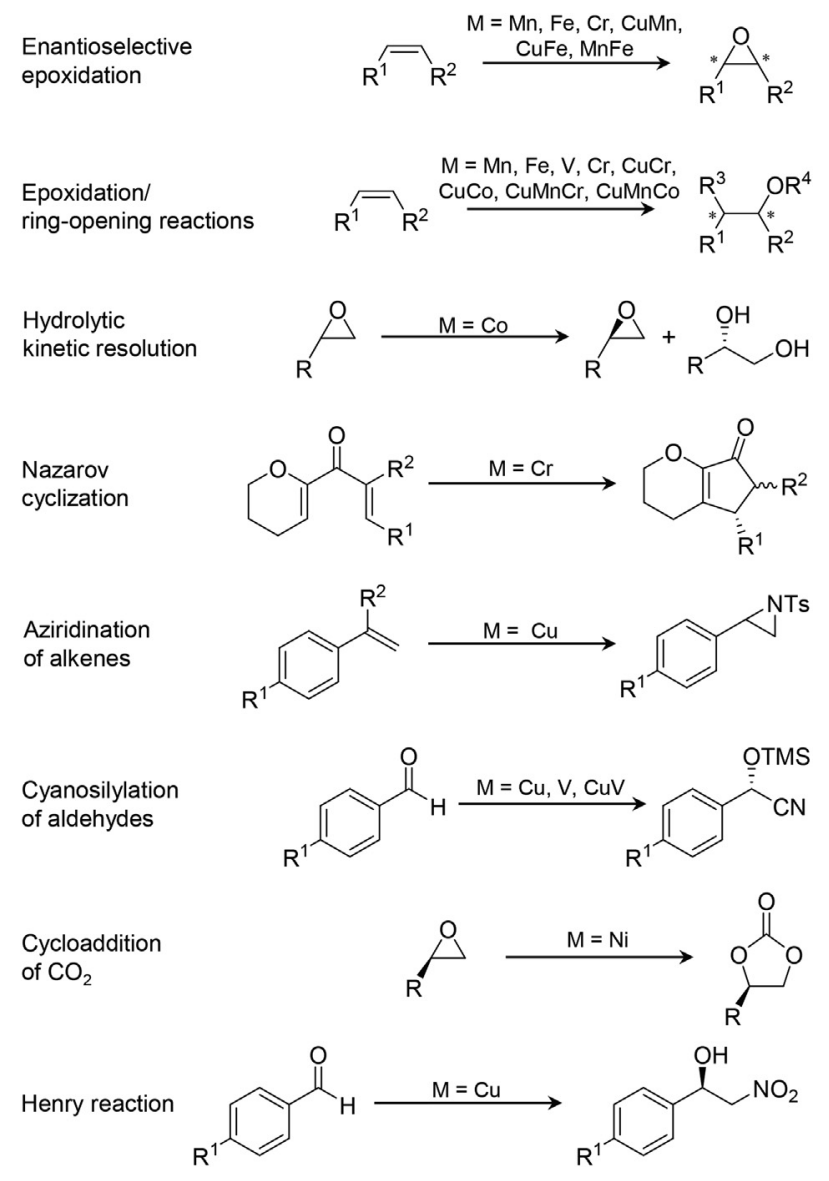

Fig. 37. Various stereoselective organic transformations using achiral M-salen-MOFs. fully performed asymmetric catalytic reactions such as Nazarov cyclization [248], aziridination [246], cycloaddition of $\mathrm{CO}_{2}$ [241], and the Henry reaction [245] using metallosalen complex-based MOFs. In many cases, various chiral MOFs have proven to be very useful catalysts for catalyzing asymmetric organic reactions, also ligands and its application to an asymmetric sequential reaction [235]. In particular, $\mathrm{Cu}, \mathrm{Mn}$, and Co-containing recently as mentioned in Fig. 16, Cui's research team reported interpenetrating MTV-MOF with three metallosalen MTV-MOF could be recycled with negligible loss of efficiency and enantioselectivity.

The synthesis of chemically stable and chiral salen MOFs such as $\mathrm{Zr}$-based UiO series was restricted by low stability of enantiopure salen ligands in harsh aqueous and acidic/basic conditions. Cui group reported that chemically stable and recyclable $\mathrm{M}$-salen-functionalized UiO-68 s ( $\mathrm{M}$ : $\mathrm{Mn}, \mathrm{Fe}, \mathrm{Cu}, \mathrm{Cr}$ and $\mathrm{V}$ ) through PSE strategy [251]. For the optimal platform, UiO-68 was selected which has the coordination bonds between $\mathrm{Zr}_{6} \mathrm{O}_{4}(\mathrm{OH})_{4}$ SBU and tpdc (tpdc $=4,4$-terphenyldicarboxylate), and highly crystalline UiO-68-tpdc-Me (tpdc-Me: 2-methyl-4,4'-terphenyldicar boxylate) with octahedral morphology was utilized for catalytic reactions. As shown in Fig. 38a, tpdc-Me and M-salen ligands have similar length and same connectivity. Therefore, PSE was attempted as a mild functionalization approach for preparing chiral M-salen-loaded UiO-68 analogues. In the asymmetric epoxidation of alkenes, (R)-UiO-68-Mn showed up to $98 \%$ ee (enantiomeric excess) and (R)-UiO-68-Fe showed $98 \%$ ee. For the oxidative kinetic resolution of racemic secondary alcohols, Mnfunctionalized UiO-68 showed $99.7 \%$ ee under the optimized condition. Cyanosilylation of aldehyde was successfully performed with $(R)-U i O-68-V$ with $80-87 \%$ ee. Finally, asymmetric aminolysis of trans-stilbene oxide was achieved with Cr-immobilized UiO-68 with $99 \%$ ee (Fig. 38b). Indeed, sequential reactions for epoxidation of alkenes and ring-opening of epoxides were investigated using dually functionalized UiO-68-Mn-Cr since UiO-68-Mn is good catalyst for epoxidation and UiO-68-Cr could carry out epoxide ring opening reaction. A sequential transformation from alkenes to ring-opened product was successfully performed with overall $80-85 \%$ yields and maximum $99.5 \%$ ee. The catalyst could be reused without significant loss of activity, and the XRPD pattern and surface area of the catalyst retained almost the same as those of the initial catalyst even after 10 cycles [251].

\subsection{Ethylene oligomerization}

The catalytic oligomerization of ethylene is one of the most hackneyed commercial applications of catalysis in the petrochemical industry $[290,291]$. The increasing interest in oligomers has fuelled both academic and industrial efforts to develop and study catalysts for the selective dimerization of ethylene [292,293]. As mentioned, MOFs are attractive and appropriate platforms for seeding single-site catalysts [294-297]. In order to introduce active catalytic sites for selective ethylene dimerization, coordinating functionalities have been engineered into the pores of MOFs via both pre-integrated ligand and sequential attachment approaches.

The group led by Long directly applied bpydc ligands in MOF synthesis $\left(\mathrm{Zr}_{6} \mathrm{O}_{4}(\mathrm{OH})_{4}(\text { bpydc })_{6}, \mathbf{1}\right)$ and subsequently metalated the MOFs with $\mathrm{Ni}(\mathrm{DME}) \mathrm{Br}_{2}$ (DME = 1,2-dimethoxyethane), yielding $\mathbf{1}\left(\mathrm{NiBr}_{2}\right)_{6}$ (Fig. 39a) and the active sites in the MOF framework are generally underwent the Cossee-Arlman mechanism as presented in Fig. 39b [56]. Chain growth entails continuous ethylene insertion into the metal-alkyl intermediate, and chain termination occurs by $\beta$-hydrogen elimination of the alkyl chain and subsequent replacement of generated olefins with ethylene.

Moreover, a mixed-linker framework, $\mathrm{Zr}_{6} \mathrm{O}_{4}(\mathrm{OH})_{4}(\text { bpydc })_{0.84}$ (bpdc) $)_{5.16}(\mathbf{2})$, was synthesized in the development of a catalyst with uniformly dispersed coordinating sites, with lower 


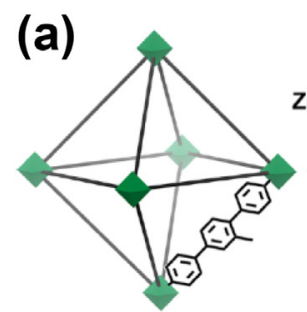

UiO-68-Me

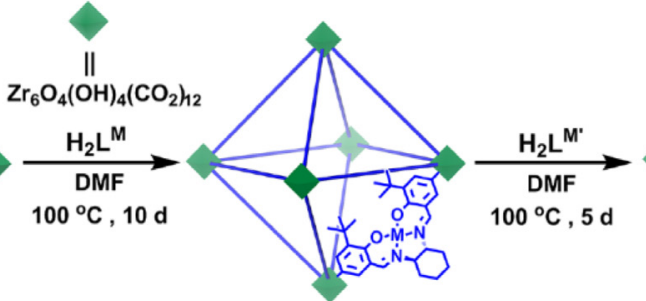

UiO-68-M

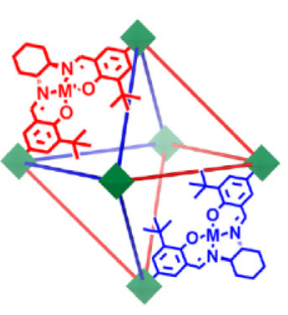

UiO-68-M-M'

(b)

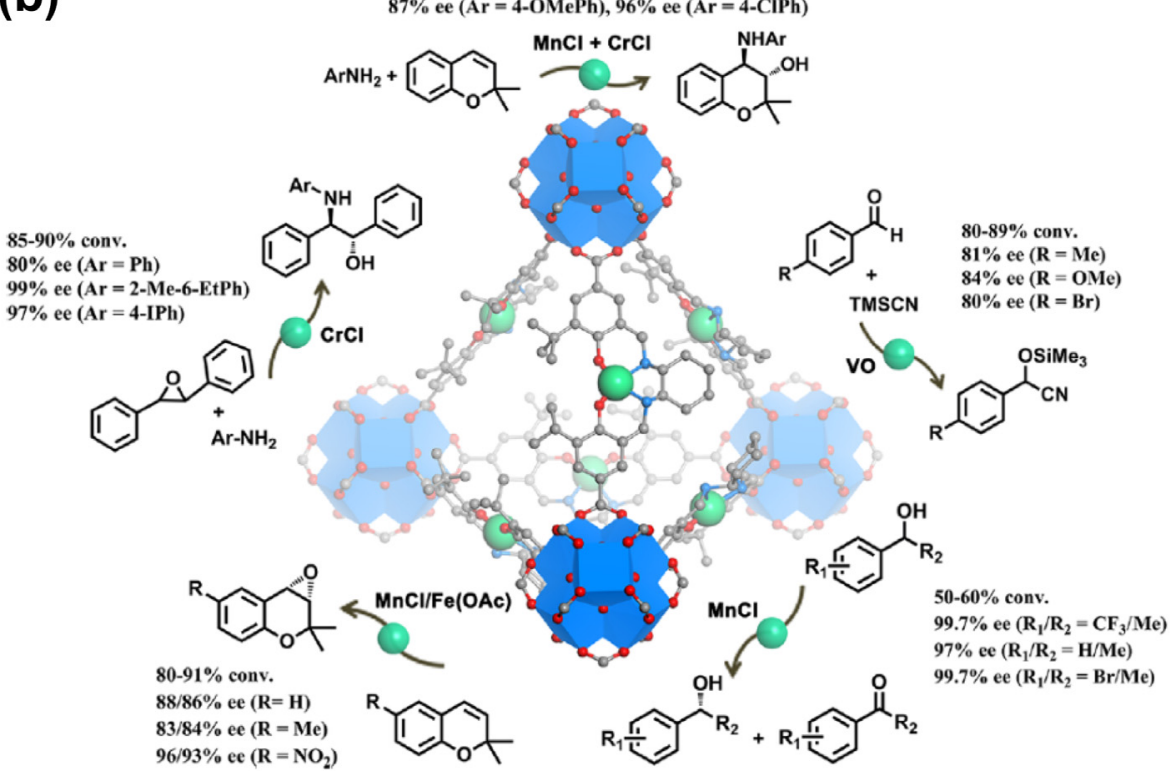

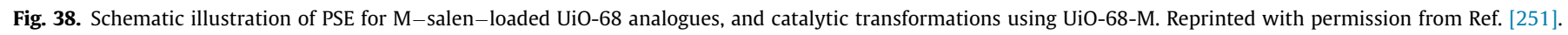

concentration compared to $\mathbf{1}$, where $\mathbf{2}\left(\mathrm{NiBr}_{2}\right)_{0.84}$ anchoring $\mathrm{Ni}(\mathrm{II})$ complexes was finally obtained. The ethylene oligomerization reactions were carried out under 59 bar of ethylene at $55{ }^{\circ} \mathrm{C}$ for $1 \mathrm{~h}$ in the presence of a co-catalyst, Et ${ }_{2} \mathrm{AlCl}$. The catalyst $\mathbf{1}\left(\mathrm{NiBr}_{2}\right)_{6}$ consumed ethylene at a low turnover frequency (TOF) of $4300 \pm 400 \mathrm{~mol}_{\text {ethylene }} \mathrm{mol}_{\mathrm{Ni}}^{-1} \mathrm{~h}^{-1}$ and produced $23 \pm 1 \mathrm{wt} \%$ of $\mathrm{C}_{4-18}$ oligomers, resulting from the constriction of the pore apertures and porosity due to complete metalation. Interestingly, the isolation of $\mathrm{Ni}(\mathrm{II})$ bipyridine complexes in the framework minimized the steric hindrance, thereby improving the catalytic activity. The mixed-linker catalyst, $\mathbf{2}\left(\mathrm{NiBr}_{2}\right)_{0.84}$, exhibited much higher TOF values $\left(36000 \pm 3000 \mathrm{~mol}_{\text {ethylene }} \mathrm{mol}_{\mathrm{Ni}}^{-1} \mathrm{~h}^{-1}\right)$ than 1 $\left(\mathrm{NiBr}_{2}\right)_{6}$ and produced $73 \pm 6 \mathrm{wt} \%$ of $\mathrm{C}_{4-18}$ oligomers.

Canivet and colleagues developed a novel process for the postfunctionalization of MOFs that enabled immobilization of an active organometallic catalyst for ethylene dimerization [259]. (Fe)MIL$101-\mathrm{NH}_{2}$, composed of trimeric $\mathrm{Fe}(\mathrm{II})$ octahedral clusters linked by 2 -aminoterephtalate, was chosen as a platform. As illustrated in Fig. 39c, they synthesized organometallics $\left(\mathrm{Ni}(\mathrm{Py}-\mathrm{CHO}) \mathrm{Cl}_{2}\right)$ that were then supported on the MOF pores; the organometallics were directly anchored into the MOF by imine condensation with amine groups, forming a diimino nickel complex (Ni@(Fe)MIL-101). The porous Ni@(Fe)MIL-101 catalyst showed dramatically higher activity $\left(3166 \mathrm{~h}^{-1}\right)$ than its molecular analogue, $\mathrm{Ni}(\mathrm{bipy}) \mathrm{Cl}_{2}\left(210 \mathrm{~h}^{-1}\right)$, and showed high selectivity for 1-butene (Table 5). Jie and colleagues synthesized a series of mixed-linker MOFs $\left(\mathrm{Zn}_{4} \mathrm{O}(\mathrm{BDC})_{\mathrm{x}}\right.$ $\left.\left(\mathrm{NH}_{2}-\mathrm{BDC}\right)_{3-\mathrm{x}}\right)$ and then immobilized active nickel complexes on the MOFs for ethylene oligomerization via imine condensation, as shown in Fig. 39d (MixMOFs-Ni) [298]. The MixMOFs-Ni series catalysts maintained their structural crystallinity, producing good activity and selectivity.

\subsection{Photocatalysis}

MOFs are the interesting photocatalyst platform to incorporate photosensitizing components and catalytic centers for solar energy to chemical conversion [299-301]. Because porphyrins, large conjugated systems, have the high light harvesting efficiency, porphyrinic MOFs have been studied in photocatalysis. PCN-222, which is a representative $\mathrm{Zr}$-based porphyrinic MOF, was examined for aerobic oxidative coupling reaction of amines [302] and $\mathrm{CO}_{2}$ reduction to formate by Jiang group [221]. In these reactions, under visible light irradiation electron transfer from the porphyrin to $\mathrm{Zr}$-oxo clusters resulted in oxygen-centered active sites and porphyrin $\pi$-cation radicals, which were verified by the electron spin resonance (ESR) technique.

As a photocatalyst for the $\mathrm{CO}_{2}$ reduction to formate under visible light irradiation, the robust Zr-based MOF incorporating bis( $4^{\prime}$ (4-carboxyphenyl)-terpyridine) $\mathrm{Ru}(\mathrm{II}),\left(\mathrm{Ru}(\mathrm{cptpy})_{2}\right.$ ) was prepared (Fig. 40a) [303]. Ru(II) was pre-metalated via coordination with $\mathrm{H}_{2}$ cptpy to form the $\mathrm{Ru}(\mathrm{cptpy})_{2}$ linker, and its subsequent solvothermal reaction with $\mathrm{ZrOCl}_{2} \cdot 8 \mathrm{H}_{2} \mathrm{O}$ produced the infinite one-dimensional packing network, AUBM-4, in which the $\mathrm{ZrO}_{8}$ SBUs are connected with two $\mathrm{Ru}(\mathrm{cptpy})_{2}$. The luminescence spectra for Ru(cptpy $)_{2}$ and AUBM-4 showed the metal-to-ligand charge transfer (MLCT) state originated from Ru(II) complexes, and their time resolved luminescence traces revealed that the AUBM- 4 has a longer lifetime than $\mathrm{Ru}(\mathrm{cptpy})_{2}$ (Fig. $40 \mathrm{~b}$ and c). The $\mathrm{CO}_{2}$ 

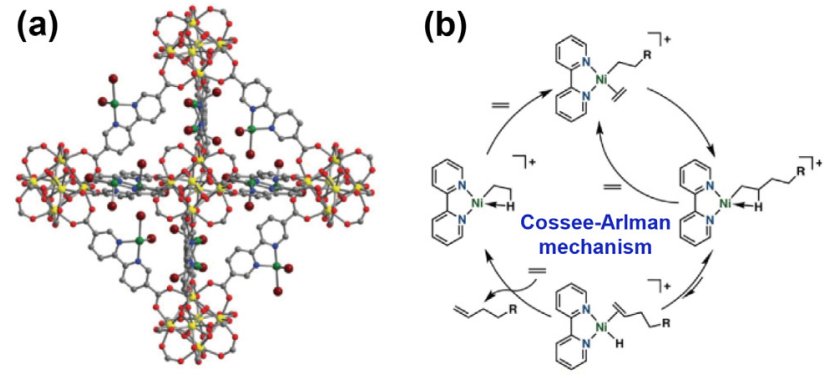

(c)

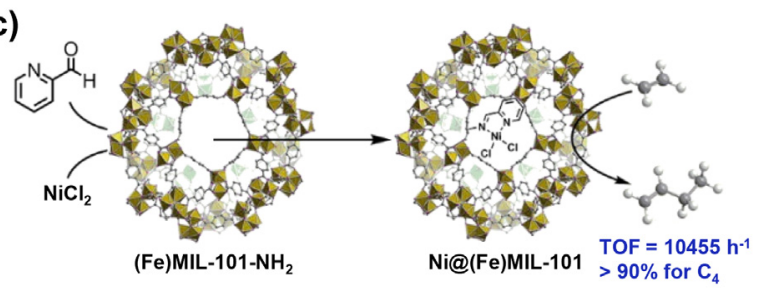

(d)

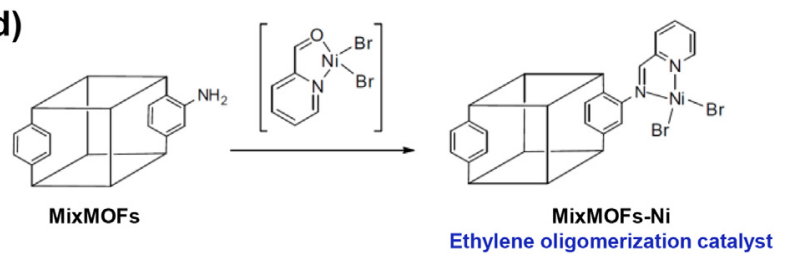

Fig. 39. (a) The crystal structure of $\mathrm{Zr}_{6} \mathrm{O}_{4}(\mathrm{OH})_{4}(\text { bpydc })_{6}\left(\mathrm{NiBr}_{2}\right)_{5.64}$ as determined by analysis of single-crystal XRD; yellow, green, dark red, red, blue, and gray spheres represent $\mathrm{Zr}, \mathrm{Ni}, \mathrm{Br}, \mathrm{O}, \mathrm{N}$, and $\mathrm{C}$ atoms, respectively. (b) Cossee-Arlman mechanism for ethylene oligomerization or polymerization catalyzed by nickel(II) bipyridine or a-diimine complexes. (c) One-Pot Synthesis of the MOF-Anchored Nickel Complex Ni@(Fe)MIL-101 for the liquid-phase ethylene dimerization. (d) The postsynthetic modification of MixMOFs to yield MOFs-containing Ni catalysts. Reproduced with permission from Ref. [56,259,298].

photoreduction by using AUBM-4 was conducted in the presence of triethanolamine (TEOA) as a sacrificial agent in acetonitrile solution under $150 \mathrm{~W}$ xenon lamp irradiation. The formate production monitored by ion chromatography showed the highest conversion rate $\left(366 \mu \mathrm{mol} \cdot \mathrm{g}^{-1} \cdot \mathrm{h}\right)$ among the previously reported MOF catalysts. It might be attributed to the long emission lifetime and fast MLCT in AUBM-4 incorporating Ru(cptpy $)_{2}$ and high surface area and coordinating sites for $\mathrm{CO}_{2}$ to access, which was supported by Density Functional Theory (DFT) calculations (Fig. 40d).

Another interesting example of photoactive MOFs was reported by Lin group [304]. To construct multicomponent photocatalysts using MOF system, a pre-integrated ligand, 4,4'-di(4-benzoato)-2, 2 '-bipyridine (DBB) was employed for pre- as well as postmetalation. As shown in Fig. 41a, a pre-metalated linker, [Ir(III) $\left.\left(\mathrm{dF}\left(\mathrm{CF}_{3}\right) \mathrm{ppy}\right)_{2}\left(\mathrm{H}_{2} \mathrm{DBB}\right)\right] \mathrm{Cl}\left(\mathrm{dF}\left(\mathrm{CF}_{3}\right) \mathrm{ppy}=2\right.$-(2,3-difluorophenyl)-5- (a)
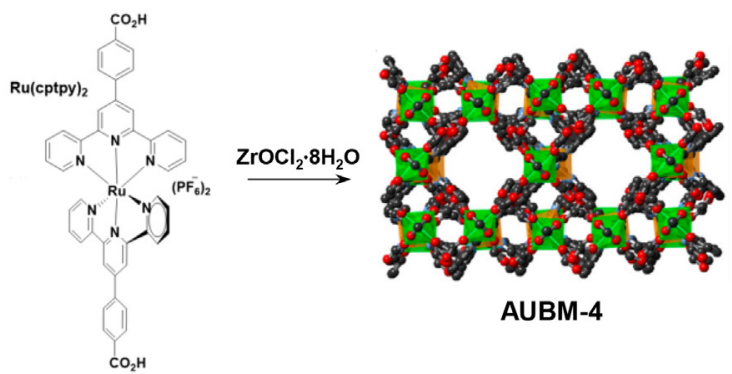

AUBM-4
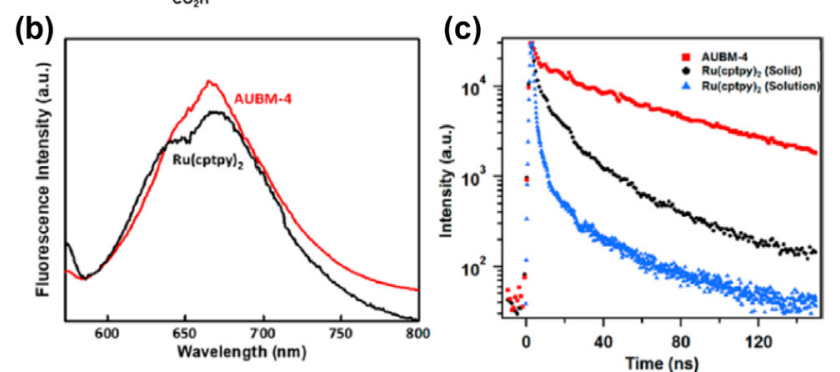

(d)

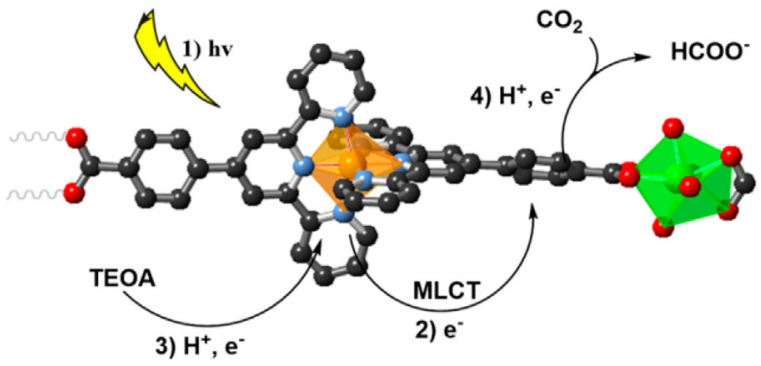

Fig. 40. (a) Synthesis and crystal structure of AUBM-4 with Ru(cptpy $)_{2}$ linker (b) photoluminescence spectra and (c) Time resolved luminescence traces at $520 \mathrm{~nm}$ of $\mathrm{Ru}(\mathrm{cptpy})_{2}$ and AUBM-4. (d) Proposed mechanism for $\mathrm{CO}_{2}$ photoreduction over AUBM-4 under visible light irradiation. Reprinted with permission from Ref. [303].

(trifluoromethyl)pyridine) was prepared as a photosensitize, and its further solvothermal reaction with $\mathrm{ZrCl}_{4}$ and $\mathrm{H}_{2} \mathrm{DBB}$ resulted in $\mathrm{Zr}_{12}\left(\mu_{3}-\mathrm{O}\right)_{8}\left(\mu_{3}-\mathrm{OH}\right)_{8}\left(\mu_{2}-\mathrm{OH}\right)_{6}(\mathrm{DBB})_{4.5}\left[\mathrm{Ir}\left(\mathrm{dF}\left(\mathrm{CF}_{3}\right) \mathrm{ppy}\right)_{2}(\mathrm{DBB})\right]_{4.5}$ $\left(\mathrm{Zr}_{12}\right.$-Ir MOF). The vacant coordinating sites in DBB of $\mathrm{Zr}_{12}$-Ir MOF were occupied by $\mathrm{Ni}(\mathrm{II})$ via post-metalation, finally producing $\mathrm{Zr}_{12}$-Ir-Ni MOF, in which the distance between $\mathrm{Ir}(\mathrm{III})$ and Ni(II) centers is ca. $0.6 \mathrm{~nm}$ (Fig. 41b). This is a dual catalytic MOF incorporating Ir(III) photoredox catalyst and Ni(II) cross-coupling catalyst, which showed the high TON of C-S bond formation between various aryl iodides and thiols. Especially, the coupling reaction of 4iodo-benzonitrile and thiophenol reach TON of 38500, an order of magnitude higher than that of its homogeneous counterpart. This highly efficient photocatalytic activity is due to the short distance between two catalytic centers to facilitate electron and radical transfer.

Table 5

Intrinsic activity and selectivity of Ni-catalyzed ethylene oligomerization.

\begin{tabular}{|c|c|c|c|c|}
\hline \multirow[t]{2}{*}{ Catalysts } & \multirow[t]{2}{*}{ Intrinsicactivity $\left(\mathrm{h}^{-1}\right)$} & \multicolumn{3}{|c|}{ Selectivity (\%) } \\
\hline & & $\mathrm{C}_{4}$ & $\mathrm{C}_{6}$ & $\mathrm{C}_{8}$ \\
\hline None & 0 & 0 & 0 & 0 \\
\hline $\mathrm{Ni}($ bpy $) \mathrm{Cl}_{2}$ & 210 & 92 & 7.5 & 0.5 \\
\hline (Fe)MIL-101--NH & 0 & 0 & 0 & 0 \\
\hline (Fe)MIL-101- $\mathrm{NH}_{2}+\mathrm{NiCl}_{2}$ & 0 & 0 & 0 & 0 \\
\hline (Fe)MIL-101- $\mathrm{NH}_{2}+$ PyCHO & 0 & 0 & 0 & 0 \\
\hline $\mathrm{Ni@(Fe)MIL-101}$ & 3166 & 95 & 4.5 & 0.5 \\
\hline
\end{tabular}


(a)

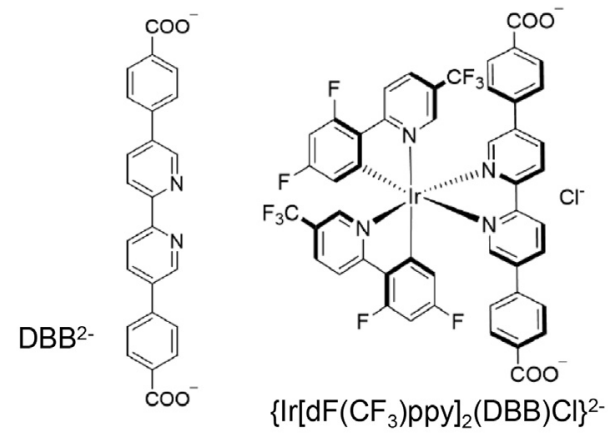

(b)

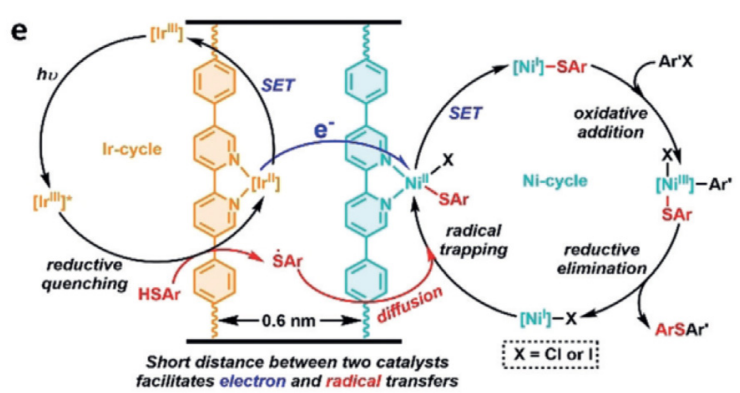

Fig. 41. (a) Structures of linkers, $\mathrm{DBB}^{2-}$ and $\left\{\left[\mathrm{Ir}(\mathrm{III})\left(\mathrm{dF}^{2}\left(\mathrm{CF}_{3}\right) \mathrm{ppy}\right)_{2}(\mathrm{DBB})\right] \mathrm{Cl}\right\}^{2-}$. (b) Proposed mechanism for the $\mathrm{C}-\mathrm{S}$ cross-coupling reaction catalysed by $\mathrm{Zr}_{12}-\mathrm{Ir}-\mathrm{Ni}$. Reprinted with permission from Ref. [304].

\section{Conclusion and future outlooks}

In the last two decades, the synthesis and preparation of a variety of MOFs along with the structural analysis have been intensively studied. Various combinations of metals in the periodic table and chelating ligands such as carboxylic acid and heterocyclic compounds allowed superior diversity of MOF libraries in the literature. Moreover, the possibilities for functionalizations of MOF pores through additional pore engineering and the modifications on ligands permit the great potential of this inorganic-organic hybrid material for a variety of applications compared to traditional inorganic porous materials. At the same time, the multiple functionalizations on organic ligands can be considered for a convenient method for preparing multi-functional porous materials.

Pore properties and environments of MOFs have been engineered using various combinations of metal clusters and ligands. In order to achieve delicate pore engineering, a variety of approaches for introducing and controlling the functionality in MOF pores have been developed by many research groups. The MOFs having well-tailored pore environments can be the good materials for the desired applications, especially for heterogeneous catalysts via anchoring catalytically active metal sites to MOF pores. Unlike the simple functionalization and engineering of MOF pores with covalent chemical tags, an attempt to employ catalytically-active (i.e., coordinatively-active) species into MOF as a heterogeneous catalytic site to be more careful since the fundamental structures of MOFs are also based on the coordination bonds between metals and ligands. A proper strategical approach and metal selections for both MOF constructions and catalysis should be prudently performed and applied to MOF platform.

In this review, we summarized various strategies of pore engineering to grant catalytic activities to the MOF supports, categorizing them into two prominent approaches: pre-integrated ligand and sequential attachment. The section for the former approach introduced heterocycles and NHCs, porphyrins, and salens, which are ligands having coordinating functionalities for immobilizing catalytic sites when synthesizing MOFs. The latter approach was covered as post-synthetic attachment of coordinating functionalities via well-known reactions such as imine condensation, ringopening, and Click reaction. In addition, we summarized representative catalytic applications by utilization of those MOF catalysts such as $\mathrm{CO}_{2}$ hydrogenation, electrocatalytic reactions, organic transformations and ethylene oligomerizations.

While the pore engineering of MOFs has been successful, even allowing multi-functional catalysts for complex catalytic systems, the MOF-based heterogeneous also showed several challenging issues. For instance, the pore sizes of MOF-based catalysts are generally decreased by installing catalytically-active species in MOF pore by either pre-functionalization or post-synthetic attachment. The shrunk pore can restrict the diffusion of reactant and product for reactions. Therefore, the installation of catalytic species should be considered with the maintenance of diffusivity and reaction efficiency.

Lastly, the different pore environments of the surface of MOF crystals and the inside of MOF crystals should be carefully deliberated. Although the surface of MOF crystal has more free spaces for diffusion and allows the fast conversion for catalytic reactions, the reaction environments, especially for stereospecific reactions, are significantly differed from the reaction site at the inside of framework [305-307]. Taking the above limitations and issues into account, it is anticipated that the separated designs for catalytic sites at the surface of MOFs and inside of crystals, thus enabling real multi-functional and efficient catalyst platform from MOFs by pore engineering. These synthetic strategies will provide opportunities for covering and approaching the development of MOF-based heterogeneous catalysts and show the insight for the practical functionalization and related applications of MOFs.

\section{Declaration of Competing Interest}

The authors declare that they have no known competing financial interests or personal relationships that could have appeared to influence the work reported in this paper.

\section{Acknowledgements}

This work was supported by the National Research Foundation (NRF) Grant funded by the Ministry of Science and ICP in South Korea (No. NRF-2016R1A5A1009405 and NRF-2017R1A2B4008757).

\section{References}

[1] M.E. Davis, Acc. Chem. Res. 26 (1993) 111.

[2] A. Corma, Chem. Rev. 95 (1995) 559.

[3] A. Corma, Chem. Rev. 97 (1997) 2373.

[4] C.E. Song, S.-G. Lee, Chem. Rev. 102 (2002) 3495.

[5] G. Busca, Chem. Rev. 107 (2007) 5366.

[6] U. Díaz, D. Brunel, A. Corma, Chem. Soc. Rev. 42 (2013) 4083.

[7] G. Zhan, H.C. Zeng, Coord. Chem. Rev. 320-321 (2016) 181.

[8] O.M. Yaghi, M. O’Keeffe, N.W. Ockwig, H.K. Chae, M. Eddaoudi, J. Kim, Nature 423 (2003) 705.

[9] J.-R. Li, R.J. Kuppler, H.-C. Zhou, Chem. Soc. Rev. 38 (2009) 1477.

[10] H. Sato, W. Kosaka, R. Matsuda, A. Hori, Y. Hijikata, R.V. Belosludov, S. Sakaki, M. Takata, S. Kitagawa, Science 343 (2014) 167.

[11] S. Kitagawa, R. Kitaura, S.-I. Noro, Angew. Chem., Int. Ed. 43 (2004) 2334.

[12] L.J. Murray, M. Dincă, J.R. Long, Chem. Soc. Rev. 38 (2009) 1294.

[13] L. Ma, C. Abney, W. Lin, Chem. Soc. Rev. 38 (2009) 1248.

[14] S. Qiu, G. Zhu, Coord. Chem. Rev. 253 (2009) 2891.

[15] B. Chen, S. Xiang, G. Qian, Acc. Chem. Res. 43 (2010) 1115.

[16] A. Corma, H. García, F.X. Llabrés i Xamena, Chem. Rev. 110 (2010) 4606

[17] J. Lee, O.K. Farha, J. Roberts, K.A. Scheidt, S.T. Nguyen, J.T. Hupp, Chem. Soc. Rev. 38 (2009) 1450.

[18] K.K. Tanabe, S.M. Cohen, Chem. Soc. Rev, 40 (2011) 498.

[19] M. Kim, S.M. Cohen, CrystEngComm 14 (2012) 4096.

[20] C. Zou, C.-D. Wu, Dalton Trans. 41 (2012) 3879.

[21] W. Lu, Z. Wei, Z.-Y. Gu, T.-F. Liu, J. Park, J. Park, J. Tian, M. Zhang, Q. Zhang, T. Gentle III, M. Bosch, H.-C. Zhou, Chem. Soc. Rev. 43 (2014) 5561.

[22] L. Chen, H. Chen, R. Luque, Y. Li, Chem. Sci. 5 (2014) 3708.

[23] H. He, J.A. Perman, G. Zhu, S. Ma, Small 12 (2016) 6309. 
[24] Y. Kim, S. Huh, CrystEngComm 18 (2016) 3524.

[25] L. Zhu, X.-O. Liu, H.-L. Jiang, L.-B. Sun, Chem. Rev. 117 (2017) 8129.

[26] P. Deria, J.E. Mondloch, O. Karagiaridi, W. Bury, J.T. Hupp, O.K. Farha, Chem. Soc. Rev. 43 (2014) 5896.

[27] J.D. Evans, C.J. Sumby, C.J. Doonan, Chem. Soc. Rev. 43 (2014) 5933.

[28] Y. Wen, J. Zhang, Q. Xu, X.-T. Wu, Q.-L. Zhu, Coord. Chem. Rev. 376 (2018) 248.

[29] Y. Zhang, X. Yang, H.-C. Zhou, Polyhedron 154 (2018) 189.

[30] C. Wang, B. An, W. Lin, ACS Catal. 9 (2019) 130.

[31] Z. Yin, S. Wan, J. Yang, M. Kurmoo, M.-H. Zeng, Coord. Chem. Rev. 378 (2019) 500.

[32] C. Wang, Z. Xie, K.E. deKrafft, W. Lin, J. Am. Chem. Soc. 133 (2011) 13445.

[33] B. An, L. Zeng, M. Jia, Z. Li, Z. Lin, Y. Song, Y. Zhou, J. Cheng, C. Wang, W. Lin, J. Am. Chem. Soc. 139 (2017) 17747.

[34] K.M. Choi, D. Kim, B. Rungtaweevoranit, C.A. Trickett, J.Y.D. Barmanbek, A.S Alshammari, P. Yang, O.M. Yaghi, J. Am. Chem. Soc. 139 (2017) 356.

[35] U.J. Ryu, S.J. Kim, H.-K. Lim, H. Kim, K.M. Choi, J.K. Kang, Sci. Rep. 7 (2017) 612.

[36] M. Liu, Y.-F. Mu, S. Yao, S. Guo, X.-W. Guo, Z.-M. Zhang, T.-B. Lu, Appl. Catal. B: Environ. 245 (2019) 496.

[37] H. Fei, S.M. Cohen, Chem. Commun. 50 (2014) 4810.

[38] L. Chen, S. Rangan, J. Li, H. Jiang, Y. Li, Green. Chem. 16 (2014) 3978.

[39] K. Manna, T. Zhang, W. Lin, J. Am. Chem. Soc. 136 (2014) 6566.

[40] A.E. Platero-Prats, A.B. Gómez, L. Samain, X. Zou, B. Martín-Matute, Chem. Eur. J 21 (2015) 861.

[41] X. Li, R.V. Zeeland, R.V. Maligal-Ganesh, Y. Pei, G. Power, L. Stanley, W. Huang, ACS Catal. 6 (2016) 6324.

[42] G. Liu, M. Zeller, K. Su, J. Pang, Z. Ju, D. Yuan, M. Hong, Chem. Eur. J. 22 (2016) 17345.

[43] M.B. Chambers, X. Wang, N. Elgrishi, C.H. Hendon, A. Walsh, J. Bonnefoy, J. Canivet, E.A. Quadrelli, D. Farrusseng, C. Mellot-Draznieks, M. Fontecave, ChemSusChem 8 (2015) 603.

[44] S. Øien, G. Agostini, S. Svelle, E. Borfecchia, K.A. Lomachenko, L. Mino, E. Gallo S. Bordiga, U. Olsbye, K.P. Lillerud, C. Lamberti, Chem. Mater. 27 (2015) 1042.

[45] L. Braglia, E. Borfecchia, K.A. Lomachenko, A.L. Bugaev, A.A. Guda, A.V. Soldatov, B.T.L. Bleken, S. Øien-Ødegaard, U. Olsbye, K.P. Lillerud, S. Bordiga, G. Agostini, M. Manzoli, C. Lanberti, Faraday Discuss. 201 (2017) 265.

[46] L. Braglia, E. Borfecchia, A. Martini, A.L. Bugaev, A.V. Soldatov, S. Øiendegaard, B.T. Lønstad-Bleken, U. Olsbye, K.P. Lillerud, K.A. Lomachenko, G. Agostini, M. Manzoli, C. Lanberti, Phys. Chem. Chem. Phys. 19 (2017) 27489

[47] H. Fei, M.D. Sampson, Y. Lee, C.P. Kubiak, S.M. Cohen, Inorg. Chem. 54 (2015) 6821.

[48] S. Diring, A. Carné-Sánchez, J. Zhang, S. Ikemura, C. Kim, H. Inaba, S. Kitagawa, S. Furukawa, Chem. Sci. 8 (2017) 2381.

[49] M.I. Gonzalez, E.D. Bloch, J.A. Mason, J.A. Mason, S.J. Teat, J.R. Long, Inorg. Chem. 54 (2015) 2995

[50] L. Braglia, E. Borfecchia, L. Maddalena, S. Øien, K.A. Lomachenko, A.L. Bugaev, S. Bordiga A.V Soldatov, K. P. Lillerud, C. Lamberti, Catal. Today 283 (2017) 89.

[51] B. An, J. Zhang, K. Cheng, P. Ji, C. Wang, W. Lin, J. Am. Chem. Soc. 139 (2017) 3834.

[52] Y. Song, D. Yang, S. Yu, X. Teng, Z. Chang, F. Pan, X. Bu, Z. Jiang, B. Wang, S. Wang, X. Cao, Sep. Purif. Technol. 210 (2019) 258.

[53] P. Neves, A.C. Gomes, T.R. Amarante, F.A.A. Paz, M. Pillinger, I.S. Gonçalves, A. A. Valente, Micropor. Mesopor. Mat. 202 (2015) 106.

[54] Y. Zhou, B. Yan, Nanoscale 7 (2015) 4063.

[55] X. Zhang, K. Jiang, H. He, D. Yue, D. Zhao, Y. Cui, Y. Yang, G. Qian, Sensor. Actuat. B: Chem. 254 (2018) 1069.

[56] M.I. Gonzalez, J. Oktawiec, J.R. Long, Faraday Discuss. 201 (2017) 351.

[57] Y. Zhou, B. Yan, F. Lei, Chem. Commun. 50 (2014) 15235.

[58] J.-X. Wu, B. Yan, Dalton Trans. 45 (2016) 18585.

[59] J.-X. Wu, B. Yan, Analyst 142 (2017) 4633.

[60] J.-X. Wu, B. Yan, J. Colloid, Interface Sci. 504 (2017) 197.

[61] J. Wang, J. Luo, B. Zhi, G. Li, Q. Huo, Y. Liu, CrystEngComm 16 (2014) 9810.

[62] S. Huh, S. Jung, Y. Kim, S.-J. Kim, S. Park, Dalton Trans. 39 (2010) 1261.

[63] J. Wang, J. Luo, J. Zhao, D.-S. Li, G. Li, Q. Huo, Y. Liu, Cryst. Growth Des. 14 (2014) 2375.

[64] C.A. Kent, D. Liu, T.J. Meyer, W. Lin, J. Am. Chem. Soc. 134 (2012) 3991.

[65] E.D. Bloch, D. Britt, C. Lee, C.J. Doonan, F.J. Uribe-Romo, H. Furukawa, J.R. Long, O.M. Yaghi, J. Am. Chem. Soc. 132 (2010) 14382.

[66] S.-J. Qin, B. Yan, Anal. Chim. Acta 1012 (2018) 82

[67] J. Luo, B.-S. Liu, X.-R. Zhang, R.-T. Liu, J. Mol. Struct. 1177 (2019) 444.

[68] K.C. Szeto, K.P. Lillerud, M. Tilset, M. Bjørgen, C. Prestipino, A. Zecchina, C. Lamberti, S. Bordiga, J. Phys. Chem. B 110 (2006) 21509.

[69] K.C. Szeto, K.O. Kongshaug, S. Jakobsen, M. Tilset, K.P. Lillerud, Dalton Trans. (2008) 2054.

[70] J. Huang, W. Wang, H. Li, ACS Catal. 3 (2013) 1526.

[71] S.-L. Huang, A.-Q. Jia, G.-X. Jin, Chem. Commun. 49 (2013) 2403.

[72] Y.-Y. Liu, R. Decadt, T. Bogaerts, K. Hemelsoet, A.M. Kaczmarek, D. Poelman, M. Waroquier, V.V. Speybroeck, R.V. Deun, P.V.D. Voort, J. Phys. Chem. C 117 (2013) 11302.

[73] J.-N. Hao, B. Yan, Nanoscale 8 (2016) 2881.

[74] X. Lin, Y. Hong, C. Zhang, R. Huang, C. Wang, W. Lin, Chem. Commun. 51 (2015) 16996.

[75] Y. Ren, O. Jiang, J. Li, H. Zeng, Appl. Organometal. Chem. 30 (2016) 699.

[76] F. Ding, Y. Li, P. Yan, Y. Deng, D. Wang, Y. Zhang, I. Dragutan, V. Dragutan, K. Wang, Molecules 23 (2018) 2435.

[77] E.Y. Lee, M.P. Suh, Angew. Chem., Int. Ed. 43 (2004) 2798.
[78] W.M. Bloch, A. Burgun, C.J. Coghlan, R. Lee, M.L. Coote, C.J. Doonan, C.J. Sumby, Nat. Chem. 6 (2014) 906.

[79] H.-J. Lee, H. Kwon, J. Sim, D. Song, Y. Kim, J. Kim, K. Kim, E. Lee, CrystEngComm 19 (2017) 1528.

[80] K. Oisaki, O. Li, H. Furukawa, A.U. Czaja, O.M. Yaghi, J. Am. Chem. Soc. 132 (2010) 9262.

[81] J.M. Roberts, O.K. Farha, A.A. Sarjeant, J.T. Hupp, K.A. Scheidt, Cryst. Growth Des. 11 (2011) 4747.

[82] G.-Q. Kong, X. Xu, C. Zou, C.-D. Wu, Chem. Commun. 47 (2011) 11005.

[83] F. Carson, E. Martínez-Castro, R. Marcos, G.G. Miera, K. Jansson, X. Zou, B. Martín-Matute, Chem. Commun. 51 (2015) 10864.

[84] Y.-L. Wei, Y. Li, Y.-Q. Chen, Y. Dong, J.-J. Yao, X.-Y. Han, Y.-B. Dong, Inorg. Chem. 57 (2018) 4379.

[85] J. Chun, H.S. Lee, I.G. Jung, S.W. Lee, H.J. Kim, S.U. Son, Organometallics 29 (2010) 1518.

[86] I.T. Siraj, M.D. Spicer, Int. J. Chem. Eng. Appl. 4 (2013) 199.

[87] P. Suresh, S. Radhakrishnan, C.N. Babu, A. Sathyanarayana, N. Sampath, G. Prabusankar, Dalton Trans. 42 (2013) 10838.

[88] A. Burgun, R.S. Crees, M.L. Cole, C.J. Doonan, C.J. Sumby, Chem. Commun. 50 (2014) 11760

[89] Y. Dong, Y. Li, Y.-L. Wei, J.-C. Wang, J.-P. Ma, J. Ji, B.-J. Yao, Y.-B. Dong, Chem. Commun. 52 (2016) 10505.

[90] E.-Y. Choi, P.M. Barron, R.W. Novotney, C. Hu, Y.-U. Kwon, W. Choe, CrystEngComm 10 (2008) 824.

[91] S. Matsunaga, S. Kato, N. Endo, W. Mori, Chem. Lett. 42 (2013) 298.

[92] K. Lu, C. He, W. Lin, J. Am. Chem. Soc. 136 (2014) 16712.

[93] E.-Y. Choi, C.A. Wray, C. Hu, W. Choe, CrystEngComm 11 (2009) 553.

[94] E.-Y. Choi, P.M. Barron, R.W. Novotny, H.-T. Son, C. Hu, W. Choe, Inorg. Chem. 48 (2009) 426.

[95] P.M. Barron, C.A. Wray, C. Hu, Z. Guo, W. Choe, Inorg. Chem. 49 (2010) 10217.

[96] L. Meng, Q. Cheng, C. Kim, W.-Y. Gao, L. Wojtas, Y.-S. Chen, M.J. Zaworotko, X. P. Zhang, S. Ma, Angew. Chem., Int. Ed. 51 (2012) 10082.

[97] X.-S. Wang, M. Chrzanowski, C. Kim, W.-Y. Gao, L. Wojtas, Y.-S. Chen, X.P. Zhang, S. Ma, Chem. Commun. 448 (2012) 7173.

[98] S.R. Ahrenholtz, C.C. Epley, A.J. Morris, J. Am. Chem. Soc. 136 (2014) 2464.

[99] H. Wu, F. Yang, X.-L. Lv, B. Wang, Y.-Z. Zhang, M.-J. Zhao, J.-R. Li, J. Mater. Chem. A 5 (2017) 14525.

[100] P.M. Barron, H.-T. Son, C. Hu, W. Choe, Cryst. Growth Des. 9 (2009) 1960.

[101] H. Cheng, Y. Liu, Y. Hu, Y. Ding, S. Lin, W. Cao, Q. Wang, J. Wu, F. Muhammad, X. Zhao, D. Zhao, Z. Li, H. Xing, H. Wei, Anal. Chem. 89 (2017) 11552.

[102] H. Ang, L. Hong, ACS Appl. Mater. Interfaces 9 (2017) 28079.

[103] H. Chung, P.M. Barron, R.W. Novotny, H.-T. Son, C. Hu, W. Choe, Cryst. Growth Des. 9 (2009) 3327.

[104] J.M. Verduzco, H. Chung, C. Hu, W. Choe, Inorg. Chem. 48 (2009) 9060.

[105] A. Karmaker, I. Goldberg, CrystEngComm 12 (2010) 4095.

[106] S. Matsunaga, N. Endo, W. Mori, Eur. J. Inorg. Chem. (2011) 4550.

[107] B.J. Burnett, P.M. Barron, C. Hu, W. Choe, J. Am. Chem. Soc. 133 (2011) 9984.

[108] C.Y. Lee, O.K. Farha, B.J. Hong, A.A. Sarjeant, S.T. Nguyen, J.T. Hupp, J. Am. Chem. Soc. 133 (2011) 15858.

[109] B.J. Burnett, W. Choe, CrystEngComm 14 (2012) 6129.

[110] X.-S. Wang, M. Chrzanowski, W.-Y. Gao, L. Wojtas, Y.-S. Chen, M.J. Zaworotko, S. Ma, Chem. Sci. 3 (2012) 2823.

[111] J.A. Johnson, Q. Lin, L.-C. Wu, N. Obaidi, Z.L. Olson, T.C. Reeson, Y.-S. Chen, J. Zhang, Chem. Commun. 49 (2013) 2828

[112] S. Takaishi, E.J. DeMarco, M.J. Pellin, O.K. Farha, J.T. Hupp, Chem. Sci. 4 (2013) 1509.

[113] J. Park, D. Feng, S. Yuan, H.-C. Zhou, Angew. Chem., Int. Ed. 54 (2015) 430.

[114] J.-S. Qin, D.-Y. Du, M. Li, X.-Z. Lian, L.-Z. Dong, M. Bosch, Z.-M. Su, Q. Zhang, S.L. Li, Y.-Q. Lan, S. Yuan, H.-C. Zhou, J. Am. Chem. Soc. 138 (2016) 5299.

[115] T. Sakuma, H. Sakai, Y. Araki, T. Wada, T. Hasobe, Phys. Chem. Chem. Phys. 18 (2016) 5453.

[116] W.-Y. Gao, C.-Y. Tsai, L. Wojtas, T. Thiounn, C.-C. Lin, S. Ma, Inorg. Chem. 55 (2016) 7291.

[117] M.H. Beyzavi, N.A. Vermeulen, K. Zhang, M. So, C.-W. Kung, J.T. Hupp, O.K. Farha, ChemPlusChem 81 (2016) 708.

[118] Y. Zhou, W. Yang, M. Qin, H. Zhao, Appl. Organometal. Chem. 30 (2016) 188.

[119] M.-H. Xie, X.-L. Yang, Y. He, J. Zhang, B. Chen, C.-D. Wu, Chem. Eur. J. 19 (2013) 14316.

[120] C. Zou, T. Zhang, M.-H. Xie, L. Yan, G.-Q. Kong, X.-L. Yang, A. Ma, C.-D. Wu, Inorg. Chem. 52 (2013) 3620.

[121] X.-L. Yang, C.-D. Wu, Inorg. Chem. 53 (2014) 4797.

[122] O.K. Farha, A.M. Shultz, A.A. Sarjeant, S.T. Nguyen, J.T. Hupp, J. Am. Chem. Soc. 133 (2011) 5652.

[123] M.C. So, M.H. Beyzavi, R. Sawhney, O. Shekhah, M. Eddaoudi, S.S. Al-Juaid, J.T. Hupp, O.K. Farha, Chem. Commun. 51 (2015) 85.

[124] A. Urtizberea, E. Natividad, P.J. Alonso, M.A. Andrés, I. Gascón, M. Goldmann, O. Roubeau, Adv. Funct. Mater. 28 (2018) 1801695.

[125] R. Makiura, H. Kitagawa, Eur. J. Inorg. Chem. (2010) 3715.

[126] R. Makiura, S. Motoyama, Y. Umemura, H. Yamanaka, O. Sakata, H. Kitagawa, Nat. Mater. 9 (2010) 565.

[127] X. Wang, W.-Y. Gao, Z. Niu, L. Wojtas, J.A. Perman, Y.-S. Chen, Z. Li, B. Aguila, S. Ma, Chem. Commun. 54 (2018) 1170.

[128] X.-S. Wang, L. Meng, Q. Cheng, C. Kim, L. Wojtas, M. Chrzanowski, Y.-S. Chen, X.P. Zhang, S. Ma, J. Am. Chem. Soc. 133 (2011) 16322.

[129] G. Xu, T. Yamada, K. Otsubo, S. Sakaida, H. Kitagawa, J. Am. Chem. Soc. 134 (2012) 16524 
[130] G. Xu, K. Otsubo, T. Yamada, S. Skaida, H. Kitagawa, J. Am. Chem. Soc. 135 (2013) 7438.

[131] W.-Y. Gao, L. Wojtas, S. Ma, Chem. Commun. 50 (2014) 5316.

[132] R. Rahimi, S. Shariatinia, S. Zargari, M.Y. Berijani, A. Ghaffarinejad, Z.S. Shojaie, RSC adv. 5 (2015) 46624.

[133] R. Elzein, C.-M. Chang, I. Ponomareva, W.-Y. Gao, S. Ma, R. Schlaf, ACS Appl, Mater. Interfaces 8 (2016) 31403.

[134] Y. Ma, X. Li, A. Li, P. Yang, C. Zhang, B. Tang, Angew. Chem., Int. Ed. 56 (2017) 13752.

[135] S. Matsunaga, N. Endo, W. Mori, Eur. J. Inorg. Chem. (2012) 4885.

[136] X.-L. Yang, C. Zou, Y. He, M. Zhao, B. Chen, S. Xiang, M. O'Keeffe, C.-D. Wu, Chem. Eur. J. 20 (2014) 1447.

[137] M.-H. Xie, X.-L. Yang, C.-D. Wu, Chem. Commun. 47 (2011) 5521.

[138] X.-S. Wang, M. Chrzanowski, L. Wojtas, Y.-S. Chen, S. Ma, Chem. Eur. J. 19 (2013) 3297.

[139] S. Lipstman, I. Goldberg, Cryst. Growth Des. 13 (2013) 942.

[140] N.C. Smythe, D.P. Butler, C.E. Moore, W.R. McGowan, A.L. Rheingold, L.G. Beauvais, Dalton Trans. 41 (2012) 7855.

[141] X.-L. Yang, M.-H. Xie, C. Zou, Y. He, B. Chen, M. O’Keeffe, C.-D. Wu, J. Am. Chem. Soc. 134 (2012) 10638.

[142] A. Fateeva, S. Devautour-Vinot, N. Heymans, T. Devic, J.-M. Grenèchem, S. Wuttke, S. Miller, A. Lago, C. Serre, G. De Weireld, G. Maurin, A. Vimont, G. Férey, Chem. Mater. 23 (2011) 4641.

[143] A. Fateeva, J. Clarisse, G. Pilet, J.-M. Grenèche, F. Nouar, B.K. Abeykoon, F. Guegan, C. Goutaudier, D. Luneau, J.E. Warren, M.J. Rosseinsky, T. Devic, Cryst. Growth Des. 15 (2015) 1819.

[144] K. Wang, D. Feng, T.-F. Liu, J. Su, S. Yuan, Y.-P. Chen, M. Bosch, X. Zou, H.-C. Zhou, J. Am. Chem. Soc. 136 (2014) 13983.

[145] A. Aziz, A.R. Ruiz-Salvador, N.C. Hernández, S. Calero, S. Hamad, R. GrauCrespo, J. Mater. Chem. A 5 (2017) 11894.

[146] D. Feng, Z.-Y. Gu, J.-R. Li, H.-L. Jiang, Z. Wei, H.-C. Zhou, Angew. Chem., Int. Ed. 51 (2012) 10307.

[147] W. Morris, B. Volosskiy, S. Demir, F. Gándara, P.L. McGrier, H. Furukawa, D. Cascia, J.F. Stoddart, O.M. Yaghi, Inorg. Chem. 51 (2012) 6443.

[148] D. Feng, W.-C. Chung, Z. Wei, Z.-Y. Gu, H.-L. Jiang, Y.-P. Chen, D.J. Darensbourg, H.-C. Zhou, J. Am. Chem. Soc. 135 (2013) 17105.

[149] J.S. Anderson, A.T. Gallagher, J.A. Mason, T.D. Harris, J. Am. Chem. Soc. 136 (2014) 16489.

[150] Q. Liu, X. Bu, A. Kong, C. Mao, X. Zhao, F. Bu, P. Feng, J. Am. Chem. Soc. 137 (2015) 2235.

[151] I. Hod, M.D. Sampson, P. Deria, C.P. Kubiak, O.K. Farha, J.T. Hupp, ACS Catal. 5 (2015) 6302.

[152] Y. Sun, L. Sun, D. Feng, H.-C. Zhou, Angew. Chem., Int. Ed. 55 (2016) 6471.

[153] A.T. Gallagher, C.D. Malliakas, T.D. Harris, Inorg. Chem. 56 (2017) 4654.

[154] A.T. Gallagher, J.Y. Lee, V. Kathiresan, J.S. Anderson, B.M. Hoffman, T.D. Harris, Chem. Sci. 9 (2018) 1596.

[155] Y. Chen, T. Hoang, S. Ma, Inorg. Chem. 51 (2012) 12600.

[156] D. Feng, H.-L. Jiang, Y.-P. Chen, Z.-Y. Gu, Z. Wei, H.-C. Zhou, Inorg. Chem. 52 (2013) 12661.

[157] D. Feng, Z.-Y. Gu, Y.-P. Chen, J. Park, Z. Wei, Y. Sun, M. Bosch, S. Yuan, H.-C. Zhou, J. Am. Chem. Soc. 136 (2014) 17714.

[158] S. Sohrabi, S. Dehghanpour, M. Ghalkhani, ChemCatChem 8 (2016) 2356.

[159] P.M. Usov, B. Huffman, C.C. Epley, M.C. Kessinger, J. Zhu, W.A. Maza, A.J. Morris, ACS Appl. Mater. Interfaces 9 (2017) 33539.

[160] L. Li, Q. Yang, S. Chen, X. Hou, B. Liu, J. Lu, H.-L. Jiang, Chem. Commun. 53 (2017) 10026.

[161] N. Huang, S. Yuan, H. Drake, X. Yang, J. Pang, J. Qin, J. Li, Y. Zhang, Q. Wang, D. Jiang, H.-C. Zhou, J. Am. Chem. Soc. 139 (2017) 18590.

[162] Y.-Z. Chen, Z.U. Wang, H. Wang, J. Lu, S.-H. Yu, H.-L. Jiang, J. Am. Chem. Soc. 139 (2017) 2035.

[163] C.-W. Kung, T.-H. Chang, L.-Y. Chou, J.T. Hupp, O.K. Farha, K.-C. Ho, Chem. Commun. 51 (2015) 2414

[164] H. Zhang, J. Wei, J. Dong, G. Liu, L. Shi, P. An, G. Zhao, J. Kong, X. Wang, X. Meng, J. Zhang, J. Ye, Angew. Chem., Int. Ed. 55 (2016) 14310.

[165] Y.-Z. Chen, H.-L. Jiang, Chem. Mater. 28 (2016) 6698.

[166] S. Yuan, J.-S. Qin, L. Zou, Y.-P. Chen, X. Wang, Q. Zhang, H.-C. Zhou, J. Am. Chem. Soc. 138 (2016) 6636.

[167] H-.Q. Xu, K. Wang, M. Ding, D. Feng, H.-L. Jiang, H.-C. Zhou, J. Am. Chem. Soc. 138 (2016) 5316.

[168] T. Rhauderwiek, H. Zhao, P. Hirschle, M. Döblinger, B. Bueken, H. Reinsch, D. De Vos, S. Wuttke, U. Kolb, N. Stock, Chem. Sci. 9 (2018) 5467.

[169] L. Li, S. Shen, R. Lin, Y. Bai, H. Liu, Chem. Commun. 53 (2017) 9986.

[170] X. Xu, S. Li, Q. Liu, Z. Liu, W. Yan, L. Zhao, W. Zhang, L. Zhang, F. Deng, H. Cong, H. Deng, ACS Appl. Mater. Interfaces 11 (2019) 973.

[171] H.-L. Jiang, D. Feng, K. Wang, Z.-Y. Gu, Z. Wei, Y.-P. Chen, H.-C. Zhou, J. Am. Chem. Soc. 135 (2013) 13934.

[172] P. Deria, J. Yu, P. Balaraman, J. Mashni, S.N. White, Chem. Commun. 52 (2016) 13031.

[173] P. Deria, D.A. Gómez-Gualdrón, I. Hod, R.Q. Snurr, J.T. Hupp, O.K. Farha, J. Am. Chem. Soc. 138 (2016) 14419.

[174] G.-Y. Zhang, C. Cai, S. Cosnier, H.-B. Zeng, X.-J. Zhang, D. Shan, Nanoscale 8 (2016) 11649 .

[175] K.C. Park, C. Seo, G. Gupta, J. Kim, C.Y. Lee, ACS Appl. Mater. Interfaces 9 (2017) 38670.

[176] Y. Zhao, Y. Dong, F. Lu, C. Ju, L. Liu, J. Zhang, B. Zhang, Y. Feng, J. Mater. Chem. A 5 (2017) 15380
[177] H. Cui, Y. Wang, Y. Wang, Y.-Z. Fan, L. Zhang, C.-Y. Su, CrystEngcomm 18 (2016) 2203.

[178] J. He, X. Wu, Z. Long, X. Hou, Microchem. J. 145 (2019) 68.

[179] L. Xu, Y.-P. Luo, L. Sun, Y. Xu, Z.-S. Cai, M. Fang, R.-X. Yuan, H.-B. Du, Chem. Eur. J. 22 (2016) 6268.

[180] C. Zou, M.-H. Xie, G.-Q. Kong, C.-D. Wu, CrystEngComm 14 (2012) 4850.

[181] W. Jiang, J. Yang, Y.-Y. Liu, S.-Y. Song, J.-F. Ma, Chem. Eur. J. 22 (2016) 16991

[182] W.-Y. Gao, Z. Zhang, L. Cash, L. Wojtas, Y.-S. Chen, S. Ma, CrystEngComm 15 (2013) 9320.

[183] J.A. Johnson, X. Zhang, T.C. Reeson, Y.-S. Chen, J. Zhang, J. Am. Chem. Soc. 136 (2014) 15881.

[184] N. Kornienko, Y. Zhao, C.S. Kley, C. Zhu, D. Kim, S. Lin, C.J. Chang, O.M. Yaghi, P. Yang, J. Am. Chem. Soc. 137 (2015) 14129.

[185] Z. Lin, Z.-M. Zhang, Y.-S. Chen, W. Lin, Angew. Chem., Int. Ed. 55 (2016) 13739.

[186] A. Fateeva, P.A. Chater, C.P. Ireland, A.A. Tahir, Y.Z. Khimyak, P.V. Wiper, J.R. Darwent, M.J. Rosseinsky, Angew. Chem., Int. Ed. 51 (2012) 7440.

[187] W. Zhang, W. Gao, T. Pham, P. Jiang, S. Ma, Cryst. Growth Des. 16 (2016) 1005

[188] M.S. Deenadayalan, N. Sharma, P.K. Verma, C.M. Nagaraja, Inorg. Chem. 55 (2016) 5320.

[189] Y. Kataoka, K.S. Kataoka, H. Murata, M. Handa, W. Mori, T. Kawamoto, Inorg. Chem. Commun. 68 (2016) 37.

[190] T. Rhauderwiek, N. Heidenreich, H. Reinsch, S. Øien-Ødegaard, K.A. Lomachenko, U. Rütt, A.V. Soldatov, K.P. Lillerud, N. Stock, Cryst. Growth Des. 17 (2017) 3462.

[191] Y. Wang, H. Cui, Z.-W. Wei, H.-P. Wang, L. Zhang, C.-Y. Su, Chem. Sci. 8 (2017) 775.

[192] S. Sun, M. Pan, X. Hu, W. Shao, J. Li, F. Zhang, Catal. Lett. 146 (2016) 1087.

[193] B.F. Abrahams, B.F. Hoskins, R. Robson, J. Am. Chem. Soc. 113 (1991) 3606.

[194] N. Zheng, J. Zhang, X. Bu, P. Feng, Cryst. Growth Des. 7 (2007) 2576.

[195] C. Zou, Z. Zhang, X. Xu, Q. Gong, J. Li, C.-D. Wu, J. Am. Chem. Soc. 134 (2012) 87.

[196] M.-H. Xie, X.-L. Yang, C. Zou, C.-D. Wu, Inorg. Chem. 50 (2011) 5318.

[197] A.M. Shultz, O.K. Farha, J.T. Hupp, S.T. Nguyen, J. Am. Chem. Soc. 131 (2009) 4204.

[198] S. Lipstman, I. Goldberg, Beilstein J. Org. Chem. 5 (2009) 77.

[199] R.W. Seidel, I.M. Oppel, Z. Anorg, Allg. Chem. 636 (2010) 446.

[200] S. Jin, H.-J. Son, O.K. Farha, G.P. Wiederrecht, J.T. Hupp, J. Am. Chem. Soc. 135 (2013) 955.

[201] H.-J. Son, S. Jin, S. Patwardhan, S.J. Wezenberg, N.C. Jeong, M. So, C.E. Wilmer, A.A. Sarjeant, G.C. Schatz, R.Q. Snurr, O.K. Farha, G.P. Wiederrecht, J.T. Hupp, J. Am. Chem. Soc. 135 (2013) 862.

[202] G. Dutta, A.K. Jana, S. Natarajan, Chem. Eur. J. 23 (2017) 8932.

[203] B. Wurster, D. Grumelli, D. Hötger, R. Gutzler, K. Kern, J. Am. Chem. Soc. 138 (2016) 3623.

[204] B. Mandal, J.S. Chung, S.G. Kang, J. Phys. Chem. C 122 (2018) 9899.

[205] B.F. Abrahams, B.F. Hoskins, D.M. Michail, R. Robson, Nature 369 (1994) 727.

[206] T. Ohmura, A. Usuki, K. Fukumori, T. Ohta, M. Ito, K. Tatsumi, Inorg. Chem. 45 (2006) 7988.

[207] R.W. Seidel, I.M. Oppel, CrystEngComm 12 (2010) 1051.

[208] Q. Zha, C. Ding, X. Rui, Y. Xie, Cryst. Growth Des. 13 (2013) 4583.

[209] A. Sengupta, S. Datta, C. Su, T.S. Herng, J. Ding, J.J. Vittal, K.P. Loh, ACS Appl. Mater. Interfaces 8 (2016) 16154.

[210] S. Lipstman, I. Goldberg, Cryst. Growth Des. 10 (2010) 4596.

[211] S. Lipstman, I. Goldberg, Cryst. Growth Des. 10 (2010) 5001.

[212] Y. Li, J. Xiao, T.E. Shubina, M. Chen, Z. Shi, M. Schmid, H.-P. Steinrück, J.M. Gottfried, N. Lin, J. Am. Chem. Soc. 134 (2012) 6401.

[213] I. Goldberg, Chem. Eur. J. 6 (2000) 3863.

[214] L.D. DeVries, W. Choe, J. Chem. Crystallogr. 39 (2009) 229.

[215] B.J. Burnett, P.M. Barron, W. Choe, CrystEngComm 14 (2012) 3839.

[216] B.J. Burnett, W. Choe, Dalton Trans. 41 (2012) 3889.

[217] W.-Y. Gao, M. Chrzanowski, S. Ma, Chem. Soc. Rev. 43 (2014) 5841.

[218] S. Huh, S.-J. Kim, Y. Kim, CrystEngComm 18 (2016) 345.

[219] C.F. Pereira, M.M.Q. Simões, J.P.C. Tomé, F.A.A. Paz, Molecules 21 (2016) 1348

[220] T. Toyao, N. Ueno, K. Miyahara, Y. Matsui, T.-H. Kim, Y. Horiuchi, H. Ikeda, M. Matsuoka, Chem. Commun. 51 (2015) 16103.

[221] H.-Q. Xu, J. Hu, D. Wang, Z. Li, Q. Zhang, Y. Luo, S.-H. Yu, H.-L. Jiang, J. Am. Chem. Soc. 137 (2015) 13440.

[222] J. Park, Q. Jiang, D. Feng, H.-C. Zhou, Angew. Chem., Int. Ed. 55 (2016) 7188.

[223] J. Park, Q. Jiang, D. Feng, L. Mao, H.-C. Zhou, J. Am. Chem. Soc. 138 (2016) 3518.

[224] C.-W. Kung, Y.-S. Li, M.-H. Lee, S.-Y. Wang, W.-H. Chiang, K.-C. Ho, J. Mater. Chem. A 4 (2016) 10673.

[225] W. Lin, Q. Hu, Jiang Ke, Y. Yang, Y. Yang, Y. Cuui, G. Qian, J. Solid State Chem. 237 (2016) 307.

[226] J. Yang, Z. Wang, Y. Li, Q. Zhuang, W. Zhao, J. Gu, RSC Adv. 6 (2016) 69807.

[227] S.M. Yoon, J.H. Park, B.A. Grzybowski, Angew. Chem., Int. Ed. 56 (2017) 127.

[228] L. Feng, Y. Wang, S. Yuan, K.-Y. Wang, J.-L. Li, G.S. Day, D. Qiu, L. Cheng, W.-M. Chen, S.T. Madrahimov, H.-C. Zhou, ACS Catal. 9 (2019) 5111.

[229] S.-H. Cho, B. Ma, S.T. Nguyen, J.T. Hupp, T.E. Albrecht-Schmitt, Chem. Commun. (2006) 2563.

[230] G.A.E. Oxford, R.Q. Snurr, L.J. Broadbelt, Ind. Eng. Chem. Res. 49 (2010) 10965

[231] F. Song, C. Wang, J.M. Falkowski, L. Ma, W. Lin, J. Am. Chem. Soc. 132 (2010) 15390.

[232] A.M. Shultz, O.K. Farha, D. Adhikari, A.A. Sarjeant, J.T. Hupp, S.T. Nguyen, Inorg. Chem. 50 (2011) 3174. 
[233] F. Song, C. Wang, W. Lin, Chem. Commun. 47 (2011) 8256.

[234] A.M. Shultz, A.A. Sarjeant, O.K. Farha, J.T. Hupp, S.T. Nguyen, J. Am. Chem. Soc. 133 (2011) 13252.

[235] Q. Xia, Z. Li, C. Tan, Y. Liu, W. Gong, Y. Cui, J. Am. Chem. Soc. 139 (2017) 8259.

[236] X.-G. Guo, S. Qiu, X. Chen, Y. Gong, X. Sun, Inorg. Chem. 56 (2017) 12357.

[237] M.C. Das, Q. Guo, Y. He, J. Kim, C.-G. Zhao, K. Hong, S. Xiang, Z. Zhang, K.M. Thomas, R. Krishna, B. Chen, J. Am. Chem. Soc. 134 (2012) 8703.

[238] B. Chen, X. Zhao, A. Putkham, K. Hong, E.B. Lobkovsky, E.J. Hurtado, A.J. Fletcher, K.M. Thomas, J. Am. Chem. Soc. 130 (2008) 6411.

[239] N. Candu, M. Tudorache, M. Florea, E. Ilyes, F. Vasiliu, I. Mercioniu, S.M. Coman, I. Haiduc, M. Andruh, V.I. Pârvulescu, ChemPlusChem 78 (2013) 443

[240] P. Müller, V. Bon, I. Senkovska, J. Getzschmann, M.S. Weiss, S. Kaskel, Cryst. Growth Des. 17 (2017) 3221.

[241] J. Li, Y. Ren, C. Qi, H. Jiang, Dalton Trans. 46 (2017) 7821.

[242] C. Zhu, G. Yuan, X. Chen, Z. Yang, Y. Cui, J. Am. Chem. Soc. 134 (2012) 8058.

[243] L.-Q. Zuo, T.-F. Zhang, Z.-K. Zhang, J.-X. Hou, G.-J. Liu, J.-L. Du, L.-J. Li, Inorg. Chem. Commun. 99 (2019) 113.

[244] X. Li, M. Yang, X. Ren, K. Mei, Y. Lu, Inorg. Chem. Commun. 96 (2018) 39.

[245] Y. Fan, Y. Ren, J. Li, C. Yue, H. Jiang, Inorg. Chem. 57 (2018) 11986.

[246] Y. Liu, Z. Li, G. Yuan, Q. Xia, C. Yuan, Y. Cui, Inorg. Chem. 55 (2016) 12500.

[247] C. Zhu, Q. Xia, X. Chen, Y. Liu, X. Du, Y. Cui, ACS Catal. 6 (2016) 7590.

[248] Q. Xia, Y. Liu, Z. Li, W. Gong, Y. Cui, Chem. Commun. 52 (2016) 13167.

[249] Z. Li, Y. Liu, Q. Xia, Y. Cui, Chem. Commun. 53 (2017) 12313.

[250] Z. Li, Y. Liu, X. Kang, Y. Cui, Inorg. Chem. 57 (2018) 9786.

[251] C. Tan, X. Han, Z. Li, Y. Liu, Y. Cui, J. Am. Chem. Soc. 140 (2018) 16229.

[252] J. Li, Y. Ren, C. Yue, Y. Fan, C. Qi, H. Jiang, ACS Appl Mater. Interfaces 10 (2018) 36047.

[253] M.J. Ingleson, J.P. Barrio, J.-B. Guilbaud, Y.Z. Khimyak, M.J. Rosseinsky, Chem. Commun. (2008) 2680.

[254] S. Bhattacharjee, D.-A. Yang, W.-S. Ahn, Chem. Commun. 47 (2011) 3637.

[255] D. Saha, R. Sen, T. Maity, S. Koner, Langmuir 29 (2013) 3140.

[256] C.J. Doonan, W. Morris, H. Furukawa, O.M. Yaghi, J. Am. Chem. Soc. 131 (2009) 9492.

[257] M. Kaposi, M. Cokoja, C.H. Hutterer, S.A. Hauser, T. Kaposi, F. Klappenberger, A. Pöthig, J.V. Barth, W.A. Herrmann, F.E. Kühn, Dalton Trans. 44 (2015) 15976.

[258] A.M. Rasero-Almansa, A. Corma, M. Iglesias, F. Sánchez, ChemCatChem 5 (2013) 3092.

[259] J. Canivet, S. Aguado, Y. Schuurman, D. Farrusseng, J. Am. Chem. Soc. 135 (2013) 4195.

[260] W. Morris, C.J. Doonan, H. Furukawa, R. Banerjee, O.M. Yaghi, J. Am. Chem. Soc. 130 (2008) 12626.

[261] L. Garzón-Tovar, S. Rodríguez-Hermida, I. Imaz, D. Maspoch, J. Am. Chem. Soc. 139 (2017) 897.

[262] S. Bhattacharjee, Y.-R. Lee, W.-S. Ahn, CrystEngComm 17 (2015) 2575.

[263] S.J. Garibay, Z. Wang, K.K. Tanabe, S.M. Cohen, Inorg. Chem. 48 (2009) 7341.

[264] K.K. Tanabe, S.M. Cohen, Angew. Chem., Int. Ed. 48 (2009) 7424.

[265] K.K. Tanabe, S.M. Cohen, Inorg. Chem. 49 (2010) 6766.

[266] M.A. Gotthardt, A. Beilmann, R. Schoch, J. Engelke, W. Kleist, RSC Adv. 3 (2013) 10676

[267] T. Gadzikwa, O.K. Farha, K.L. Mulfort, J.T. Hupp, S.T. Nguyen, Chem. Commun. (2009) 3720 .

[268] Y. Goto, H. Sato, S. Shinkai, K. Sada, J. Am. Chem. Soc. 130 (2008) 14354.

[269] M. Savonnet, D. Bazer-Bachi, N. Bats, J. Perez-Pellitero, E. Jeanneau, V. Lecocq, C. Pinel, D. Farrusseng, J. Am. Chem. Soc. 132 (2010) 4518.

[270] C. Liu, T. Li, N.L. Rosi, J. Am. Chem. Soc. 134 (2012) 18886.
[271] M. Savonnet, A. Camarata, J. Canivet, D. Bazer-Bachi, N. Bats, V. Lecocq, C. Pinel, D. Farrusseng, Dalton Trans. 41 (2012) 3945.

[272] H.-L. Jiang, D. Feng, T.-F. Liu, J.-R. Li, H.-C. Zhou, J. Am. Chem. Soc. 134 (2012) 14690.

[273] G. Tuci, A. Rossin, X. Xu, M. Ranocchiari, J.A. van Bokhoven, L. Luconi, I. Manet, M. Melucci, G. Giambastiani, Chem. Mater. 25 (2013) 2297.

[274] S. Wu, L. Chen, B. Yin, Y. Li, Chem. Commun. 51 (2015) 9884.

[275] L. Zhang, J. Chen, T. Fan, K. Shen, M. Jiang, Y. Li, Chem. Commun. 54 (2018) 4188.

[276] G.C. Welch, R.R. San Juan, J.D. Masuda, D.W. Stephan, Science 314 (2006) 1124.

[277] C.-H. Lim, A.M. Holder, J.T. Hynes, C.B. Musgrave, Inorg. Chem. 52 (2013) 10062.

[278] D.W. Stephan, G. Erker, Angew. Chem., Int. Ed. 54 (2015) 6400

[279] Z. Niu, W.D.C. Bhagya Gunatilleke, Q. Sun, P.C. Lan, J. Perman, J.-G. Ma, Y. Cheng, B. Aguila, S. Ma, Chem 4 (2018) 2587.

[280] D.W. Stephan, Chem 4 (2018) 2483.

[281] Z. Niu, W. Zhang, P.C. Lan, B. Aguila, S. Ma, Angew. Chem., Int. Ed. 58 (2019) 7420.

[282] J. Ye, J.K. Johnson, ACS Catal. 5 (2015) 2921.

[283] J. Ye, J.K. Johnson, ACS Catal. 5 (2015) 6219.

[284] J. Ye, J.K. Johnson, Catal. Sci. Technol. 6 (2016) 8392.

[285] S. Shyshkanov, T.N. Nguyen, F.M. Ebrahim, K.C. Stylianou, P.J. Dyson, Angew. Chem., Int. Ed. 58 (2019) 5371.

[286] S. Shyshkanov, T.N. Nguyen, A. Chidambaram, K.C. Stylianou, P.J. Dyson, Chem. Commun. 55 (2019) 10964

[287] Y. Xu, Q. Li, H. Xue, H. Pang, Coord. Chem. Rev. 376 (2018) 292.

[288] P.-Q. Liao, J.-Q. Shen, J.-P. Zhang, Coord. Chem. Rev. 373 (2018) 22.

[289] M. Ding, R.W. Flaig, H.-L. Jiang, O.M. Yaghi, Chem. Soc. Rev. 48 (2019) 2783.

[290] F. Speiser, P. Braunstein, L. Saussine, Acc. Chem. Res. 38 (2005) 784.

[291] A. Finiels, F. Fajula, V. Hulea, Catal. Sci. Technol. 4 (2014) 2412.

[292] S. Tobisch, T. Ziegler, J. Am. Chem. Soc. 126 (2004) 9059.

[293] C. Bianchini, G. Mantovani, A. Meli, F. Migliacci, Organometallics 22 (2003) 2545.

[294] S.T. Madrahimov, J.R. Gallagher, G. Zhang, Z. Meinhart, S.J. Garibay, M. Delferro, J.T. Miller, O.K. Farha, J.T. Hupp, S.T. Nguyen, ACS Catal. 5 (2015) 6713.

[295] V. Bernales, A.B. League, Z. Li, N.M. Schweitzer, A.W. Paters, R.K. Carlson, J.T. Hupp, C.J. Cramer, O.K. Farha, L. Gagliardi, J. Phys. Chem. C 120 (2016) 23576.

[296] E.D. Metzger, C.K. Brozek, R.J. Comito, M. Dincă, ACS Cent. Sci. 2 (2016) 148.

[297] R.J. Comito, K.J. Fritzsching, B.J. Sundell, K. Schmidt-Rohr, M. Dincă, J. Am. Chem. Soc. 138 (2016) 10232.

[298] B. Liu, S. Jie, Z. Bu, B.-G. Li, RSC Adv. 4 (2014) 62343.

[299] J.-D. Xiao, H.-L. Jiang, Acc. Chem. Res. 52 (2019) 356.

[300] Y. Chen, D. Wang, X. Deng, Z. Li, Catal. Sci. Technol. 7 (2017) 4893.

[301] T. Zhang, W. Lin, Chem. Soc. Rev. 43 (2014) 5982.

[302] C Xu, H Liu, D Li, J-H Su, H-L Jiang, Chem. Sci. 9 (2018) 3152.

[303] M.E. Mahmoud, H. Audi, A. Assoud, T.H. Ghaddar, M. Hmadeh, J. Am. Chem. Soc. 141 (2019) 7115.

[304] Y.-Y. Zhu, G. Lan, Y. Fan, S.S. Veroneau, Y. Song, D. Micheroni, W. Lin, Angew. Chem., Int. Ed. 57 (2018) 14090.

[305] J. Han, M.S. Lee, P.K. Thallapally, M. Kim, N. Jeong, ACS Catal. 9 (2019) 3969.

[306] J. Han, S. Kim, M.S. Lee, M. Kim, N. Jeong, J. Vis. Exp. 155 (2020) e60624.

[307] Kim S , Lee J , Jeoung S , Moon H R , Kim M , Chem. Eur. J. (n.d. ), https://doi. $\operatorname{org} / 10.1002 /$ chem.20200933. 